\title{
WERDC
}

US Army Corps

of Engineers ${ }_{\circledast}$

Engineer Research and

Development Center

Environmental Quality/Installations

\section{Simulated Vehicle Decontamination and Field Evaluation of the Decontamination Effluent Treatment System (DETS), 27 June 2017, and Associated Background Studies}

Victor F. Medina, Scott A. Waisner, Edith Martinez-Guerra,

November 2018

Jared Johnson, Jonathan Brame, Elizabeth Gao,

and Martin Page

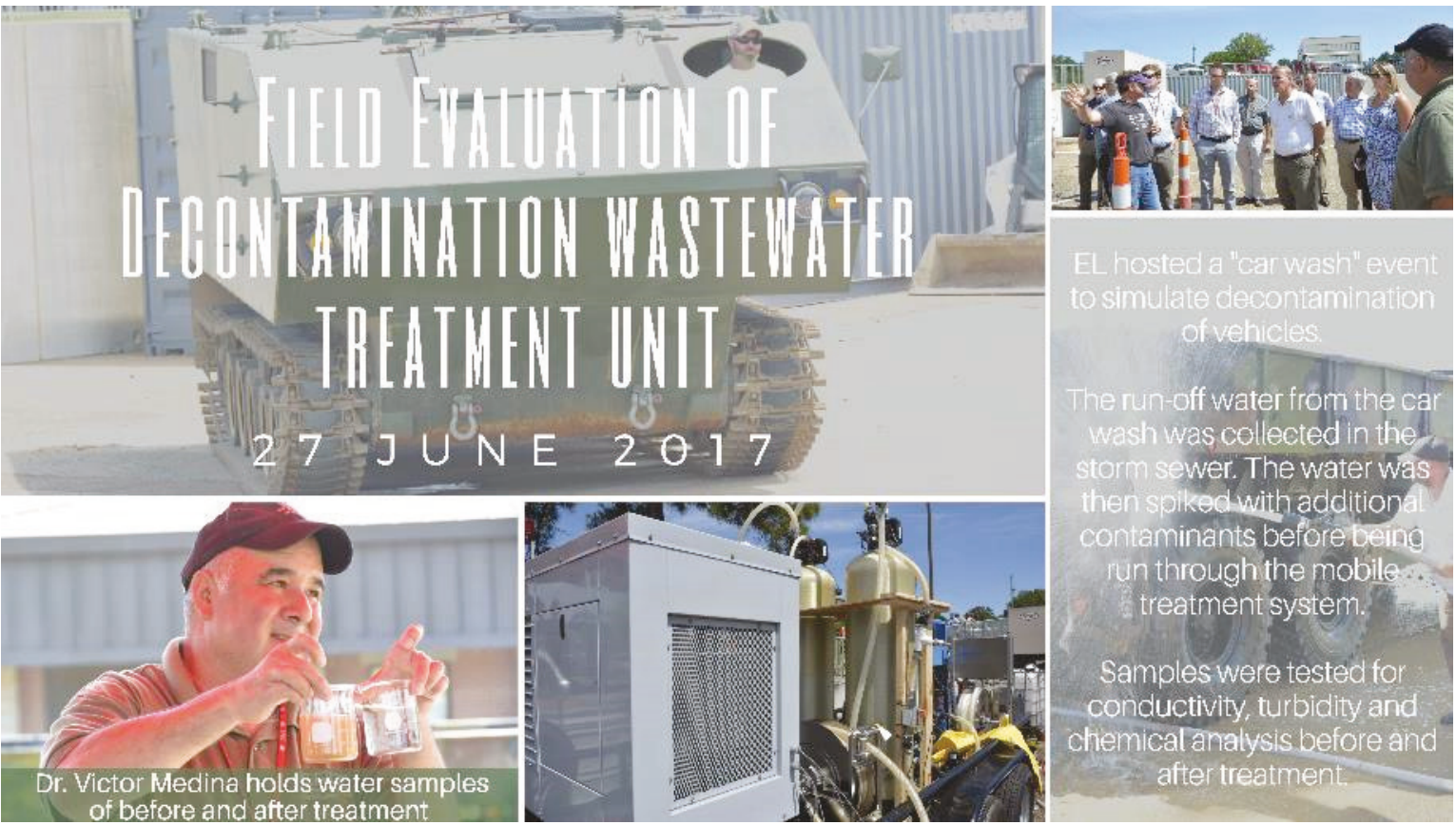


The U.S. Army Engineer Research and Development Center (ERDC) solves the nation's toughest engineering and environmental challenges. ERDC develops innovative solutions in civil and military engineering, geospatial sciences, water resources, and environmental sciences for the Army, the Department of Defense, civilian agencies, and our nation's public good. Find out more at www.erdc.usace.army.mil.

To search for other technical reports published by ERDC, visit the ERDC online library at http://acwc.sdp.sirsi.net/client/default. 


\title{
Simulated Vehicle Decontamination and Field Evaluation of the Decontamination Effluent Treatment System (DETS), 27 June 2017, and Associated Background Studies
}

\author{
Victor F. Medina, Scott A. Waisner, Edith Martinez-Guerra, \\ Jared Johnson, and Jonathan Brame \\ Environmental Laboratory \\ U.S. Army Engineer Research and Development Center \\ 3909 Halls Ferry Road \\ Vicksburg, MS 39180-6199 \\ Elizabeth Gao, and Martin Page \\ Construction Engineering Research Laboratory \\ U.S. Army Engineer Research and Development Center \\ 2902 Newmark Dr. \\ Champaign, IL 61826-9005
}

Final Report

Approved for public release; distribution is unlimited.

\author{
Prepared for Environmental Quality/Installations Program. \\ Under Work Unit 33143
}




\section{Abstract}

A technical evaluation of a capability to treat and/or recycle the effluent from the Army's aqueous based chemical, biological, radiological and nuclear (CBRN) decontamination operations was conducted on 26-28 June 2017 at the U.S. Army Engineer Research and Development Center (ERDC) Waterways Experiment Station (WES), 3909 Halls Ferry Rd, Vicksburg, MS. The Decontamination Effluent Treatment System (DETS) is a reactor system specifically designed to address decontamination effluent. The objectives of the evaluation were to show an ability to reduce chemical hazards, reduce logistical burdens, and eliminate possible political impacts. The DETS is a fully functional system designed to treat waters containing contaminants, minimize decontamination water requirements, be rapidly deployable and easy to maintain, while minimizing the volume of decontamination waste requiring management/disposal. The field evaluation consisted of a simulation of vehicle decontamination followed by on-site treatment of the resulting effluent water.

DISCLAIMER: The contents of this report are not to be used for advertising, publication, or promotional purposes. Citation of trade names does not constitute an official endorsement or approval of the use of such commercial products. All product names and trademarks cited are the property of their respective owners. The findings of this report are not to be construed as an official Department of the Army position unless so designated by other authorized documents. 


\section{Contents}

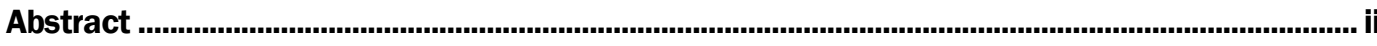

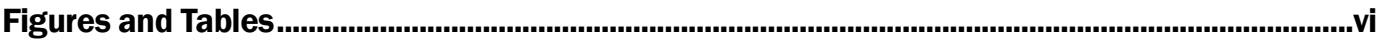

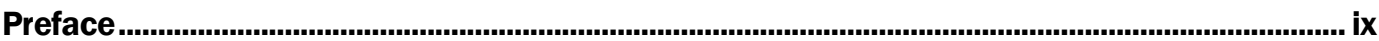

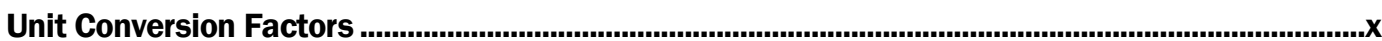

Acronyms and Abbreviations .......................................................................................................... xi

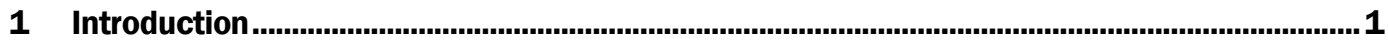

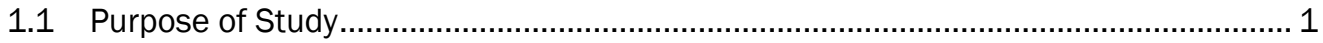

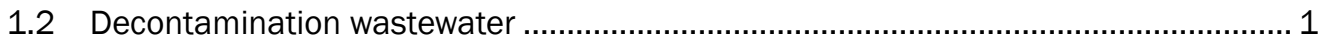

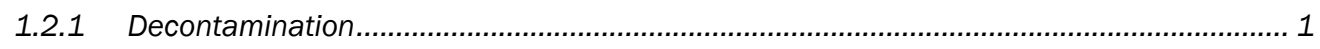

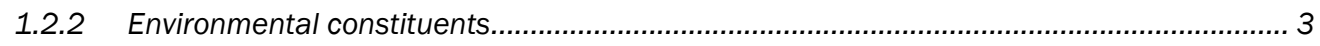

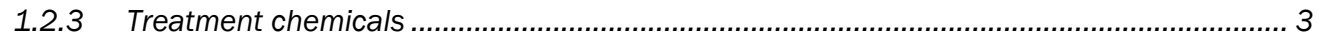

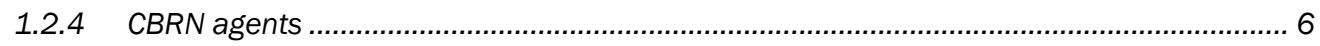

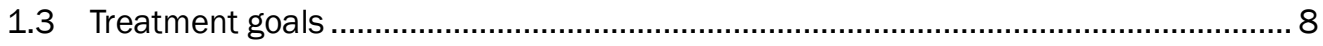

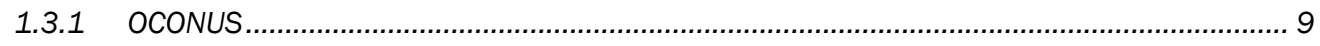

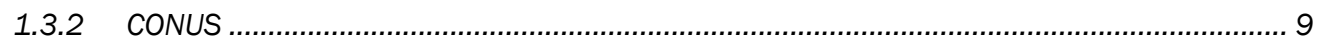

1.4 Current treatment systems for environmentally released CBRN agents .................. 10

1.4.1 Existing Army water treatment systems....................................................................... 10

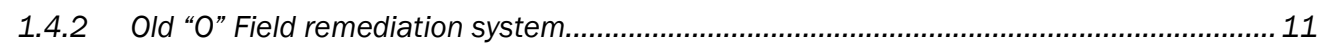

1.4.3 Treatment of contaminated water in the field............................................................... 12

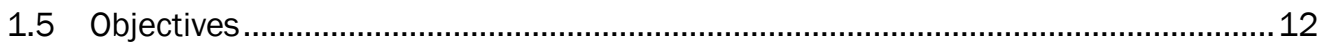

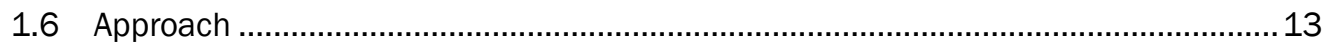

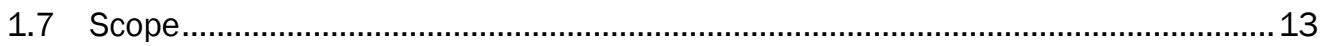

2 Design and Preliminary Testing of the Treatment System ..................................................14

2.1 Overview of design.................................................................................. 14

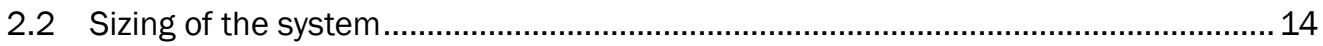

2.3 Treatment unit processes........................................................................ 15

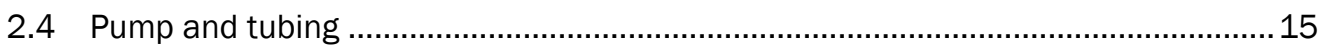

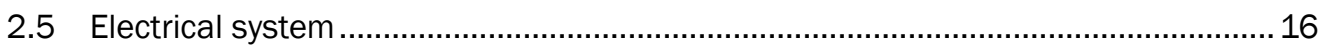

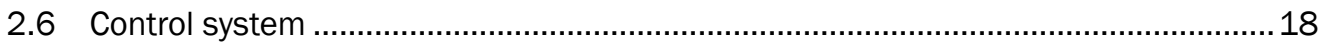

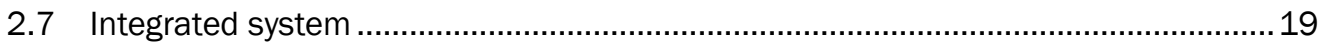

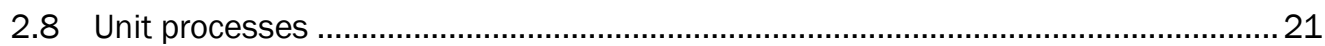

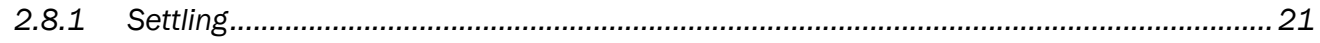

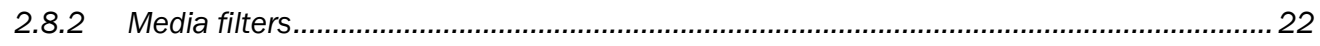

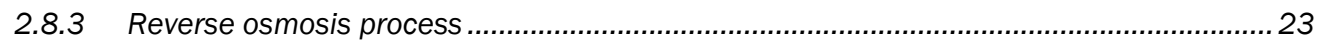

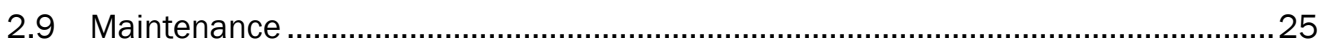

2.10 System costs, size \& weight ............................................................................ 25

3 Simulated Decontamination Operation...............................................................................27

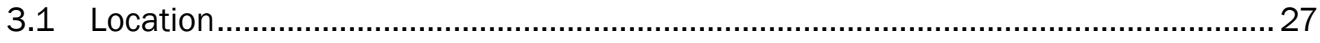




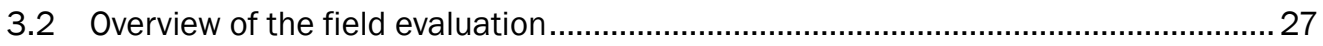

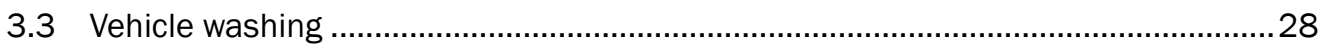

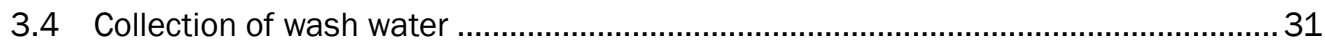

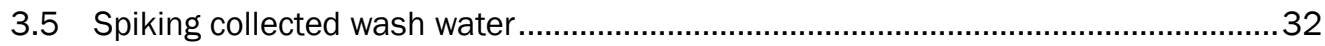

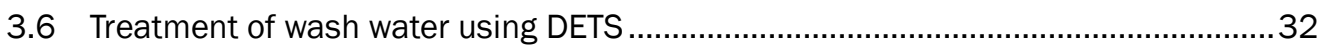

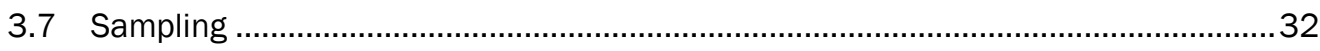

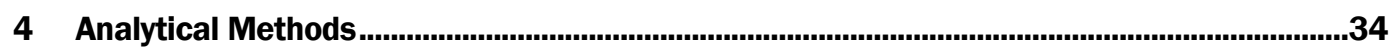

4.1 Malathion quantification based on phosphate analysis .......................................34

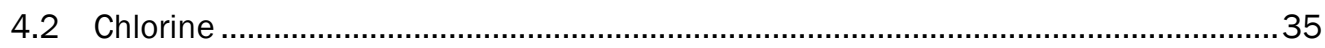

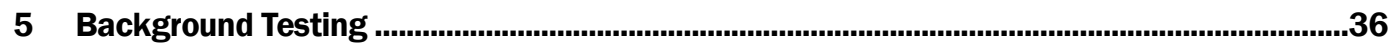

5.1 Evaluation of treatment approaches that were not included in the pilot-

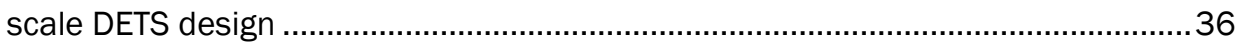

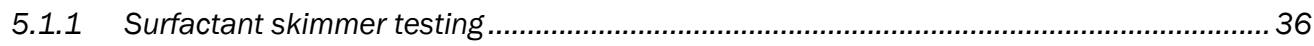

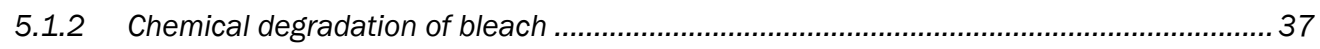

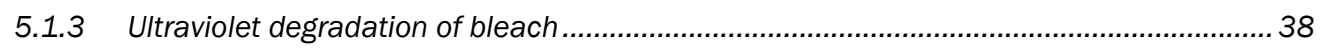

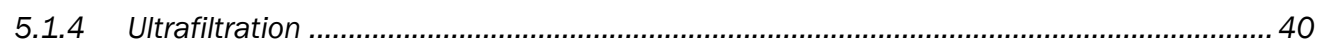

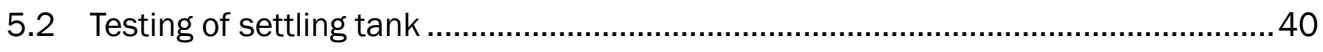

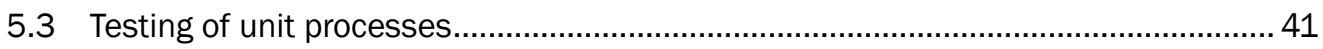

5.3.1 Scaled column testing of the media filters ................................................................... 41

5.3.2 Flat plate reactor evaluation of reverse osmosis ............................................................ 44

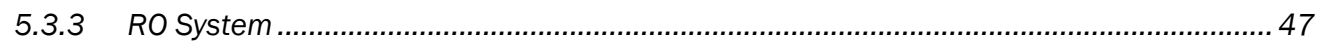

5.4 Laboratory testing of complete system …….................................................. 48

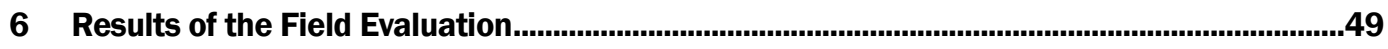

6.1 Assessment of the simulated decontamination effort ............................................49

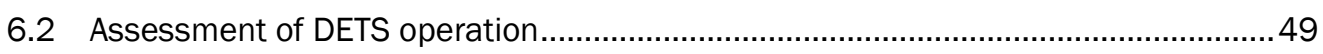

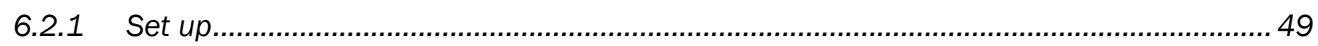

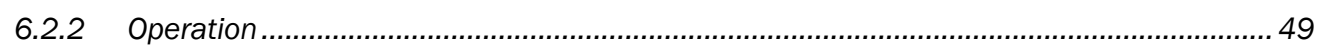

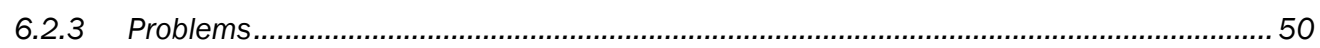

6.3 Analytical results of influent and treated water ….................................................52

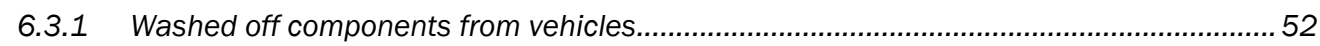

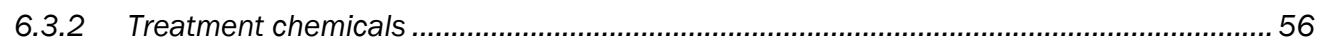

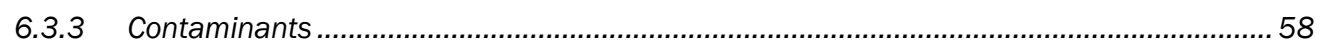

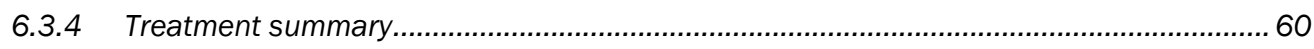

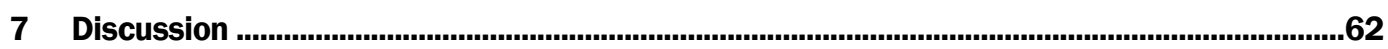

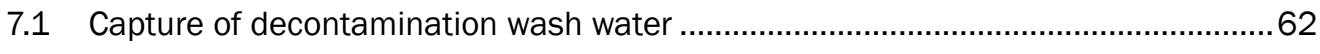

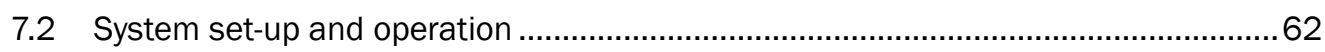

7.3 Treatment of constituents ............................................................................. 63

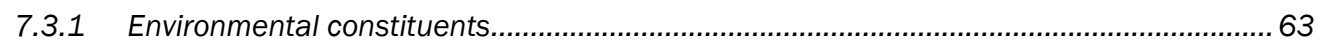

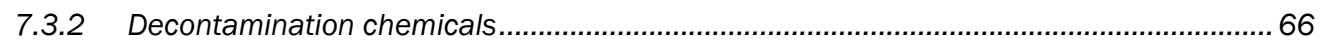

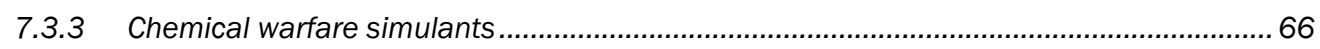

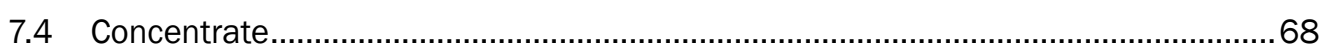

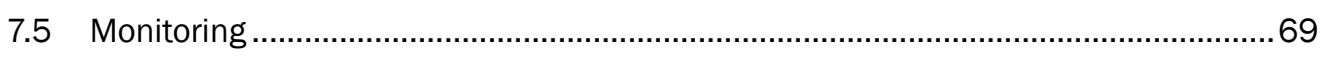

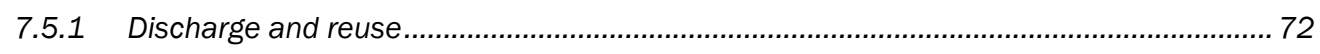




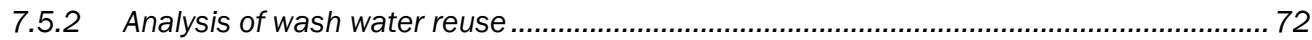

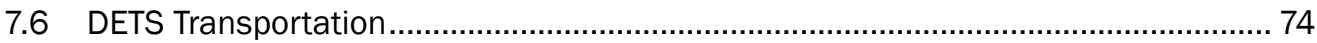

7.7 Feedback from invited stakeholders ........................................................... 75

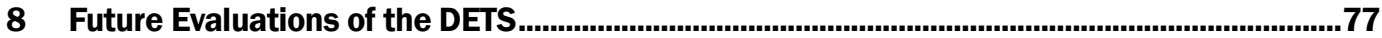

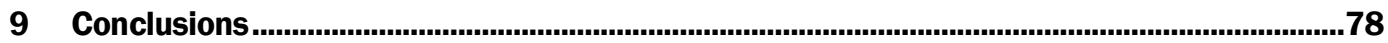

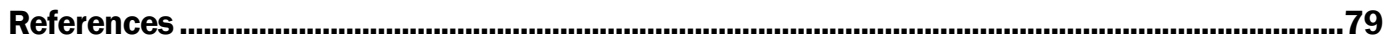

Appendix A: Public Affairs Storyboard Prepared on DETS Field Evaluation ..................................84

Appendix B: Specification Sheets on the Bredel 40 Pump (no endorsement implied) ................85

Appendix C: Specifications on Kubota Generator used in the study (no endorsement

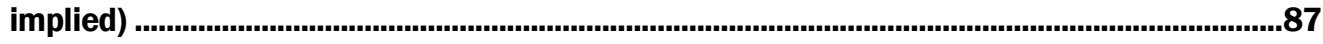

Appendix D: Specification Sheet for Fold-a-Tank (no endorsement implied) ............................91

Appendix E: Technical Specification Documents on Sand and Anthracite Used in Sand Media Bed (no endorsement implied) ....................................................................................92

Appendix F: Operating Manual for the Reverse Osmosis System (first six pages, no endorsement implied) ...............................................................................................................96

Appendix G: List of Stakeholder Participants who attended the DETS Field Evaluation .......... 101

Appendix H: Notes Collected from the Stakeholder Discussion immediately following the DETS Field Evaluation (Brame and Medina).

Appendix I: Report on the DETS Field Evaluation Prepared by Mr. Howard Beardsley, JPEOCBD

Report Documentation Page 


\section{Figures and Tables}

\section{Figures}

Figure 1. FY 16 publication estimating composition of decontamination wash water (Brame et al. 2016).

Figure 2. Surfactant/Water sample collected by ERDC from a CSTA training exercise showing high concentrations ( 3\%) of surfactant........................................................................... 4

Figure 3. Process flow diagram for the treatment system at the old "O" Field. ................................12

Figure 4. The Bredel 40 pump and hose reel used in the DETS. .....................................................16

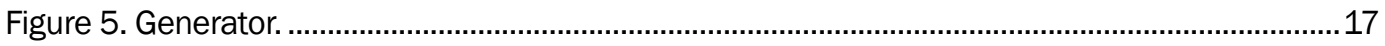

Figure 6. Generator grounding stake......................................................................................

Figure 7. EZ-Touch I/O control processor. ………………….....................................................18

Figure 8. Programming the EZ-touch processor using a laptop computer.........................................19

Figure 9. The touch screen control system (left) and the controls and monitoring gauges

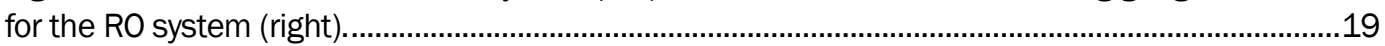

Figure 10. Schematic of the DETS (The ultraviolet [UV] treatment was not used in the field

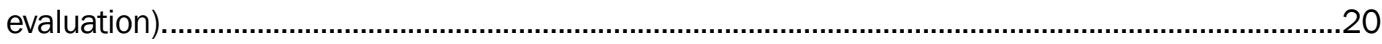

Figure 11. The trailer mounted DETS (photograph and labelling courtesy of Mr. Howard

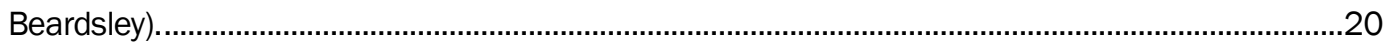

Figure 12. Aerial view of area for the simulated vehicle decontamination event on 27 June 2017............27

Figure 13. Overview of the DETS field evaluation........................................................................28

Figure 14. Soapy water and mops prepared for vehicle decontamination.......................................29

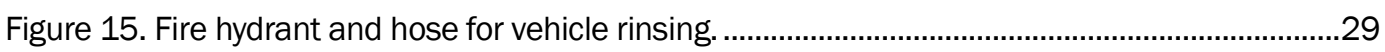

Figure 16. Rinsing vehicles using fire hose. .................................................................................30

Figure 17. Washing vehicles with soap.....................................................................................30

Figure 18. Washing large dirt clods off asphalt driveway. ..............................................................30

Figure 19. Open storm drain with inflatable pig to allow collection of wash water...........................31

Figure 20. Drain with grate replaced and sump pump hosing/power visible....................................31

Figure 21. 250 gallon tote used as the influent vessel for the treatment system............................32

Figure 22. Auto-sampler set up to collect samples during study........................................................33

Figure 23. Triplicate assessment of Malathion measurement based on digestion and phosphate measurement by comparing measured phosphate to theoretical...................................35

Figure 24. Picture of the foam separation skimmer........................................................................36

Figure 25. Results of a foam skimming test..............................................................................37

Figure 26. Sodium Thiosulfate. Chemical formula and powder form................................................37

Figure 27. Results of the bleach titration using sodium thiosulfate at an initial bleach

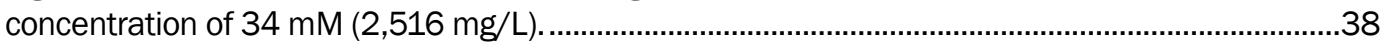

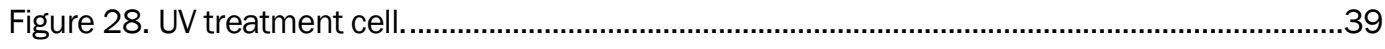

Figure 29. Hypochlorite degradation by LP-UV radiation. ...............................................................39

Figure 30. Ultrafiltration columns tested for treatment of cesium and Malathion. ............................40 
Figure 31. Pictures of the 2,500 gallon sedimentation tank set-up for sediment removal testing near creek at WES and picture inside tank showing sediment colored water.

Figure 32. Picture of column testing setup. ..............................................................................

Figure 33. Adsorptive removal of surfactant by GAC column.............................................................43

Figure 34. Treatment of Malathion by activated carbon..................................................................43

Figure 35. Treatment of Malathion with $10 \mathrm{mg} / \mathrm{L}$ LAS surfactant by activated carbon......................44

Figure 36. Pictures and schematic of the Osmonics Flat Plate RO system used in this

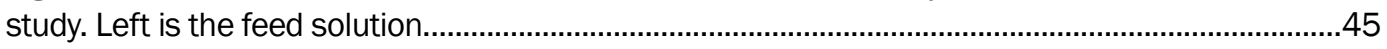

Figure 37. Scanning electron microscopy of the DOW membrane...................................................46

Figure 38. Pressure vs. flux for the three membranes studied. .....................................................46

Figure 39. Osmonics study of removal of Cesium using three RO membranes (Table 6). ................47

Figure 40. The Applied Membranes Inc. six-stage RO system........................................................4 47

Figure 41. Treatment of Malathion ( 8 to $9 \mathrm{mg} / \mathrm{L}$ ) by the six-stage RO system. ................................48

Figure 42. Comparison of reactor influent and effluent of a laboratory test conducted on

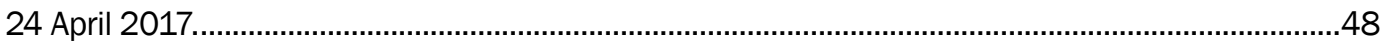

Figure 43. Cartridge Filter protecting the RO system from fine sediments....................................50

Figure 44. Wood bracing used for unit processes in this study. The wood bracing was replaced by welded metal bracing (Figure 61) ..............................................................................51

Figure 45. Supplemental generator used in this study to address amperage surge associated with the mechanical phase converter. ………....................................................................52

Figure 46. Comparison of samples collected from the system influent (left) and effluent (right). ...........53

Figure 47. Turbidity (influent and effluent) during the course of the field evaluation........................53

Figure 48. Total suspended solids (influent and effluent) during the course of the field

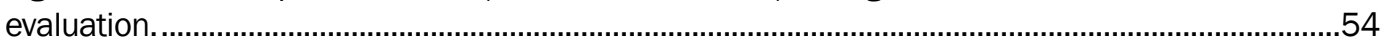

Figure 49. Rotometers to RO system, with the two on the left showing high turbidity in the system, and product flow on the right.

Figure 50. Conductivity measurements (influent and effluent) during the course of the field evaluation.

Figure 51. TOC measurements (influent and effluent) during the course of the field evaluation. .56

Figure 52. Reduction of surfactant concentrations during the experiment.

Figure 53. Colorimetric results for total chlorine. Sample on the left is the influent sample and has red color indicating high total chlorine concentration. The sample on the right is from the effluent and has no color, as chlorine is largely removed.

Figure 54. Bleach measured as available chlorine for samples collected during the field evaluation

Figure 55. Cesium concentrations for samples collected during the field evaluation.

Figure 56. Malathion concentrations in the course of the field evaluation as measured by counting phosphorus using IC.

Figure 57. NEXT-BETA-ABG radiological detector that could be adapted for the DETS. .70

Figure 58. A small, contained spectrophotometer that could be adapted for on-line monitoring.

Figure 59. GE Sievers online TOC analyzer. 
Figure 60. Total usable water volume and reject generated volume based on an initial 600 gallons of decontamination water and $85 \%$ recovery for two scenarios, one with no treatment of concentrate $(\mathrm{r} 1)$ and the second with a single treatment of the concentrate.

Figure 61. Bracing added to trailer to enhance support for system components (30

November 2017).

\section{Tables}

Table 1. Radiological isotopes of concern in decontamination operations.

Table 2. Planning Factors of Operational DECON (Army G3/5/7 Decontamination

Planning Factors)

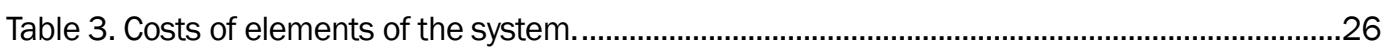

Table 4. Table summarizing analytical methods used on water samples...........................................34

Table 5. Evaluation of suspended solids removal using 2,500 gallon collapsible setting tank with 250 minute residence time. .......................................................................................... 41

Table 6. Three RO Membranes used in the laboratory test. ............................................................45

Table 7. Malathion measurements of sample four conducted by GC/NPD (USEPA 8141A)

in comparison to the same sample measured by the phosphorus counting method........................60

Table 8. Summary of treatment of key constituents by the DETS field evaluation.............................61

Table 9. Concentrations of constituents in collected concentrate and comparison to initial

concentrations.................................................................................................................................... 61 


\section{Preface}

The work was performed and funded for the Environmental Quality/Installations Program under the "Deployable Treatment of Decontamination Effluent" program and was funded by the under Work Unit 33143. Dr. Elizabeth Ferguson, Senior Scientific Technical Leader (SSTL), was the director of the Environmental Quality/Installations (EQI) Program, Dr. John Ballard served as the program manager.

This work was performed by the U.S. Army Engineer Research and Development Center (ERDC), Environmental Laboratory (EL), Vicksburg, MS. At the time of publication of this report, Dr. W. Andy Martin was Chief of the Environmental Engineering Branch (EPE), Mr. Warren P. Lorentz was Chief of the Environmental Processes and Engineering Division (EP), the Deputy Director of EL was Dr. Jack Davis, and the Director of EL was Dr. Ilker R. Adiguzel.

The authors would like to acknowledge the contributions Dr. Chris Griggs, Mr. Luke Gurtowski, Ms. Michelle Wynter, Mr. Michael Baker, Ms. Brooke Petery, and Dr. David Gent, all of EL, and of Ms. Mariah Fossella, Ms. Sarah Grace Zetterholm and Ms. Kate Noel, who had student appointments at the time of the field evaluation, for serving various, important roles during the field evaluation.

COL Ivan P. Beckman was Commander of ERDC and Dr. David W. Pittman was the Director. 


\section{Unit Conversion Factors}

\begin{tabular}{|l|l|l|}
\hline Multiply & By & To Obtain \\
\hline cubic feet & 0.02831685 & cubic meters \\
\hline cubic inches & 1.6387064 E-05 & cubic meters \\
\hline cubic yards & 0.7645549 & cubic meters \\
\hline degrees Fahrenheit & $(\mathrm{F}-32) / 1.8$ & degrees Celsius \\
\hline feet & 0.3048 & meters \\
\hline gallons (U.S. liquid) & 3.785412 E-03 & cubic meters \\
\hline horsepower (550 foot-pounds force per second) & 745.6999 & watts \\
\hline inches & 0.0254 & meters \\
\hline pounds (mass) & 0.45359237 & kilograms \\
\hline
\end{tabular}




\section{Acronyms and Abbreviations}

\begin{tabular}{|c|c|}
\hline AOP & Advanced Oxidation Process \\
\hline APG & Aberdeen Proving Grounds \\
\hline ASTM & $\begin{array}{l}\text { American Society for Testing and Materials, } \\
\text { International }\end{array}$ \\
\hline CARA & CBRNE Analytical and Remediation Activity \\
\hline $\mathrm{CBRN}(\mathrm{E})$ & $\begin{array}{l}\text { Chemical, Biological, Radiological, Nuclear, } \\
\text { (Explosive) }\end{array}$ \\
\hline CERF & CBRNE Enhance Response Force \\
\hline CERL & Civil Engineering Research Laboratory \\
\hline CONUS & within the Continental United States \\
\hline $\mathrm{CsCl}$ & Cesium Chloride \\
\hline CSTA & Civil Support Training Authority \\
\hline CWA & Chemical Warfare Agent \\
\hline DETS & Decontamination Effluent Treatment System \\
\hline DoD & Department of Defense \\
\hline $\mathrm{cm}$ & centimeter \\
\hline EL & Environmental Laboratory \\
\hline EPE & Environmental Engineering Branch \\
\hline ERDC & $\begin{array}{l}\text { Army Engineer Research and Development } \\
\text { Center }\end{array}$ \\
\hline EQI & Environmental Quality/Installations \\
\hline g & gram \\
\hline GAC & Granular Activated Carbon \\
\hline GB & sarin \\
\hline GC/NPD & $\begin{array}{l}\text { Gas Chromatography/Nitrogen Phosphorus } \\
\text { Detector }\end{array}$ \\
\hline GE & General Electric \\
\hline $\mathrm{gpm} / \mathrm{h}$ & gallons per minute/hour \\
\hline GSL & Geotechnical and Structures Laboratory \\
\hline
\end{tabular}




$\begin{array}{ll}\text { HD } & \text { sulfur mustard agent } \\ \text { HTH } & \text { High test hypochlorite } \\ \text { IC } & \text { Ion Chromatography with UV/Visible } \\ & \text { Spectrophotometric detector } \\ \text { ID } & \text { Internal Diameter } \\ \text { I/O } & \text { Input/Output } \\ \text { JPdM-CBRNE A\&RS } & \text { Joint Product Manager -Chemical, Biological, } \\ & \text { Radiological, Nuclear, and Explosives (CBRNE) } \\ & \text { Analytics \& Response Systems } \\ \text { JPEOCBD } & \text { Joint Program Executive Office Chem/Bio } \\ & \text { Defense } \\ \text { JPM-P } & \text { Joint Program Manager-Protection } \\ \text { Kg } & \text { kilogram } \\ \text { kPa } & \text { Kilo Pascal(s) } \\ \text { L } & \text { liter(s) } \\ \text { LAS } & \text { Linear Alkylbenzene Sulfonate (a common } \\ & \text { surfactant form) } \\ \text { LWP } & \text { Lightweight Water Purifier } \\ \text { mg } & \text { milligram } \\ \text { min } & \text { minute } \\ \text { MOPP } & \text { Mission Oriented Protective Posture } \\ \text { mL } & \text { milliliter(s) } \\ \text { MW } & \text { Molecular Weight } \\ \text { NaOCL } & \text { Sodium hypochlorite } \\ \text { NAS } & \text { National Academy of Sciences } \\ \text { NORTHCOM } & \text { Northern Command } \\ \text { NTA } & \text { Non-traditional threat agent } \\ \text { NTU } & \text { Nephelometric Turbidity Units } \\ \text { OCONUS } & \text { Outside the Continental United States } \\ & \text { overseas) } \\ & \\ & \end{array}$




\begin{tabular}{|c|c|}
\hline OEBGD & $\begin{array}{l}\text { Overseas Environmental Baseline Guidance } \\
\text { Document }\end{array}$ \\
\hline PLC & programmable logic controller(s) \\
\hline POTW & $\begin{array}{l}\text { Publically Owned Treatment } \\
\text { (water/wastewater) Works }\end{array}$ \\
\hline ppm & parts per million \\
\hline psi & pounds per square inch \\
\hline RDD & radiological dispersal devise \\
\hline RDECOM & $\begin{array}{l}\text { (Army) Research Development and } \\
\text { Engineering Command }\end{array}$ \\
\hline RO & Reverse Osmosis \\
\hline ROWPU & Reverse Osmosis Water Purification Unit \\
\hline SEM & Scanning Electron Microscopy \\
\hline SLS & Sodium Laurel Sulfate \\
\hline STB & Supertropical Bleach \\
\hline SSTL & Senior Scientific Technical Leader \\
\hline TARDEC & $\begin{array}{l}\text { (Army RDECOM) Tank/Automotive Research } \\
\text { Development and Engineering Center }\end{array}$ \\
\hline TOC & Total Organic Carbon \\
\hline TRL & Technology Readiness Level \\
\hline TSS & Total Suspended Solids \\
\hline TWPS & Tactical Water Purification System \\
\hline UF & Ultrafiltration \\
\hline US & United States \\
\hline USACE & United States Army Corps of Engineers \\
\hline USAMRIID & $\begin{array}{l}\text { United States Army Medical Research Institute } \\
\text { of Infectious Diseases }\end{array}$ \\
\hline USDoD & United States Department of Defense \\
\hline USEPA & $\begin{array}{l}\text { United States Environmental Protection } \\
\text { Agency }\end{array}$ \\
\hline UV & Ultraviolet (light) \\
\hline
\end{tabular}


VFD

WES

WWTP

$\mu g$

$\mu \mathrm{S}$ variable frequency drive(s)

Waterways Experiment Station

Wastewater Treatment Plant(s)

microgram

microsiemens 


\section{Introduction}

\subsection{Purpose of Study}

This project focuses on the wastewater generated from decontamination after a Chemical, Biological, Radiological, Nuclear (CBRN) attack. The U.S. Department of Defense (DoD), U.S. Army, and U.S. Environmental Protection Agency (USEPA) currently have no capability to treat and/or recycle the effluent from its aqueous based CBRN decontamination operations. This effluent is still very hazardous and can be a major logistical and political burden. To address this, a project titled "Deployable Treatment of Decontamination Effluent" was formed to develop and evaluate technologies and approaches to achieve effective treatment. The project has led to the development of an alpha, or first, version of a full-scale treatment system, named the Deployable Effluent Treatment System (DETS).

This specific study was a large scale evaluation of the DETS. The first goal was to demonstrate that treatment is feasible and can be integrated into the CBRN process. The second goal was to assess the treatment performance of the system. The third goal was to identify shortcomings of the system with the premise that any such shortcomings would be addressed in a beta, or second, version of the treatment system. Appendix A contains a story board prepared on the field evaluation.

\subsection{Decontamination wastewater}

\subsubsection{Decontamination}

Decontamination is the process of removing or neutralizing CBRN materials from people, equipment, or the environment, following an accidental or purposeful release. Military decontamination became a priority following the introduction of large-scale chemical warfare during World War I (Smart 2002), and the U.S. military continues to maintain extensive decontamination capabilities to remove contaminants from personnel, vehicles, and equipment. Decontamination can be accomplished through physical removal (e.g., spraying, washing, or wiping to physically dislodge contaminants), neutralization (i.e., addition of reactive chemicals or enzymes), or often a combination of physical removal and neutralization. Enzymatic treatment is being adopted in Europe, but is in the exploratory state in the United States (Boone 2007). 
While effective, these processes generally require large amounts of water (Altman and Richardt 2008), this can strain supply lines and logistics (Horne 2015), especially in extreme operations. Furthermore, collection and storage of the water used for decontamination, into which the CBRN contaminants are transferred during decontamination, becomes a logistical issue and must eventually be removed and/or treated to avoid reintroducing contaminants to troops, civilians, or local ecosystems and water supplies.

A review of literature and doctrine revealed that there has not been detailed studies on decontamination effluent. To fill the need for this knowledge, an earlier task related to this project was conducted, this produced a study estimating the composition of decontamination wash water (Brame et al. 2016) (Figure 1).

Figure 1. FY 16 publication estimating composition of decontamination wash water (Brame et al. 2016).

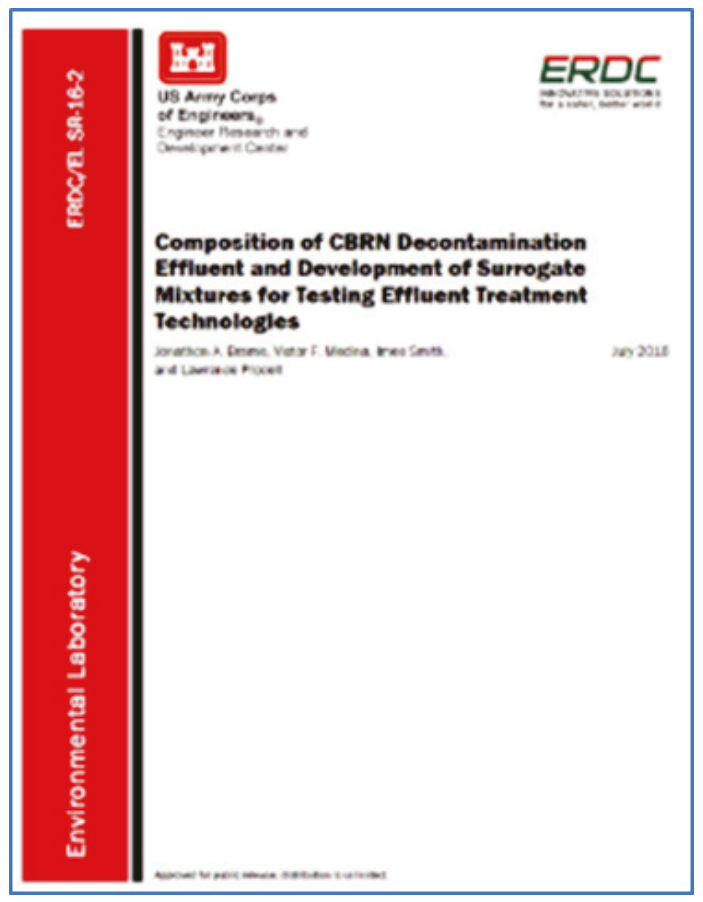

This report breaks out constituents in decontamination wash water into the following three categories:

- Environmental Constituents

- Treatment Chemicals 
- CBRN constituents, including Chemical Warfare Agents (CWAs) and Radiological Isotopes.

\subsubsection{Environmental constituents}

Environmental constituents are chemicals, particles, and other materials found in the wash water associated with the environment in which the decontamination event is occurring. The water source used for decontamination is the first source of environmental constituents. Potable water could include constituents like chlorine residuals. Other water sources could also be used, for example, groundwater may have high dissolved solids or surface water could contain suspended sediment and/or dissolved organic material. Another source of environmental constituents are those washed off of the decontamination target. This can include dirt and sediment washed off vehicles, people or surfaces, oil and grease washed off vehicles, and metal or organic contaminants (including plant material, clothing, dead skin) removed during the washing process.

\subsubsection{Treatment chemicals}

Chemicals are commonly added to water to enhance the decontamination process. These include surfactants, bleach, and other treatment chemicals.

\subsubsection{Surfactants}

Surfactants (e.g., soaps) are added to increase removal of contaminants, both organic and inorganic, from surfaces. Surfactants work by decreasing surface tensions with agents and water, allowing for increased removal of adsorbed contaminants. Furthermore, concentrated surfactants can cause cells to lyse, thereby exhibiting a disinfection process. Specialty surfactants have been developed for industrial cleaning and for decontamination, however, dish and laundry detergents are commonly used as well and can be very effective. Surfactants include the following:

- Triton-X $100-1 \% \mathrm{v} / \mathrm{v}$

- Tergitol 15S-9 (Dow Chemical) - 1\%

- Synthetic nonionic detergent, military specification MIL-D-16791. $\sim 0,1$ to $1 \%$

- Triethanolamine (commonly found in laundry detergent) - 3 to $5 \%$

- Sodium lauryl sulfate/sodium dodecyl sulfate (commonly found in dishwashing detergent) -1 to $30 \%$. 
Sodium lauryl sulfate (SLS) is a commonly used surfactant. It is a very effective degreaser and mild to the skin, making it attractive for human decontamination. It does have the disadvantage of foaming excessively. SLS is the primary surfactant found in many commercial dish detergents, most notably blue Dawn dish soap. This soap has achieved recognition for being an effective degreasing agent for wildlife affected by oil spills.

Surfactants can be added in high concentrations. Figure 2 is a water/surfactant mixture collected from a Civil Support Training (CST) exercise in Alabama that ERDC was able to observe that shows the high amount of surfactant added. The exercise used a SLS surfactant. The studies presented in this report focused on SLS surfactants. SLS is part of a family of surfactants referred to as Linear Alkylbenzene Sulfonic Acid (LAS). Surfactant measurements were normalized to LAS.

Surfactants can display aquatic and terrestrial toxicity at high concentrations (Ying 2006). However, they can also be removed from discharge water by adsorption and by biodegradation (Ying 2006). Most surfactants are amenable to biodegradation, particularly aerobic (Ying 2006).

Figure 2. Surfactant/Water sample collected by ERDC from a CSTA training exercise showing high concentrations $(\sim 3 \%)$ of surfactant.

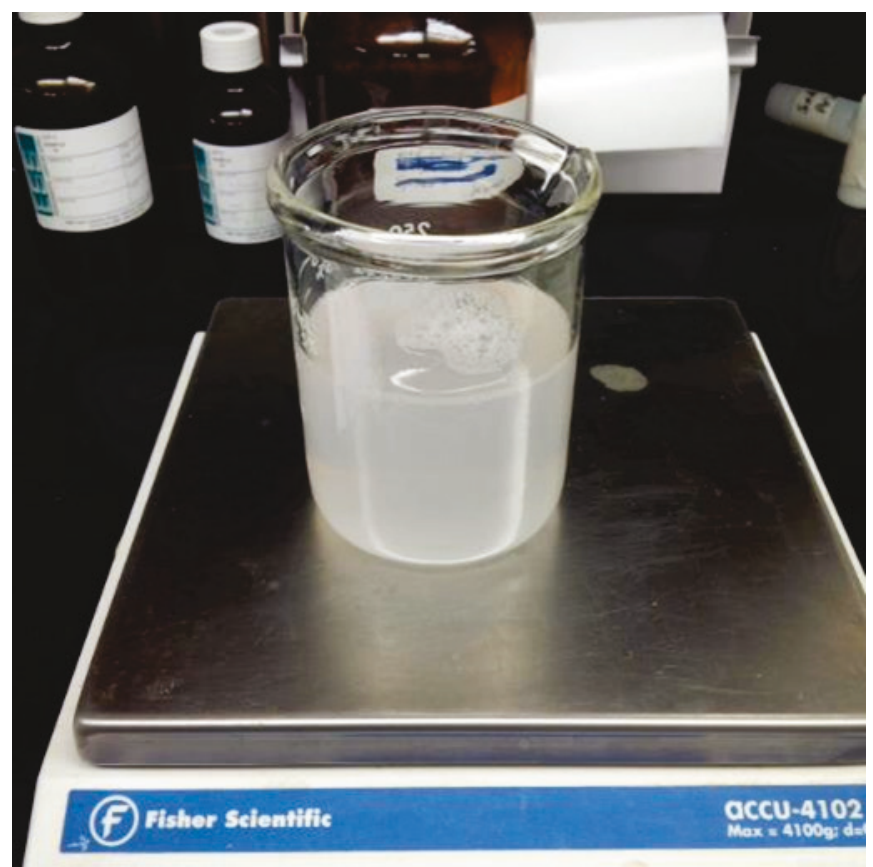




\subsubsection{Bleach}

Bleach (sodium hypochlorite, $\mathrm{NaOCl}$ ) is the most commonly used chemical to deactivate chemical and biological agents. Bleach was first used in 1917 by Germany to decontaminate a massive mustard agent release resulting from an explosion at one of their manufacturing facilities, and it proved to be very effective (Smart 2002). Since then, bleach has been found to work for most chemical and biological agents.

When applied to water, sodium hypochlorite quickly dissociates, forming the hypo-chlorite ion (Snoeyink and Jenkins 1980)

$$
\mathrm{NaOCl} \leftrightarrow \mathrm{Na}^{+}+\mathrm{OCl}^{-}
$$

The hypochlorite ion will establish an equilibrium in with hypochlorous acid (HOCl), a weak acid

$$
\mathrm{OCl}^{-}+\mathrm{H}^{+} \leftrightarrow \mathrm{HOCl}, \mathrm{pKa}=7 \cdot 5 .
$$

Hypochlorite ion is an effective catalyst for the hydrolysis of organophosphorus nerve agents (Kingery and Allen 1995).

One of the most effective bleach forms is supertropical bleach (STB), this is a powdered bleach mixed with $70 \%$ calcium oxide (Smart 2002). The calcium oxide allows the bleach to remain stable even when stored in hot, humid environments. However, STB is expensive to produce, has limited commercial uses, and can be costly and difficult to obtain. Therefore, other bleach products are used such as High Test Hypochlorite (HTH). HTH is a common bleach material that is readily available (e.g., it is commonly used in swimming pools) and is historically effective.

\subsubsection{Other}

Surfactants and bleach are by far the most commonly used decontamination additives in the United States. However, there is continuing experimentation with other additives that may become more common for use in the future. Hydrogen peroxide is a strong oxidant that can be effective at degrading chemical warfare agents and at killing biological agents. Enzyme treatments have also been explored for both chemical and biological agents, particularly in Europe (Boone 2007). Fixatives have been studied primarily for radiological agents. These are 
applied to control the migration of radiological particles, but are then removed. Powders can be used to adsorb chemicals or particulate contaminants. A treatment system design must be flexible enough to be applied to a wide range of decontamination options.

\subsubsection{CBRN agents}

CBRN agents may be divided into the three following types: chemical agents, biological agents, and radiological agents (found in both radiological and in nuclear events). An event could involve one or more agent types.

\subsubsection{Chemical agents}

There are a wide range of chemical agents that can be used in a chemical warfare attack. These include, but are not limited to the following:

- Organophosphate compounds

- Mustard agents

- Strong, gaseous oxidants

- Acids

- Metals, usually coupled with organic compounds.

Traditional CWAs are generally considered to be relatively non-persistent as many are susceptible to hydrolysis reactions (Munro et al. 1999; Prentiss 1937). However, their degradation by-products can still be toxic and are frequently more persistent. Further, agents have been found to remain in the environment for many years if conditions for degradation are not present, such as low water or $\mathrm{pH}$ out of ideal range for degradation (Munro et al. 1999).

Non-traditional threat agents (NTAs) are new materials that have properties contrary to traditional agents. For example, these can be more persistent or have a non-lethal, but debilitating effect. Chemical agents can also include improvised devises using toxic industrial chemicals or hazardous waste/materials.

Organophosphorus CWAs are very toxic, and can be easily obtained or manufactured. This project has focused on these CWAs. Brame et al. (2016) determined that the pesticide, Malathion, would be a suitable surrogate for organophosphorus CWAs. 


\subsubsection{Biological agents}

Biological agents can be divided into two classes. The first are highly pathogenic organisms that can be released into an environmental to cause infection, disease, and death. These include, but are not limited to, the following:

- Botulism

- Ebola

- Small Pox

- Anthrax.

Small pox is a highly virulent disease that has been publically eliminated due to a highly effective vaccination program. However, strains have been preserved for research purposes, and it is believed that weaponized forms were developed by the former Soviet Union. Anthrax is potentially a highly effective bioweapon. It is highly pathogenic and can be stored for long periods as spores. It is easy to cultivate and disperse.

The Second, biotoxins, are another potential biological weapon. These include, but are not limited to, the following:

- Ricin

- Strychnine

- Botulism toxins.

Biotoxins can be treated like a CWA in terms of water treatment.

Like chemical weapons, it is possible that a biological attack can focus on improvised microorganisms and toxins. Molds could be troublesome, as they also form spores that can cause debilitating respiratory injury, and algal toxins like microcystin can cause liver damage (Herman et al. 2017; Medina et al. 2016). The program chose not to simulate biological agent decontamination in the DETS research program. Future studies could explore the use of this non-infectious genera. For example, Bacillus anthracis is a highly infectious organism, but Bacillus globigii is much safer to work with and shares many similarities. 


\subsubsection{Radiological agents}

Radiological agents are those that produce ionizing radiation. Radiation is divided into three following types: alpha, beta, and gamma/X-ray. Alpha is a low energy, high mass radiation. As such, it has limited penetrating power and can easily be shielded - dead skin cells are generally sufficient. However, if ingested or inhaled, alpha particles can cause substantial damage and possibly death. Beta particles have higher energy and can penetrate the human body more readily, but are still easily blocked by clothing materials. Gamma rays are extremely penetrating, and can be very problematic. Table 1 summarizes different radioisotopes the primary form of radiation they emit.

Table 1. Radiological isotopes of concern in decontamination operations.

\begin{tabular}{|l|l|l|}
\hline Alpha particle emitters & Beta particle emitters & Gamma ray emitters \\
\hline Americium-241 $\left({ }^{241} \mathrm{Am}\right)$ & Phosphorus-32 $\left({ }^{32} \mathrm{P}\right)$ & Cobalt-60 $\left({ }^{60} \mathrm{Co}\right)$ \\
\hline $\begin{array}{l}\text { Plutonium-239/238 } \\
\left({ }^{239} \mathrm{Pu} \text { and }{ }^{238} \mathrm{Pu}\right)\end{array}$ & Strontium-90 $\left({ }^{90} \mathrm{Sr}\right)$ & Iodine-131 $\left({ }^{131}\right)$ \\
\hline Uranium $(\mathrm{U}-235)$ & & Cesium-137 $\left({ }^{137} \mathrm{Cs}\right)$ \\
\hline Thorium $($ Th-232) & & Iridium-192 $\left({ }^{192} \mathrm{Ir}\right)$ \\
\hline
\end{tabular}

Adapted from Zimmerman and Loeb (2004)

Of these various forms, ${ }^{137} \mathrm{Cs}$ stands out as a particularly problematic radiological isotope. It is readily available as it is found in a variety of commonly available equipment (i.e., X-ray machines and seed irradiators). It can be milled into fine powders, making it easy to disperse in a radiological dispersal devise (RDD), and it emits a powerful, penetrating gamma emission, that can cause severe damage to affected humans. Furthermore, it is highly soluble, and as a monovalent cation, it would likely be difficult to treat when dissolved in water. Therefore, the DETS studies have focused on this as a target radioisotope. To simulate it, a non-

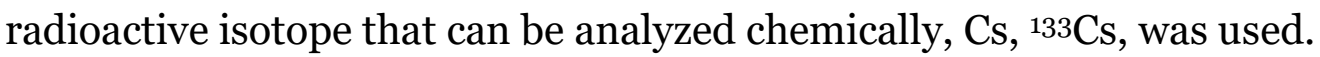

\subsection{Treatment goals}

Treatment goals vary depending on if the event is outside the United States (OCONUS) or within the United States (CONUS). 


\subsubsection{OCONUS}

Use of the DETS overseas would be straightforward from a discharge standpoint. For OCONUS operation guidance, the U.S. Army uses the Overseas Environmental Baseline Guidance Document (OEGBD) (USDoD 2007). This guidance suggests that the treated effluent can be discharged. There is not a specific requirement for chemical warfare agents, but total toxic organic compounds must be less than $0.01 \mathrm{mg} / \mathrm{L}$ (section C4.2.28).

The ERDC team discussed requirements for reuse of treated decontamination effluent for additional decontamination (particularly vehicular and equipment decontamination) with the Army Public Health Command. These discussions indicated that reuse would be appropriate because the soldiers conducting decontamination would be in a Mission Oriented Protective Posture (MOPP) wearing standard CBRN protective gear.

\subsubsection{CONUS}

Striano (2011) summarizes the results of a workshop of technologists and regulatory experts on the issue of release of treated discharges (i.e., an advanced oxidation process $[\mathrm{AOP}]$ ) into wastewater treatment plants [WWTPs] and publically owned treatment works (POTWs). It was determined that untreated discharges of decontamination water from CWAs could contaminate key infrastructure, such as sewage conveyance systems and wastewater treatment vessels and equipment. Similarly, discharges of radioisotopes, and of highly infectious microorganisms (e.g., Ebola), can contaminate sewage infrastructure and cause exposures to workers and environmental releases (USEPA 2013; Bibby et al. 2016). Pretreatment of decontamination effluent would avoid these issues.

Still, there are some regulatory concerns. WWTPs have National Pollutant Discharge Elimination System (NPDES) permits, which can have limitations on CWAs and other constituents. A treatment system should remove these, but without testing, a WWTP operator maybe skeptical. The testing of the DETS will provide confidence so that WWTP operators will be more likely to allow sanitary sewer discharge of treated wash water. Furthermore, NPDES permit waivers can be issued under emergencies and a large CBRN attack would likely qualify for a waiver. 
Ultimately, a treatment system would be more desirable than untreated decontamination water discharges. Good communication will be critical to accelerate the discharge process and to relieve concerns of WWTPs and POTW operators. Regardless of the additional knowledge this work provides, it might take some time (24-48 hr) before discharge can be fully approved. By providing data such as this document and other testing, the approval process can be greatly accelerated or even pre-approved.

\subsection{Current treatment systems for environmentally released CBRN agents}

\subsubsection{Existing Army water treatment systems}

Balling (2009) provides an excellent overview of existing water purification systems developed by the U.S. Army Research Development and Engineering Command - Tank/Automotive Research, Development, and Engineering Center (RDECOM-TARDEC). Several systems currently exist including the following:

- 3000 gph $(11,400 \mathrm{~L} / \mathrm{h})$ Reverse Osmosis Water Purification Unit (ROWPU)

- 600 gph $(2,280 \mathrm{~L} / \mathrm{h}) \mathrm{ROWPU}$

- 1500 gph (5,700 L/h) Tactical Water Purification System (TWPS)

- 75 to 125 gph (285 to 4,750 L/h) Lightweight Water Purifier (LWP)

These units are designed to be portable and to produce potable water from virtually any water source. However, the goals of these units is different than that of the DETS to include:

- The water source targeted by the DETS, decontamination water, would never be considered as a potable water source. Although the water treatment units would be able to be used for this water, the high levels of surfactants and bleach would endanger the membrane systems that are the heart of each system. Use of a water purification system for decontamination wash water may result in the de-commissioning of a water purification system, this is costly and would reduce the ability of the Army to purify drinking water.

- The treatment goals of these systems differ. The DETS focuses on allowing water to be safely discharged, or to be reused for additional decontamination. Although this requires high quality treatment, it is 
not the goal to achieve potable standards required by the water purification systems.

\subsubsection{Old "0" Field remediation system}

The Old "O" Field site located at the Aberdeen Proving Ground, Aberdeen, MD, was a disposal site used by the Edgewood Arsenal to dispose of chemical, biological, and radiological wastes, including waste munitions (i.e., white phosphorus), this historically had caused on site fires before the site was covered. The field is approximately 4.5 acres in area and has

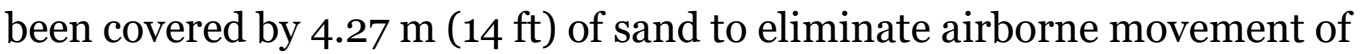
the contaminants. It is now a Superfund site, and a treatment system has been installed since 1999 to treat groundwater generated in the site.

Water is extracted from eight wells around the Old "O" Field site. The treatment system treats approximately 42,00o gallons per day at about 30 gallons per minute (so approximately three times the flow rate of the DETS). Treated water is discharged into the Gunpowder River.

Figure 3 shows the process flow diagram of the groundwater treatment system at the Old "O" Field. The process uses lime softening and sand filtration for metals and particulate removal, followed by Ultraviolet/ Oxidation and granular activated carbon adsorption to remove problematic organic compounds. 
Figure 3. Process flow diagram for the treatment system at the old " 0 " Field.

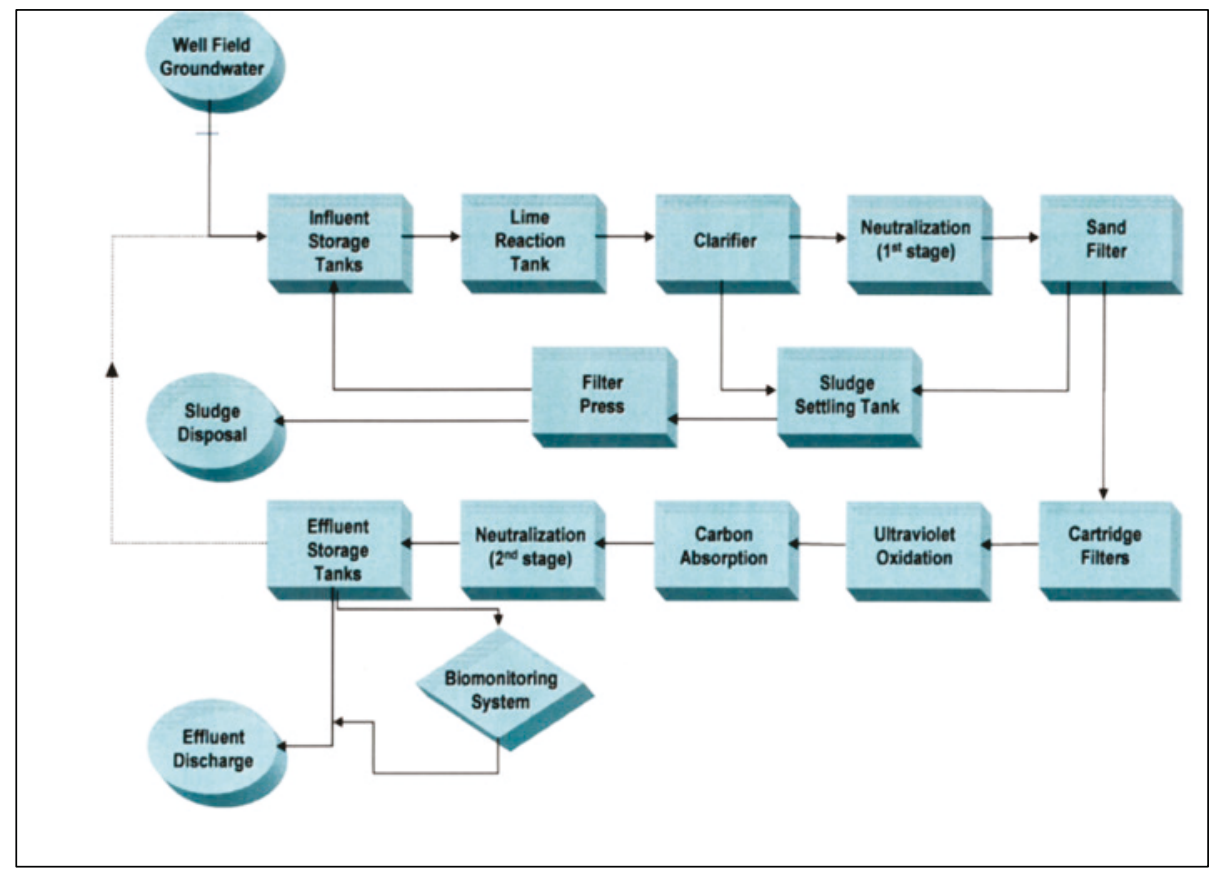

\subsubsection{Treatment of contaminated water in the field}

The ERDC team interviewed members of the $20^{\text {th }} \mathrm{CBRN}$ (E) Command CBRN(E) Analytical and Remediation Activity (CARA). These teams specialize in addressing small releases of CBRN(E) agents throughout the world. The CARA team we interviewed seindicated that the current practice of addressing $\mathrm{CBRN}(\mathrm{E})$ contaminated water is to treat it with high concentrations of bleach. However, the quantities are generally small, on the order of a 55-gallon drum.

In reviewing the aqueous CBRN treatment processes discussed in sections 1.4.2 to 1.4 .3 , it is clear that the goals of treatment are substantially different than those of the DETS. The remediation case (1.4.2) is a fixed system that incorporates more than ten separate unit processes. It would not be a suitable system to transport. The CARA approach (1.4.3) is focused on very small quantities of contaminated water, and would not be suitable for upscaling.

\subsection{Objectives}

This study was a large scale evaluation of the DETS with three goals. The first goal was to demonstrate that treatment is feasible and can be integrated into the CBRN process, the second goal was to assess the 
treatment performance of the system, and the third goal was to identify shortcomings of the system with the premise that any such shortcomings would be addressed in a beta version of the treatment system. Appendix A contains a story board prepared on the field evaluation.

\subsection{Approach}

This project focuses on the wastewater generated from decontamination after a Chemical, Biological, Radiological, Nuclear (CBRN) attack. As discussed, there is no capability to treat and/or recycle the effluent from aqueous based CBRN decontamination operations. This effluent may still be very hazardous and can be a major logistical and political burden.

\subsection{Scope}

The "Deployable Treatment of Decontamination Effluent" project was formed to develop and evaluate technologies and approaches to achieve effective treatment. The project has led to the development of an alpha version of a full-scale treatment system, called the Deployable Effluent Treatment System (DETS). 


\section{Design and Preliminary Testing of the Treatment System}

\subsection{Overview of design}

As discussed in section one, decontamination can result in a variety of potential contaminants at a wide range of concentrations. It is simply not possible to anticipate what CBRN agent would be used ahead of time, let alone the environmental conditions that may also affect treatment. Therefore, a decontamination effluent treatment system must be able to treat a wide range of potential contaminants from dilute to highly concentrated concentrations. The system must also be rapidly deployable and easy to maintain. The goal of such a system would be to minimize decontamination water requirements and minimize the volume of decontamination waste requiring management/disposal.

\subsection{Sizing of the system}

The system was sized to address a large chemical release event involving both people and vehicles. For this study, 200 people and ten large military vehicles were chosen to represent a company sized event (companies range from 80 to 250 people, an event would likely effect a portion of the unit). Water use factors were calculated from the Army G3/5/7 Decontamination Planning Factors (Table 2, as reported in Brame et al. [2016]).

Table 2. Planning Factors of Operational DECON (Army G3/5/7 Decontamination Planning Factors).

\begin{tabular}{|l|l|l|l|l|}
\hline Mission & Coverage & $\begin{array}{l}\text { Water } \\
\text { required (gal) }\end{array}$ & $\begin{array}{l}\text { STB* required } \\
\text { (lbs) }\end{array}$ & Time (min) \\
\hline Detailed troop DECON & 40 man unit & 318 & 600 & 40 \\
\hline Supported Operational DECON & Wheeled Platoon (10 vehicles) & 1500 & 0 & 30 \\
\hline $\begin{array}{l}\text { Detailed Equipment DECON } \\
\text { (Heavy decontamination) }\end{array}$ & Wheeled Platoon (10 vehicles) & 4700 & 600 & 75 \\
\hline Terrain Decontamination & $500 \mathrm{~m} \times 30 \mathrm{~m}$ area & 1500 & 300 & 40 \\
\hline
\end{tabular}

*STB is Supertropical bleach

Troop DECON assumes troops were adequately protected (as opposed to mass casualty) 
Assuming that the treatment system could treat the water generated in a day over a 12-hour period, the following flow rates were estimated:

For 200 people

$$
200 \text { people } \times \frac{8 \mathrm{gal}}{\text { person }} \times \frac{1 \mathrm{hr}}{60 \mathrm{~min}} \div 12 \mathrm{hr}=2.22 \frac{\mathrm{gal}}{\min }
$$

For ten large military vehicles

$$
10 \text { vehicles } \times \frac{470 \mathrm{gal}}{\text { vehicle }} \times \frac{1 \mathrm{hr}}{60 \mathrm{~min}} \div 12 \mathrm{hr}=6.53 \frac{\mathrm{gal}}{\mathrm{min}}
$$

Combining these gives a total rate of $8.75 \mathrm{gpm}$. This value was rounded up to a target of $10 \mathrm{gpm}(38 \mathrm{~L} / \mathrm{min})$.

\subsection{Treatment unit processes}

The system was designed to remove key contaminants from the waste stream. This includes the removal of particles and sediments, bleach, surfactants, oils and greases, and CBRN agents. As mentioned above, CBRN agents consist of chemical, biological, and radiologic contaminants, which can exist in many different forms. For example, in considering chemical agents, these can exist as dissolved chemicals, separate phases of chemical agents (which would behave similar to a particulate), integrated in a surfactant emulsion, or adsorbed on a soil particulate. The treatment system was designed specifically to be agnostic and capable of treating each of these contaminant types and forms.

\subsection{Pump and tubing}

The DETS uses a Bredel 40 hose pump (Figure 4) made by WatsonMarlow Fluid Technology Group (Wilmington, MA). This pump is designed for low maintenance, is self-priming, and has a robust design for protection against aggressive chemicals or abrasives. The pump uses a peristaltic process, this means that the water does not actually touch working parts, making service much safer in a CBRN environment. Appendix B contains the specification sheet for the Bredel 40 pump. 
Figure 4. The Bredel 40 pump and hose reel used in the DETS.

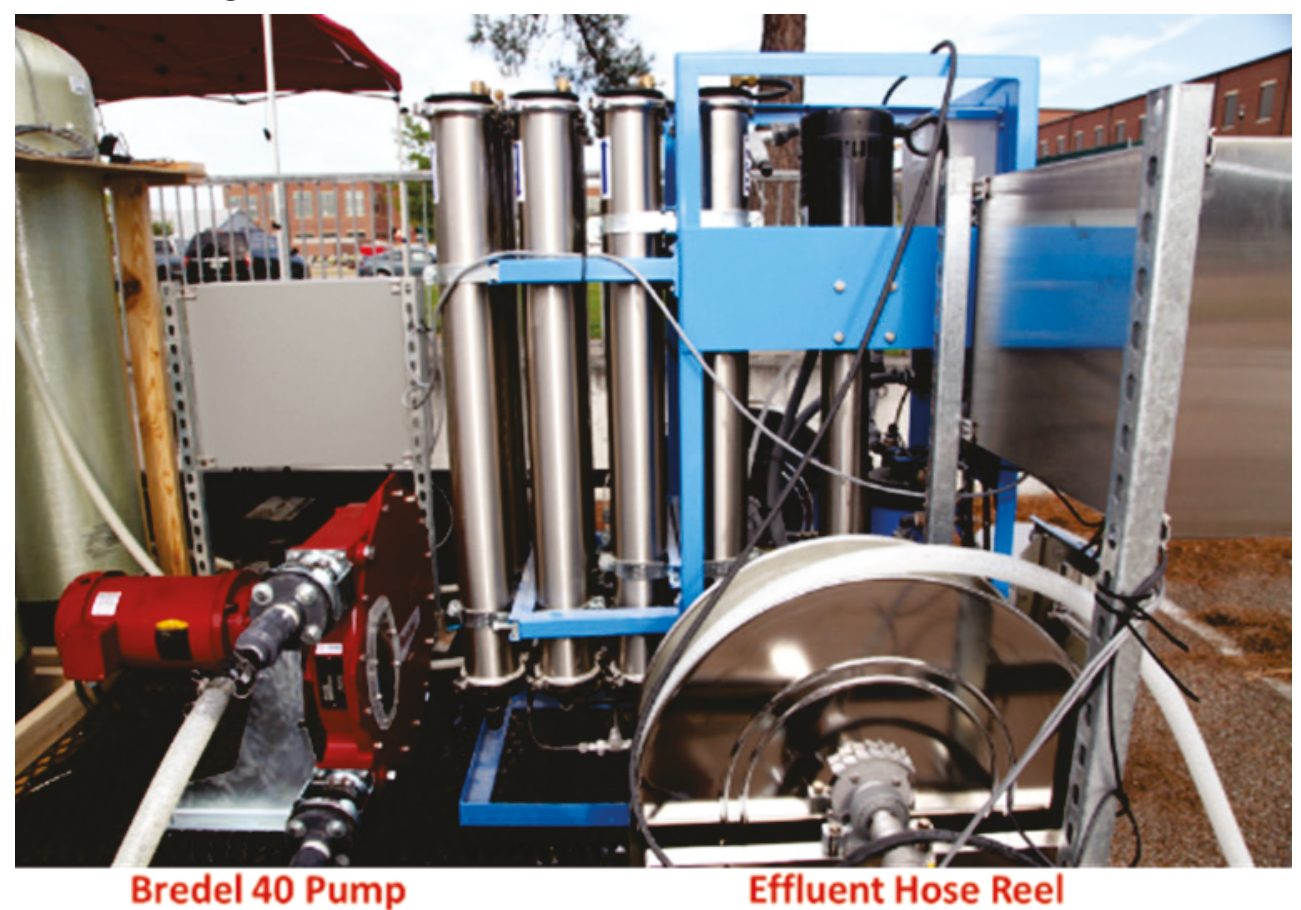

Chemical resistant tubing (3/4 in. and 1 in. internal diameter [ID]) was used to connect the various unit processes. Tubing is also available to hook the unit to the influent source, concentrate waste container, and product water container. These three tubing lengths are kept on hose reels (Reelcraft D9300 and D9400, Reelcraft Industries, Inc. Columbia City, IN).

\subsection{Electrical system}

The DETS uses 240 VAC single-phase power provided by a Kubota Diesel 9875 Watt Generator (Figure 5) (provided by Central Maine Diesel, Hampden ME, Appendix C). The generator has a 60 gallon fuel tank, a two-wire auto start control, and a sound enclosure to keep noise at

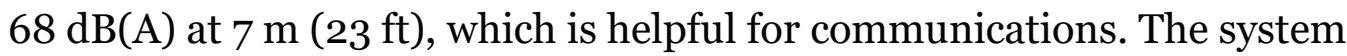
is also designed to be suitable for operation of sensitive electronic equipment. A grounding stake was used for safe operation (Figure 6). Fuel consumption varies from 0.41 to $0.84 \mathrm{gal} / \mathrm{hr}$. The system can also simply be plugged into a $240 \mathrm{VAC}$ single-phase $40 \mathrm{amp}$ source. All electrical work was conducted or monitored by the electrical shop of the ERDC Department of Public Works. 
Figure 5. Generator.

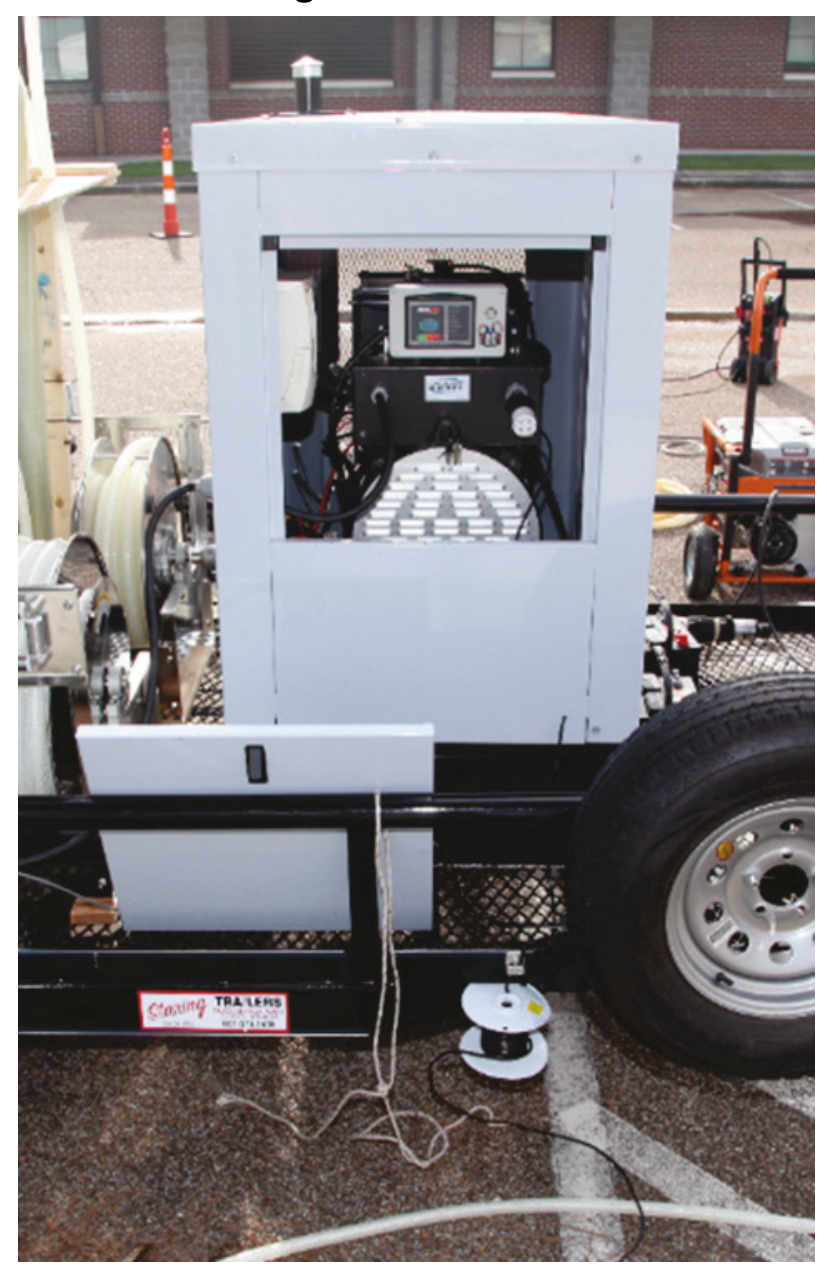

Figure 6. Generator grounding stake.

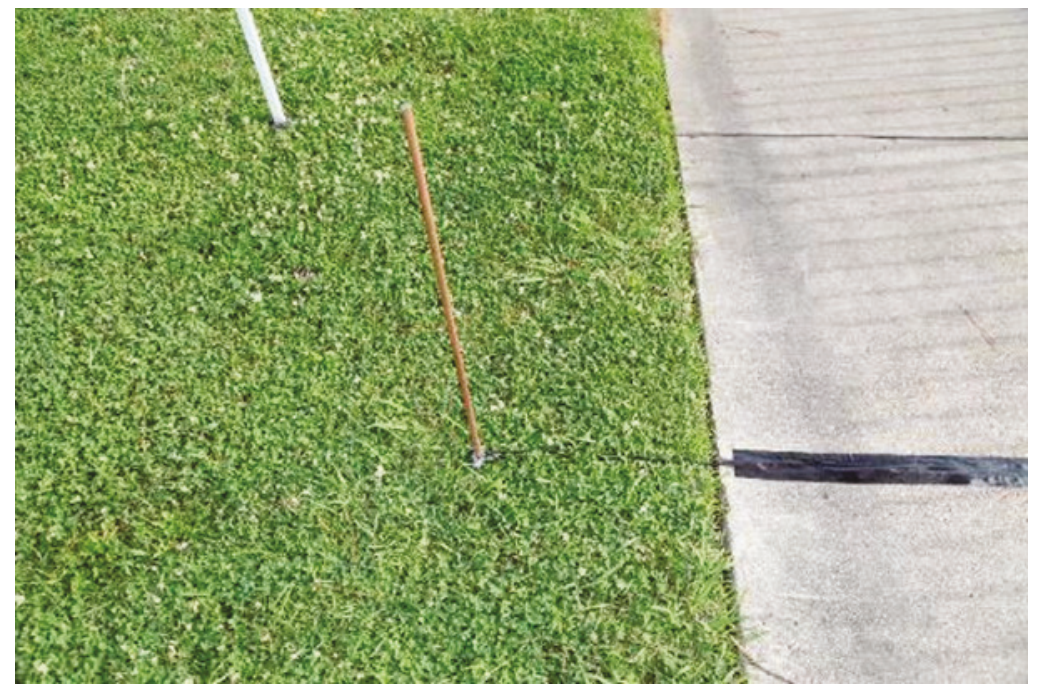




\subsection{Control system}

The DETS uses an electronic process monitoring and control system built around the EZ-Touch input/output (I/O) control processor (Figure 7). This inexpensive unit has a $25 \mathrm{~cm}$ (10 in.) pressure-sensitive touch panel control that can be programmed to form customized control and information screens. The processor uses a Modular I/O, up to 24 channels. The processor also has communications protocols for off the shelf programmable logic controllers (PLCs) and variable frequency drives (VFDs), and includes development software for rapid, custom builds of control protocols, which can be developed using a computer and uploaded to the control panel (Figure 8). The control system is mounted on the trailer in a protective case where it can be easily accessed (Figure 9). A demonstration of the control system can be viewed at https://youtube/lgpkkHbsvSA.

A pressure gauge was installed going into the multimedia sand filter, and a second gauge monitored the pressure going into the reverse osmosis (RO) system. These were monitored by the operator during the operation. The RO system also had pressure gauges to monitor operating pressure.

Figure 7. EZ-Touch I/O control processor.

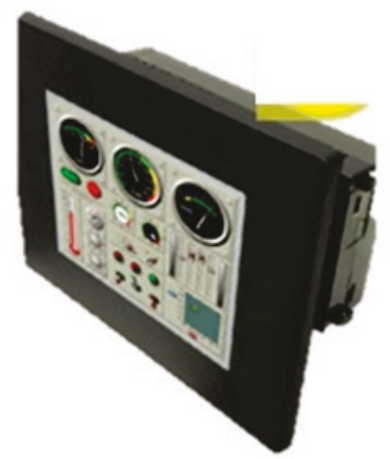


Figure 8. Programming the EZ-touch processor using a laptop computer.

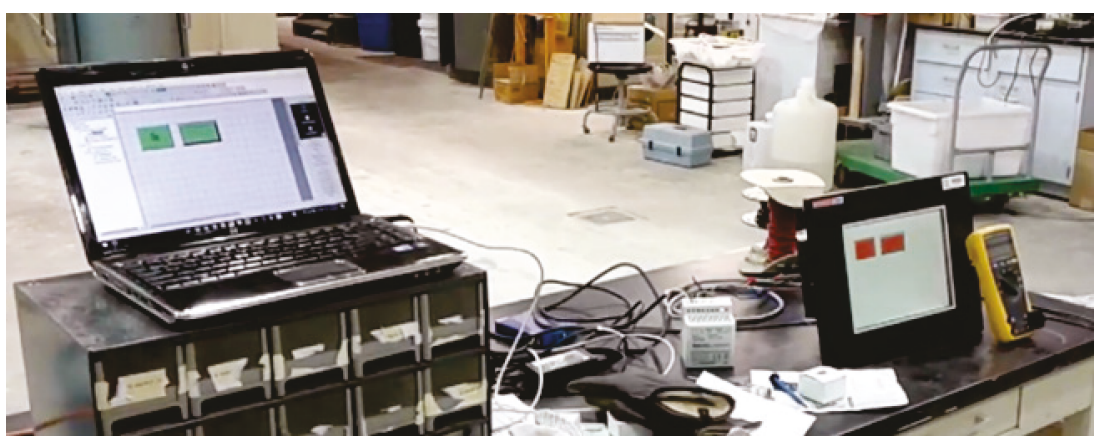

Figure 9. The touch screen control system (left) and the controls and monitoring gauges for the RO system (right).

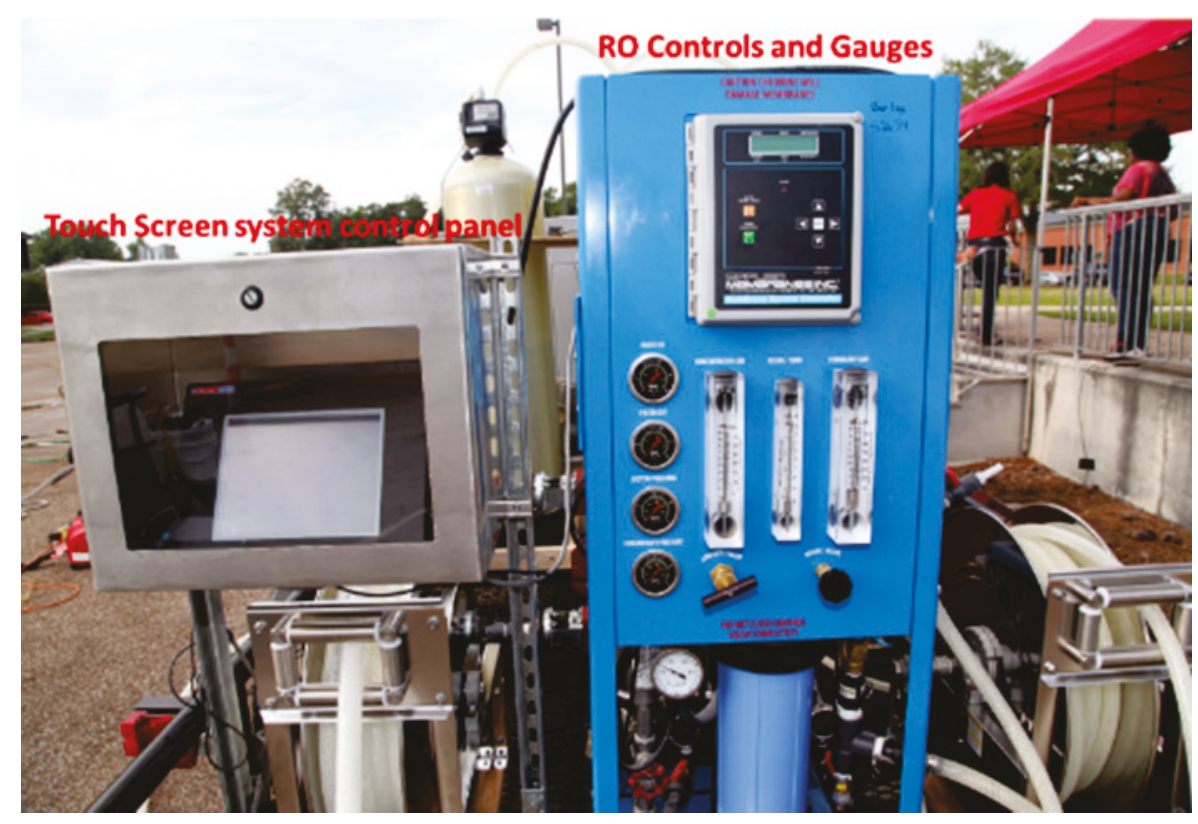

\subsection{Integrated system}

The various components described above were integrated into a single, transportable treatment system, the DETS (Figures 10 [schematic] and 11 [labelled photo]). 
Figure 10. Schematic of the DETS (The ultraviolet [UV] treatment was not used in the field evaluation).

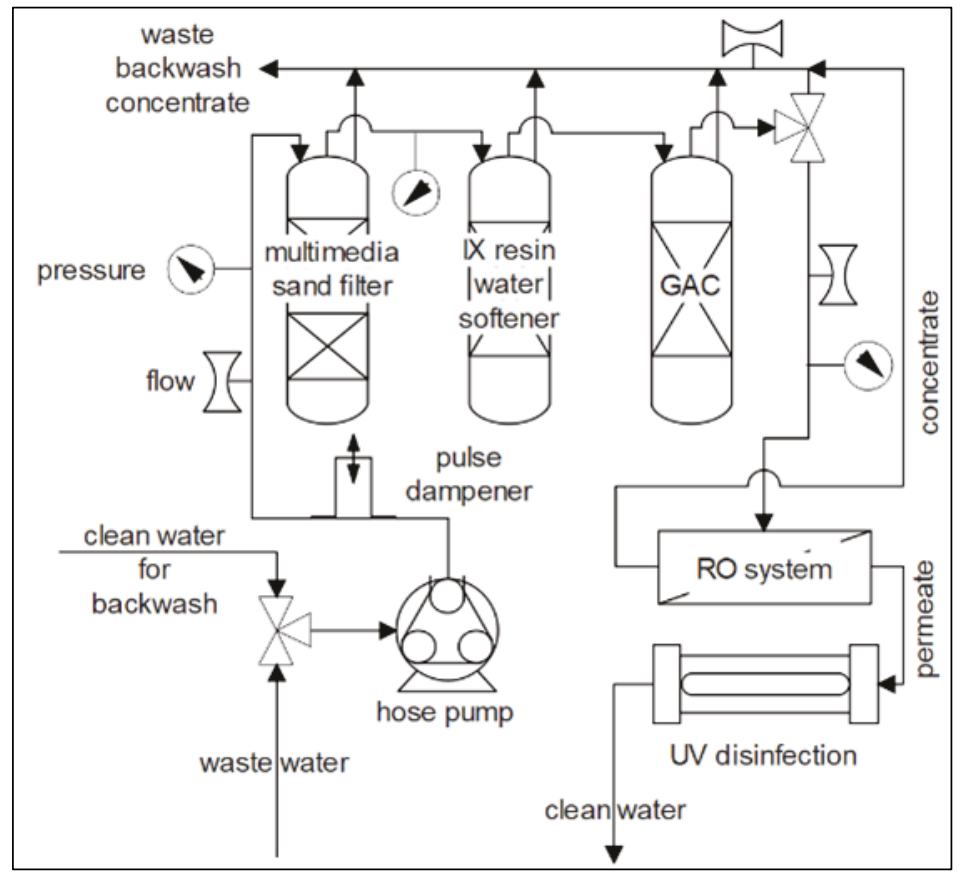

Figure 11. The trailer mounted DETS (photograph and labelling courtesy of Mr. Howard Beardsley).

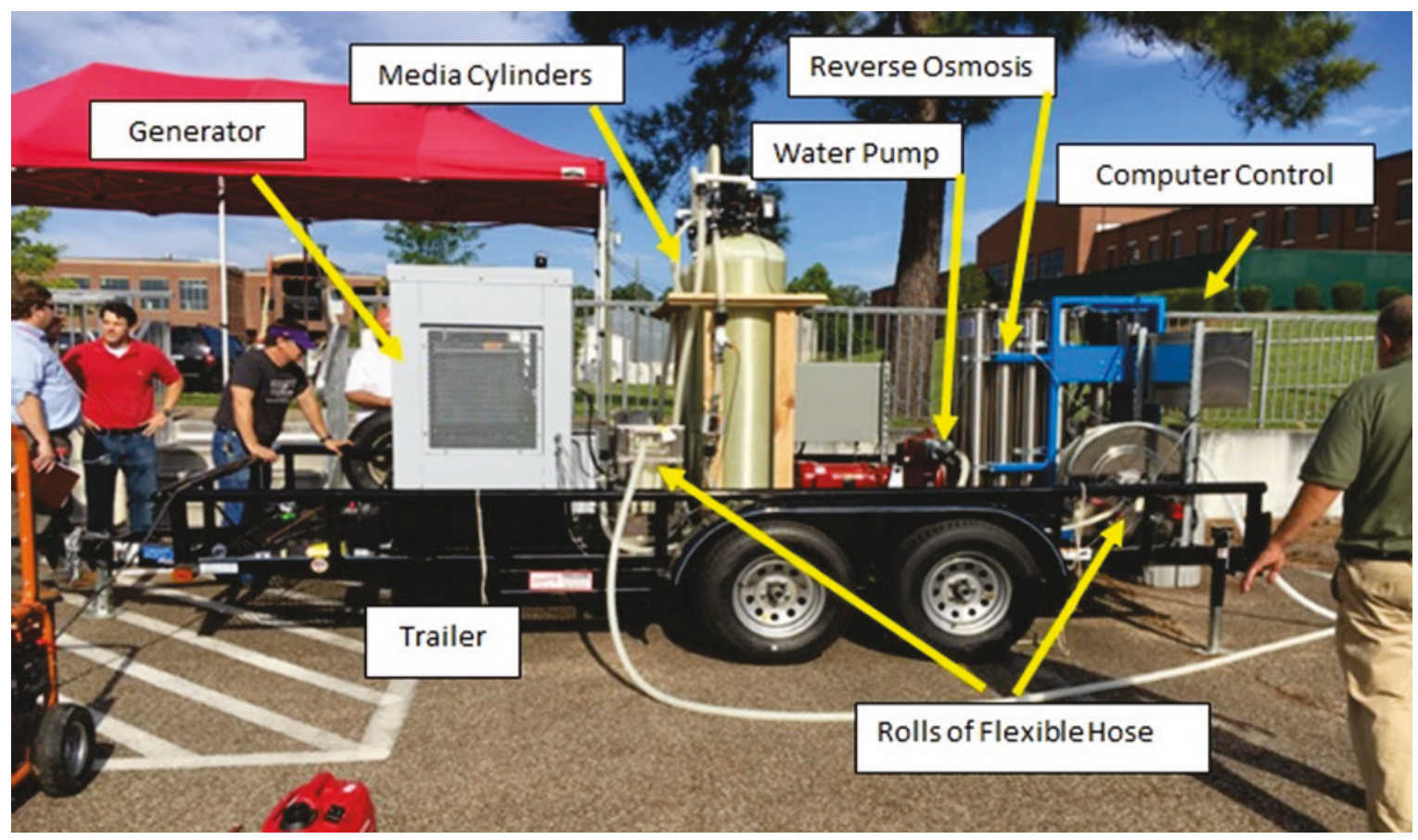


The treatment strategy of the DETS can be summarized by the following:

- Sediment - Settling (tank or blivet) and sand filter

- Hardness - Ion exchange resin

- Surfactant - Granular Activated Carbon (GAC)

- Bleach - GAC

- Oils/Greases/Misc. Organic Compounds - Incidental removal, GAC, $\mathrm{RO}$

- Chemicals - Incidental removal, GAC, RO

- Radioisotopes - Incidental removal, Sand, RO (especially Cs)

- Incidental removal refers to removal of a contaminant when removing another contaminant. For example, chemical weapon residual could be adsorbed on sediments and particulates and removed with the particulates, or attached to a surfactant and removed with the surfactant.

- Early versions of the DETS had a foam-fractionation unit, which removed surfactant as foam. The team determined that the unit was not necessary for effective treatment. However, the foam-fractionation unit had interesting performance results that are presented in Background Testing.

\subsection{Unit processes}

\subsubsection{Settling}

A settling process must address large sediment and particulates suspended in solution. These particles can effect system performance by rapidly loading the sand filter, which would necessitate frequent backwashing operations. Furthermore, sediments and particulates can adsorb key contaminants, and removing particulates may, by itself, result in decreases in CBRN agents.

To accomplish this a 3000 gallon collapsible tank (DBL-300o, FolDa-Tank Company, Milan, IL) [Appendix D] with a custom made influent center riser and floating effluent weir system. In many cases, decontamination wash water is collected in blivets or even excavated pits, which can serve a settling basins. In the experiment, wash water was collected in a 250 gallon water tote. 


\subsubsection{Media filters}

The system had three media filters, a sand filter, a water softening filter, and a GAC filter. Each media was housed in a 65 in. $(165.1 \mathrm{~cm})$ high by 16 in. (40.64 cm) diameter spun fiberglass tank containing approximately 3.5 $\mathrm{ft} 3$ (26 gallons) (99 L) of media, which were purchased from Applied Membranes, Inc. of Vista, CA. Previously, focused removal studies were conducted on these individual filters for removal of target contaminants. These studies will be presented in another article that is being prepared

The first filter was a multimedia sand filter (part number W-MB1665ETUS). The purpose of the sand filter was for further removal of sediments

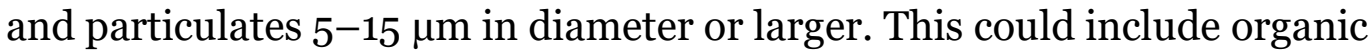
material in particulate form, such as hair, particles of clothing, rubber, and organic material sorbed to particulates. The multimedia depth filter contained a graded bed consisting of silica sand (\#20), anthracite (10x20 mesh), and gravel (\#6). These filters typically remove particles 5-15 microns in size or larger. Appendix E contains specification sheets on the sand and anthracite materials.

The second media filter was an ion exchange bed (part number WS1665EMS-US) designed for water softening (removal of divalent cationic species). This filter is necessary to limit scaling in the GAC bed and on the RO membranes that could be caused by the use of STB, which contained calcium oxide as a stabilizing agent. Appendix E contains a specification sheet for the ion exchange media.

The third filter was a GAC bed (part number W-G1665ET-US) consisting of coal based activated carbon with 12 x 40 mesh size and a bulk density of $27.5 \mathrm{lb} / \mathrm{ft}^{3}\left(440 \mathrm{~kg} / \mathrm{m}^{3}\right)$. Coal-based activated carbon has a broad range of micropore sizes, this is particularly effective for water treatment (Medina 1994). GAC is an effective removal technology for organic contaminants that can foul the RO membranes, such as oils and greases (Fulazzaky and Omar 2012). GAC is also an effective sorbent for surfactant (Weinberg and Narkis 1987; Wu and Pendleton 2001; Xiao et al. 2005) that can foul membrane and adversely affect performance. GAC has been shown to remove chlorine (Jagauribe et al. 2005; Jegatheesan et al. 2009), so it appears to be an effective treatment for bleach as well, which is also detrimental to most RO membranes (discussed below). In addition, chlorine can react with organic compounds sorbed to GAC, destroying the organic compounds and 
attenuating the chlorine (Jackson et al. 1987; Hwang et al. 1990). As such, it is a key protective technology for the RO system.

GAC can also be an effective treatment for CWAs via adsorptive removal. The National Academy of Sciences (NAS) (2009) describes GAC as a highly effective adsorbent for gaseous forms of various CWAs, including soman, VX nerve agent, and mustard. In addition to adsorptive removal, these agents tend to degrade on the GAC due to chemical reactions such as hydrolysis. Similarly, USEPA (2014) studied removal of sarin (GB) and mustard (HD) from heated air streams with GAC as a control technology for fumigation treatment of contaminated buildings. The results showed a high degree of removal of both contaminants at both 25 and $55 \mathrm{C}$, and $<1 \%$ desorption of sarin and no breakthrough of mustard. The results Baghei and Singh (2016) documented removal of sulfur mustard agent in aqueous solution with GAC, although the kinetics of removal were actually slower than the hydrolysis rate of the mustard agent. In another study, Baghel et al. (2006) showed 100\% removal of high concentrations of soman (GB) and mustard (SM). Lee and Lee (2015) developed a solid phase extraction method for sulfur mustard dissolved in water based on activated carbon fibers. GAC is commonly used in protective masks and equipment for CBRN operations. In addition, GAC also can remove metals and radioisotopes (Karnib et al. 2014, Omar and Moloukhia 2008), and might be therefore useful for removing radioisotopes and metal based CWAs. Finally, GAC can also be effective at removal of microorganisms, as demonstrated by Baghel et al. (2006).

Background studies were conducted on the treatment of the media filters using columns and flow rates sized to give a 1:1 relationship in terms of interstitial velocity and retention time. These experiments are discussed in the Results section.

\subsubsection{Reverse osmosis process}

Reverse osmosis is generally regarded as the most effective means of water treatment commercially available today. It works by forcing water through a membrane at high pressure. It is considered an agnostic treatment processes, capable of removing almost all contaminants effectively, including both organic and inorganic contaminants. This includes monovalent salts, which are very difficult to treat by other means. For example, Medina et al. (2015) demonstrated that reverse osmosis was 
effective at removing dissolved ionic species from a concentrate electrodialysis reversal treatment brine.

However, RO can be a delicate process and membranes can be fouled or damaged if not protected. Fouling can occur from biological growth on the membranes or from the accumulation of fine particulates. In the case of decontamination treatment, biofouling is of low likelihood due to two factors. First, the unit would generally not operate for extended time periods, estimated up to five days, so there would be minimal time for biological growth to occur. Second, the decontamination process typically uses additives with antimicrobial properties. Bleach (hypochlorite) is typically used for vehicle and equipment decontamination, and it obviously has strong disinfection properties (Snoeyink and Jenkins 1980). Even if bleach is not used, most surfactants also have antimicrobial properties by increasing cell membrane permeability (Ryan et al. 2006).

Of greater concern is fouling due to fine colloidal particulates, such as those that cause turbidity. Czekaj et al. (2001) discusses fouling of microfiltration membranes by fine colloidal turbidity from beer and wine production. Another issue can be scaling, this is the deposition of dissolved ionic species such as divalent cation based salts from, calcium or magnesium on the membrane surface (Warsinger et al. 2015). Polyamide materials, which are commonly used to construct RO and nanofiltration membranes, can be also degraded in the presence of hypochlorite (Do et al. 2012).

The unit chosen for this study was the Applied Membranes, Inc. (Vista CA) 124A (Appendix F). This is a highly automated, six-stage reject treatment system, capable of greater than $85 \%$ water recovery and 24-hour a day operation. The RO unit included a $5 \mu \mathrm{m}$ cartridge filter to provide protection against fine sediments. Details on the system are

- Rated at $200 \mathrm{psi}(1379 \mathrm{kPa})$ treating a $1000 \mathrm{ppm}$ sodium chloride solution at $77^{\circ} \mathrm{F}\left(25^{\circ} \mathrm{C}\right)$.

- System feed pressure minimum 40 psi (276 kPa).

- Chlorine must be removed (accomplished by GAC column).

- Water should be pretreated to avoid scaling (accomplished by water softener).

- Feed water turbidity should be reduced to less than 1 Nephelometric Turbidity Units (NTU). Pretreatment media filter was outfitted on the RO system to provide protection. 


\subsection{Maintenance}

The following maintenance could be conducted, if needed:

- Media filter tanks: The media could be vacuumed out and replaced, however, if the media is highly contaminated, this would not be a desirable method. Alternatively, these tanks could be completely exchanged if required, which would keep the media contained. Tank replacement would require a forklift or a small crate.

- Media filter backwash: This can be accomplished through the system control panel by the operator and requires 30 to 60 minutes.

- $5 \mu \mathrm{m}$ cartridge filter: This can be easily replaced in less than five minutes by one person.

- RO Membranes (The unit consists of 12 total cartridges): These can be easily replaced by a single person. Replacement of all cartridges is likely to require approximately 60 minutes.

Although these maintenance steps can be done in the field, the media and membranes could be highly contaminated after usage, so it might be advisable simply to use another unit in the field, sending the contaminated system to the rear support area for reconditioning by trained personnel.

\subsection{System costs, size and weight}

Table 3 summarizes costs of elements of the system evaluated in this study. The equipment costs were just over $\$ 60,000$. If such a unit was used in a highly contaminated environment, it may be safer to surplus the unit. Keeping costs low allows for a unit to be disposed of in its entirety if it becomes highly contaminated during treatment.

The bed dimensions were $16 \mathrm{ft}(4.9 \mathrm{~m})$ long and $6 \mathrm{ft} 5 \mathrm{in}$. $(2 \mathrm{~m})$ in width. The empty trailer weight is approximately $2600 \mathrm{lbs}$. The system was actually weighed using a vehicle scale at ERDC, and it weighed $6180 \mathrm{lbs}$ $(2809 \mathrm{~kg})$ - dry and without fuel. 
Table 3. Costs of elements of the system.

\begin{tabular}{|c|c|c|}
\hline Unit & Cost & Comments \\
\hline $\begin{array}{l}\text { Reverse osmosis unit with } \\
\text { pump \& Prefilter } \\
\text { Cleaning units for scale and } \\
\text { organics } \\
\text { Sand Filter Media Unit } \\
\text { Carbon Filter Media Unit } \\
\text { Water Softener Media Unit } \\
\text { Ultraviolet (UV) sterilization } \\
\text { unit (not used in these } \\
\text { studies) }\end{array}$ & $\$ 13,621.44$ & $\begin{array}{l}\text { Price is for all the units } \\
\text { described }\end{array}$ \\
\hline Kubota Generator & $\$ 9,922.45$ & \\
\hline $\begin{array}{l}\text { Bredel pump with mounting } \\
\text { equipment, variable } \\
\text { frequency drive (VFD) and } \\
\text { hoses }\end{array}$ & $\$ 13,283.09$ & $\begin{array}{l}\text { Two purchased, but only } 1 \\
\text { was used. Cost is for } 1 \text { unit. }\end{array}$ \\
\hline Flanges & $\$ 1,066.00$ & \\
\hline Hose Reels & $8,939.92$ & \\
\hline $\begin{array}{l}\text { Trailer } \\
\text { Trailer Upgrades }\end{array}$ & $\begin{array}{l}\$ 5,000.00 \\
\$ 1,500.00\end{array}$ & $\begin{array}{l}\text { The field evaluation } \\
\text { indicated that upgrades were } \\
\text { needed. }\end{array}$ \\
\hline $\begin{array}{l}\text { EZ Touch Control Unit with } \\
\text { associated software }\end{array}$ & $\$ 1,800.00$ & \\
\hline Instrumentation and Wiring & $\$ 5,045.00$ & \\
\hline Total & $\$ 60,177.90$ & \\
\hline
\end{tabular}




\section{Simulated Decontamination Operation}

\subsection{Location}

The field evaluation was conducted at the Waterways Experiment Station (WES), operated by ERDC, in Vicksburg, MS. Figure 12 is an aerial view of the location.

Figure 12. Aerial view of area for the simulated vehicle decontamination event on 27 June 2017.

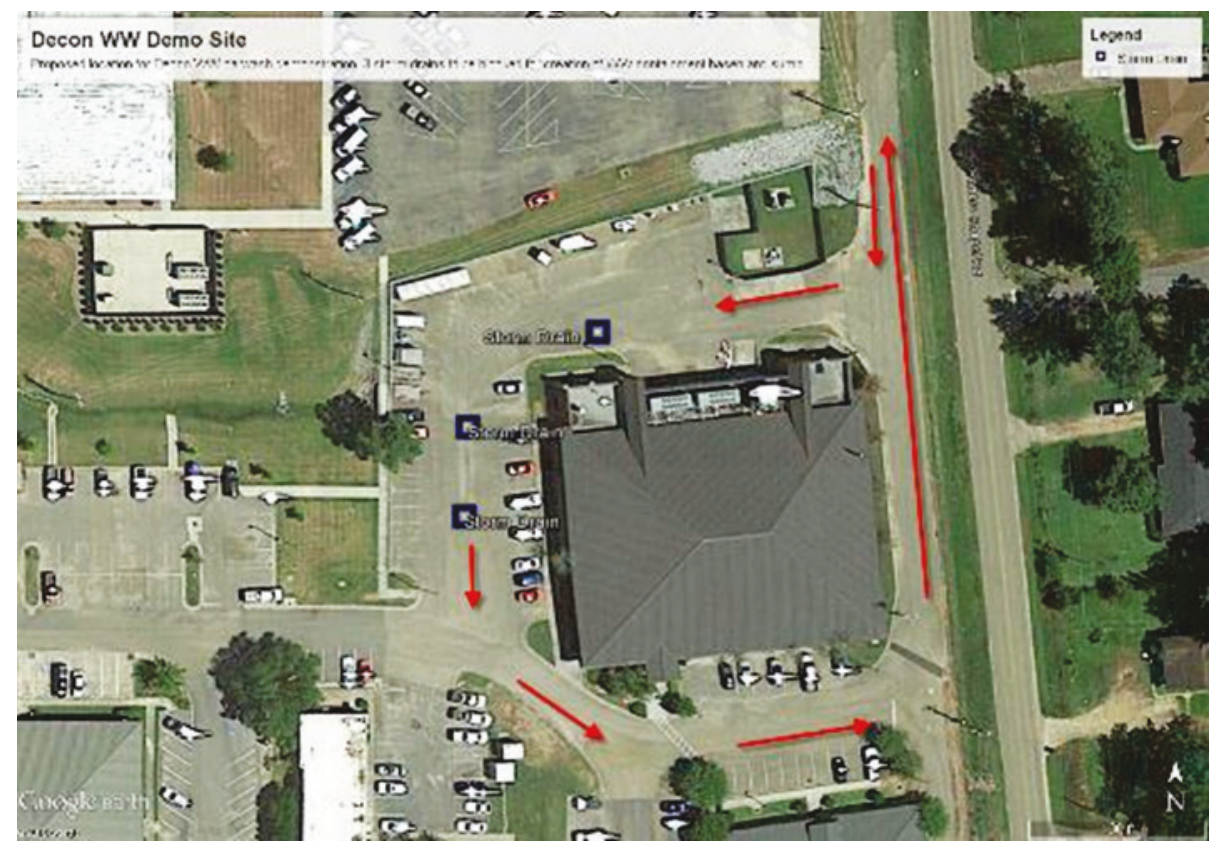

\subsection{Overview of the field evaluation}

Figure 13 is a sketch diagram detailing the processes of the DETS field evaluation, focusing on vehicle decontamination. Vehicles were moved to a wash area where they were pressure washed using a fire hose, scrubbed with soapy water (using an SLS detergent), then rinsed off with a fire hose. Water was collected using the storm drainage system that was present at the site. The drainage pipe exiting the storm drain was sealed using an inflatable pipe plug. Water was pumped from the storm drain into the reactor influent tank (250 gallon, $946 \mathrm{~L}$ ) using a general purpose sump pump. Influent water was spiked with STB, Malathion, and $133 \mathrm{Cs}$, this is described in detail below. The DETS was then used to treat the water in the influent tank. The concentrate was collected into another 250 gallon tank. The effluent was then allowed to flow into an open storm drain downstream of the test area. 
The field evaluation took approximately six hours. However, the actual operational time of the DETS was two hours, during this time the DETS treated approximately 1200 gallons (4542 L) of contaminated water.

Figure 13. Overview of the DETS field evaluation.

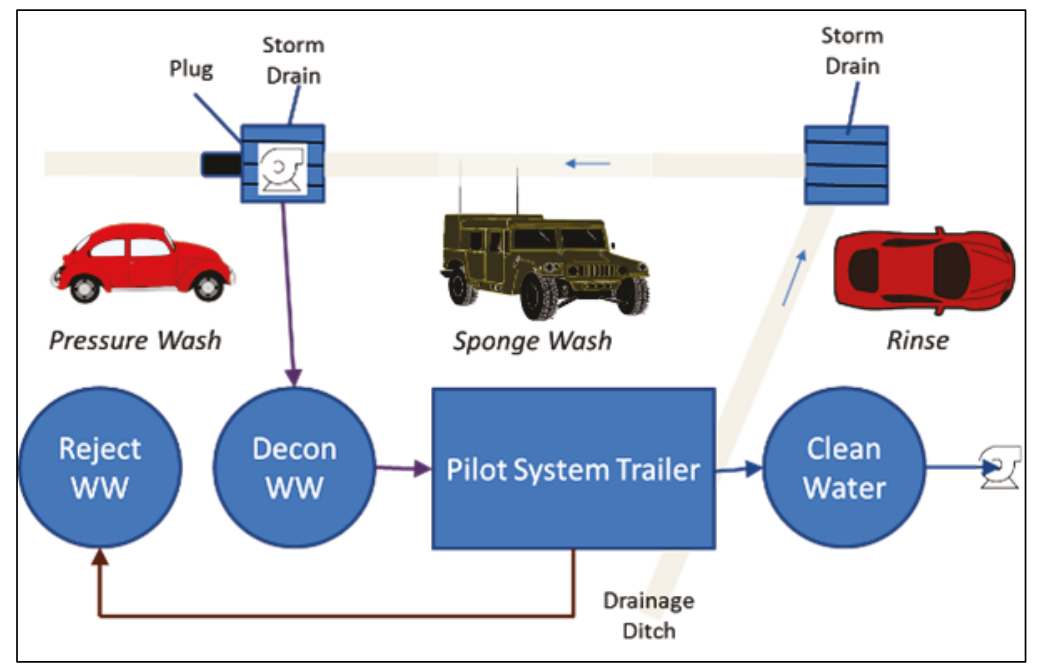

\subsection{Vehicle washing}

Prior to washing, soapy water was prepared in 30 gallon plastic containers, using a commercially available SLS based detergent (Figure 14). Fire hoses and hydrants were prepared as well (Figure 15). Vehicles were washed in a three-step process. First, the vehicles were rinsed using water from a fire hydrant sprayed from a fire hose (Figure 16). Then, soapy water was used to scrub the vehicles, removing obvious areas of dirt and soil (Figure 17). Then the vehicle was rinsed again. The military vehicles were quite dirty, and it was frequently necessary to rinse the asphalt driveway due to the accumulation of massive dirt clods (Figure 18).

Twenty cars, trucks, and minivans, and ten large military vehicles were washed. The Geotechnical and Structures Laboratory (GSL) provided three military vehicles, and they rotated the vehicles in multiple times, running through muddy roads on station each time to ensure the vehicles were dirty and simulated suitable decontamination efforts. 
Figure 14. Soapy water and mops prepared for vehicle decontamination.

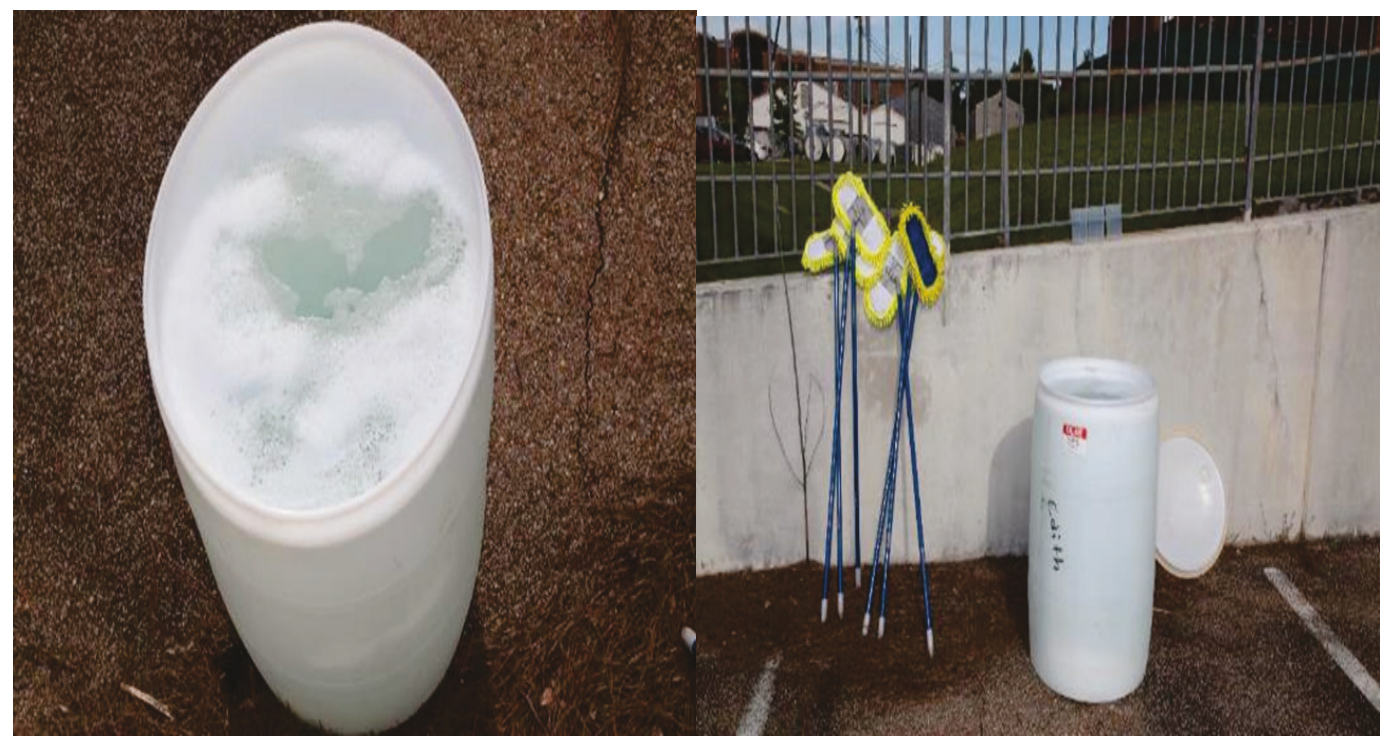

Figure 15. Fire hydrant and hose for vehicle rinsing.

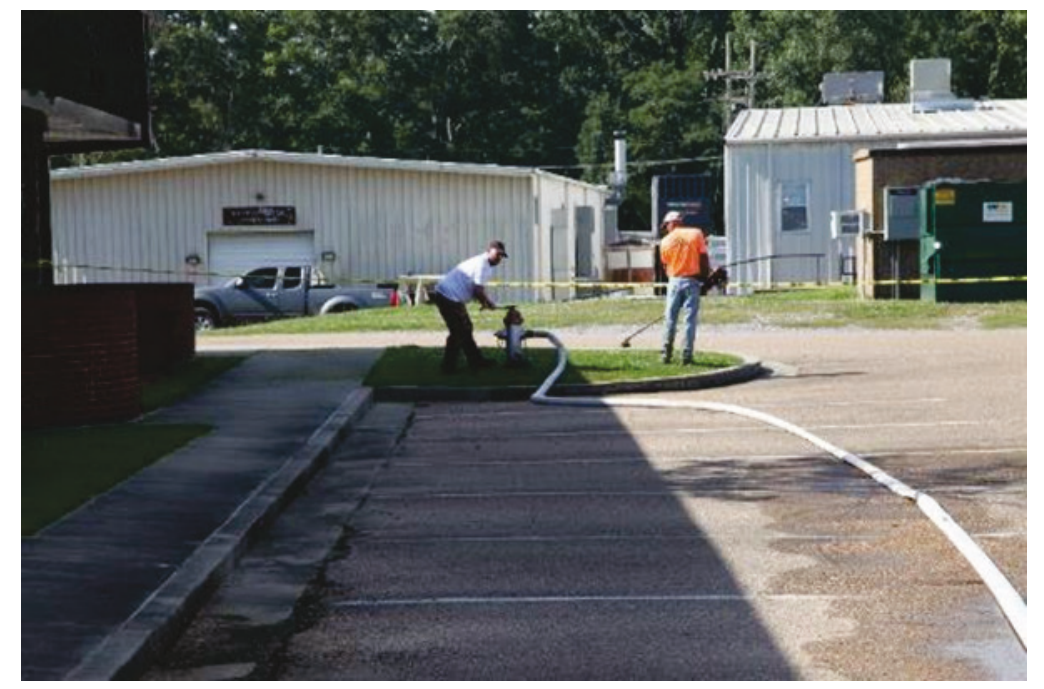


Figure 16. Rinsing vehicles using fire hose.

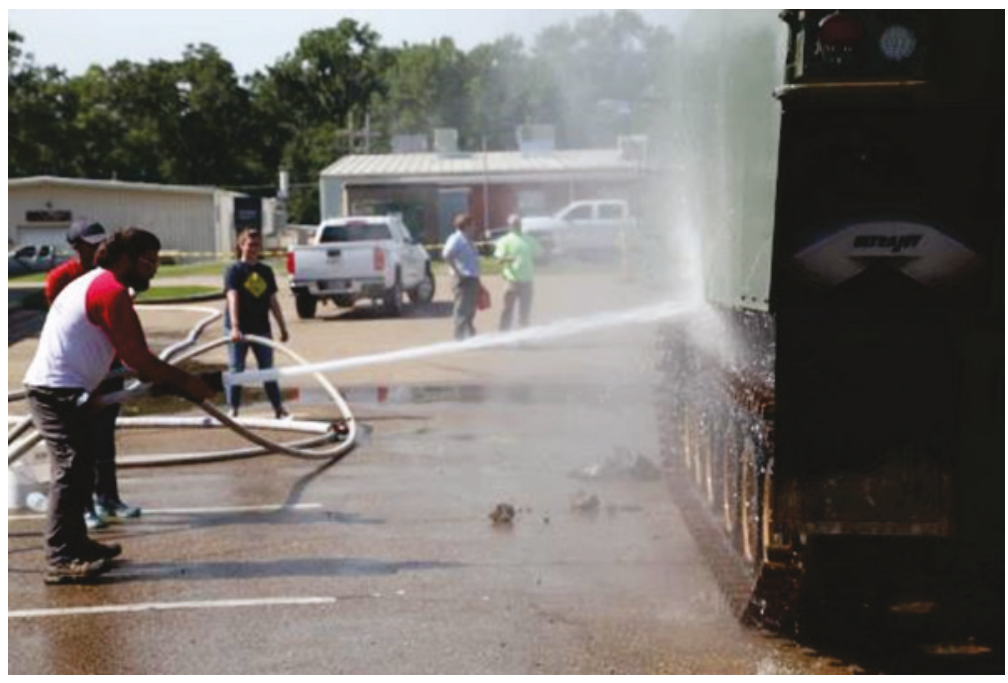

Figure 17. Washing vehicles with soap.

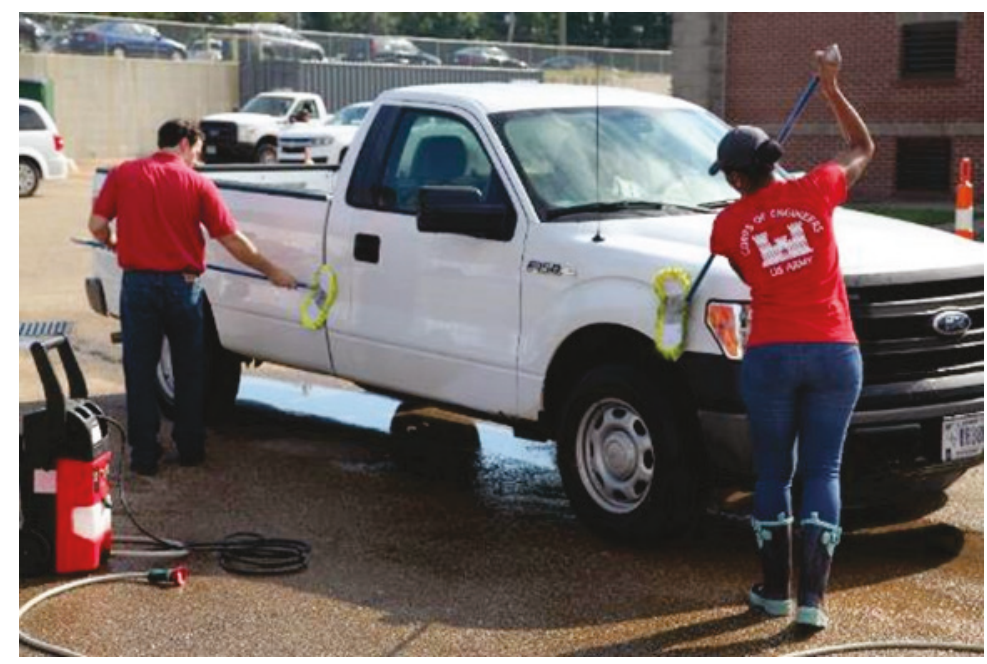

Figure 18. Washing large dirt clods off asphalt driveway.

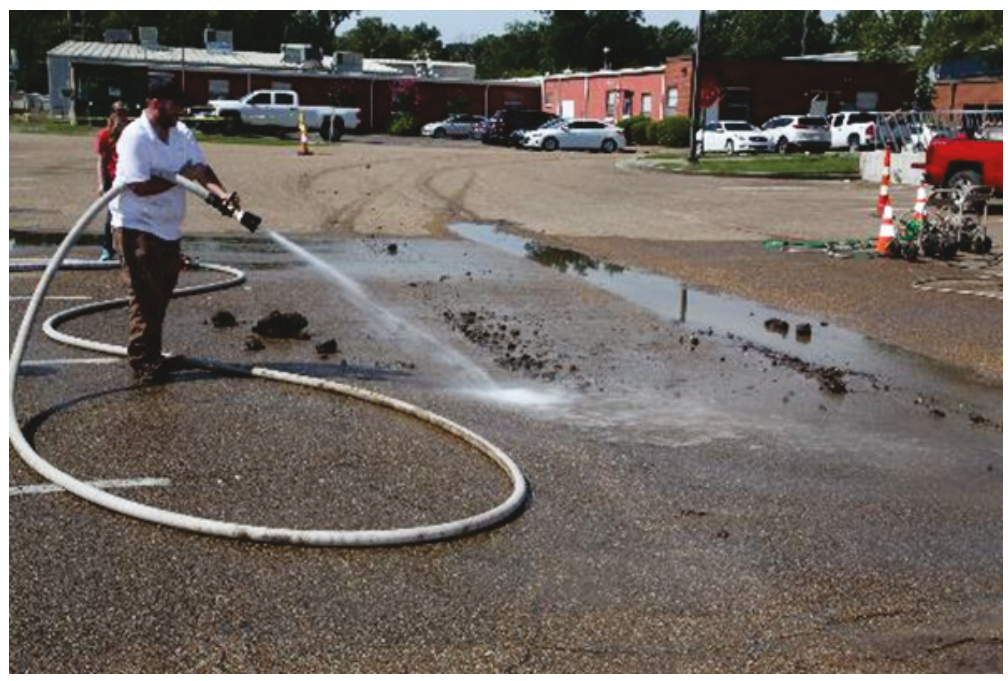




\subsection{Collection of wash water}

An asphalt covered driveway was used as the location of the vehicle decontamination site. The driveway had a storm drainage system that led to a several vault-like sumps that were covered by metal grates. One of these vaults was chosen as the location to capture the wash water. An inflatable pig was installed in the drainage line from the vault, and a sump pump was installed to transfer the collected water into the influent tank (Figure 19). The grate was replaced during the field evaluation (Figure 20). A 250 gallon tote served as the influent tank (Figure 21).

Figure 19. Open storm drain with inflatable pig to allow collection of wash water.

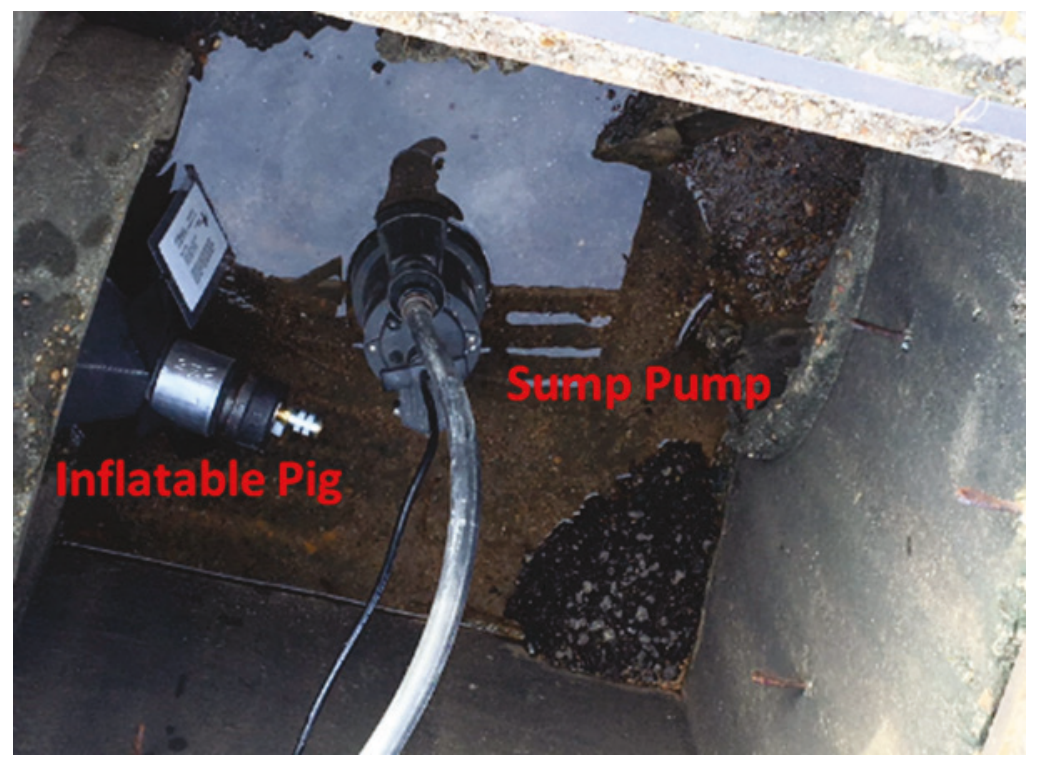

Figure 20. Drain with grate replaced and sump pump hosing/power visible.

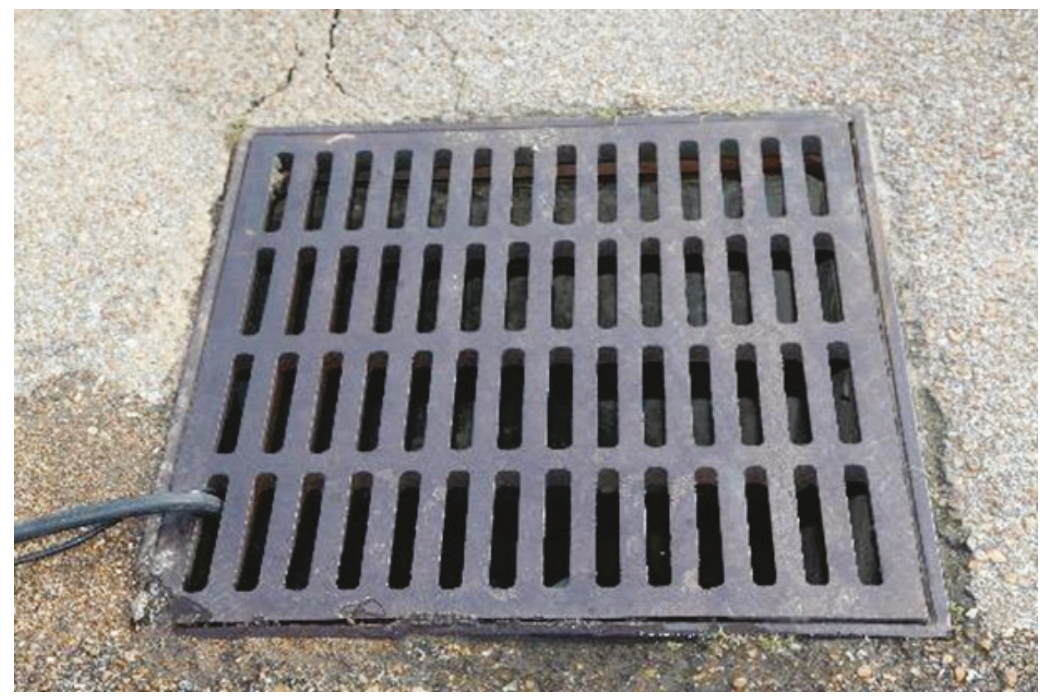


Figure 21. 250 gallon tote used as the influent vessel for the treatment system.

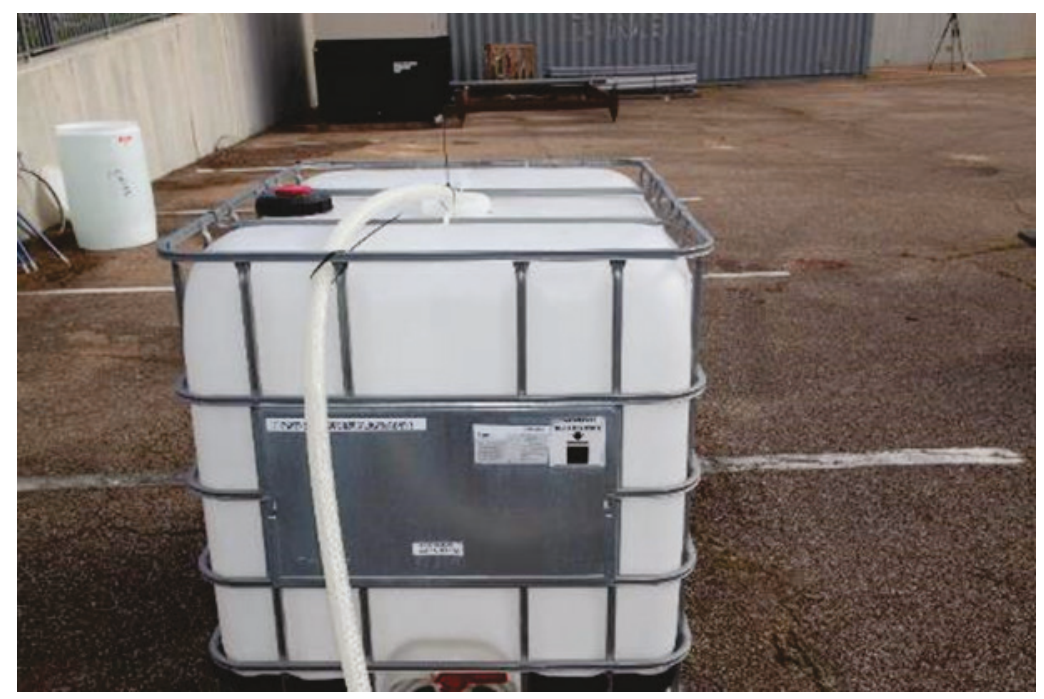

\subsection{Spiking collected wash water}

The collected wash water would contain soap, dirt, and sediment washed off the vehicles, and possibly oils and greases from the cleaned vehicles and from the asphalt parking lot. As mentioned earlier, the collected water was spiked with Malathion and cesium chloride ( $\mathrm{CsCl})$, acting as simulants of chemical warfare agents (CWA), and supertropical bleach (STB), which could be used in the decontamination process. These were prepared in five gallon concentrates with target concentrations of $3000 \mathrm{mg} / \mathrm{L}$ of each (95.5 $\mathrm{g}$ of Malathion, $56.8 \mathrm{~g}$ of $\mathrm{CsCl}$, and 188.s $\mathrm{g}$ of STB). The team had estimated that the carwash would have an average flow of five gallons per minute, so these chemicals were metered into the solution at $62 \mathrm{~mL} / \mathrm{min}$ to give a target concentration of $10 \mathrm{mg} / \mathrm{L}$.

\subsection{Treatment of wash water using DETS}

The collected wash water was run through the DETS at a flow rate of approximately twelve gpm ( $45 \mathrm{~L} / \mathrm{min})$. The total operational time of the DETS was two hours (out of a total of six hours of the field evaluation). The treated water was approximately 1200 gallons (4540 L).

\subsection{Sampling}

The decontamination system was operated for two hours. Influent and effluent samples were collected every fifteen minutes of operation, making eight pairs of samples. The first six samples were collected using auto- 
samplers (Figure 22), the last two were collected as grab samples. In addition, two grab samples were collected from the concentrate tote, one midway through the experiment (sample 4), and one at the end.

Figure 22. Auto-sampler set up to collect samples during study.

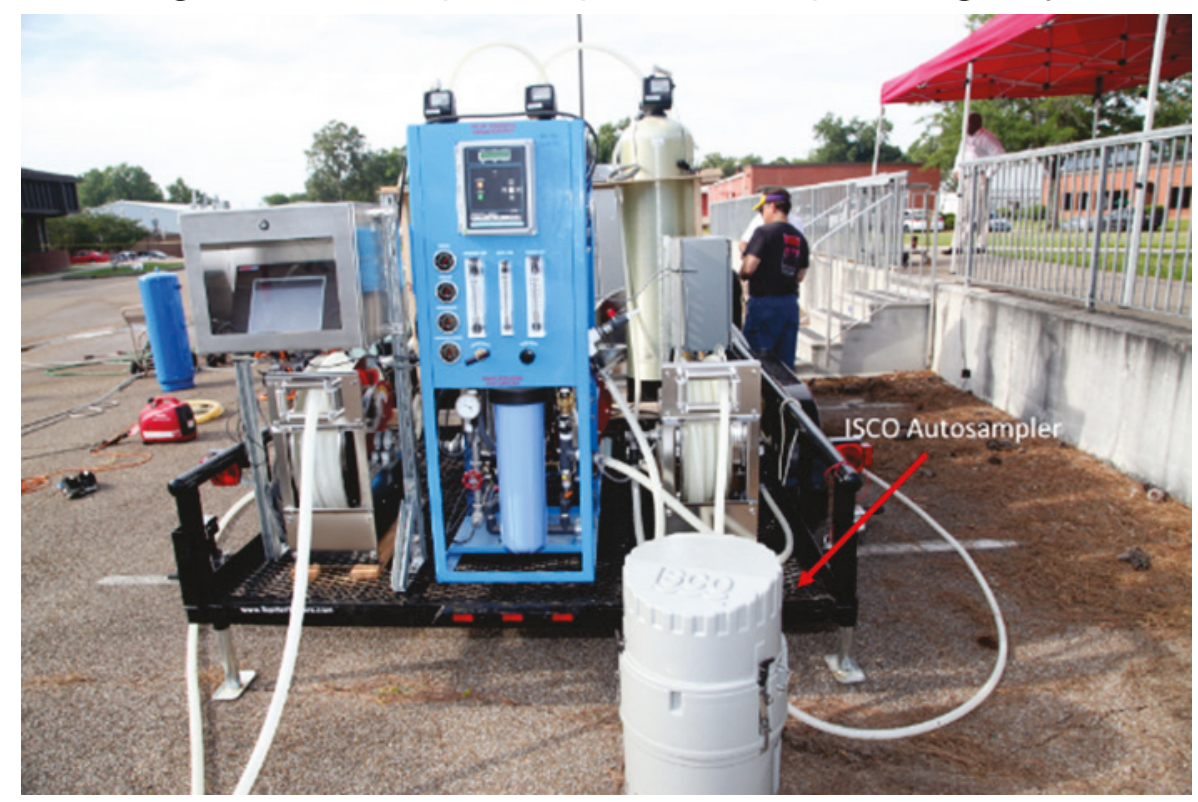




\section{Analytical Methods}

Water samples collected in the experiment were measured for the analytes specified in Table 4.

Table 4. Table summarizing analytical methods used on water samples.

\begin{tabular}{|c|c|c|c|}
\hline Analyte & Method & Laboratory & $\begin{array}{c}\begin{array}{c}\text { Quantification } \\
\text { limit }\end{array} \\
\end{array}$ \\
\hline $\mathrm{pH}$ & $\begin{array}{l}\text { USEPA Method } \\
150.1\end{array}$ & EPE & 0.01 \\
\hline Conductivity & $\begin{array}{l}\text { USEPA Method } \\
120.1\end{array}$ & EPE & $1 \mu \mathrm{S} / \mathrm{cm}$ \\
\hline Hardness & $\begin{array}{l}\text { Analytically by } \\
\text { measuring } \mathrm{Ca}^{2+} \\
\text { and } \mathrm{Mg}^{2+} \text { by IC }\end{array}$ & EPE & $0.1 \mathrm{mg} / \mathrm{L}$ \\
\hline Turbidity & $\begin{array}{l}\text { USEPA Method } \\
180.1\end{array}$ & EPE & $0.1 \mathrm{NTU}$ \\
\hline $\begin{array}{l}\text { Total suspended } \\
\text { solids }\end{array}$ & $\begin{array}{l}\text { USEPA Method } \\
160.2\end{array}$ & EPE & $0.1 \mathrm{mg} / \mathrm{L}$ \\
\hline $\begin{array}{l}\text { Hypochlorite (Total } \\
\text { Chlorine) }\end{array}$ & $\begin{array}{l}\text { Hach Method } \\
10070 . \text { Equivalent } \\
\text { to Standard } \\
\text { Method (SM) } \\
4500-\mathrm{Cl} \mathrm{G}\end{array}$ & EPE & $0.01 \mathrm{mg} / \mathrm{L}$ \\
\hline Surfactants & $\begin{array}{l}\text { Spectophotometric } \\
\text { method (Kloos } \\
\text { 2015) }\end{array}$ & EPE & $0.01 \mathrm{mg} / \mathrm{L}$ \\
\hline Cesium & $\begin{array}{l}\text { USEPA 6020A } \\
\text { using GC/MS }\end{array}$ & EPC & $0.001 \mathrm{mg} / \mathrm{L}$ \\
\hline \multirow[t]{2}{*}{ Malathion* } & $\begin{array}{l}\text { Phosphorus } \\
\text { balance following } \\
\text { digestion and } \\
\text { analysis by IC }\end{array}$ & EPE & $0.01 \mathrm{mg} / \mathrm{L}$ \\
\hline & USEPA 8141A & EPC & $0.0001 \mathrm{mg} / \mathrm{L}$ \\
\hline
\end{tabular}

*The Environmental Engineering Branch (EPE) developed a conservative method for Malathion quantification, using total phosphate as a surrogate.

\subsection{Malathion quantification based on phosphate analysis}

Malathion analyses are routinely performed by USEPA 8141A (http://www.caslab.com/EPA-Methods/PDF/8141a.pdf). However, the EPE did not have in-house analytical methods for this, and the standard turnaround time for samples was 30 days. A Malathion quantification method was developed to provide a rapid and low cost alternative for 
experiments so results could be obtained. Water samples were digested by adding $1 \mathrm{~mL}$ of sulfuric acid and 0.4 grams of sodium persulfate to $50 \mathrm{~mL}$ of sample, then the sample was heated in the autoclave to $128 \mathrm{C}$ for 30 minutes. After cooling, a $1 \mathrm{~mL}$ aliquot was taken for analysis for phosphate using ion chromatography (IC). Testing indicated that the method can accurately quantify Malathion in relatively clean water samples; Figure 23 shows the accuracy of the measurements versus theoretical phosphate concentrations expected. However, the method does have inherent probability of false-positive detections either from degraded Malathion or from other phosphorus forms in solution.
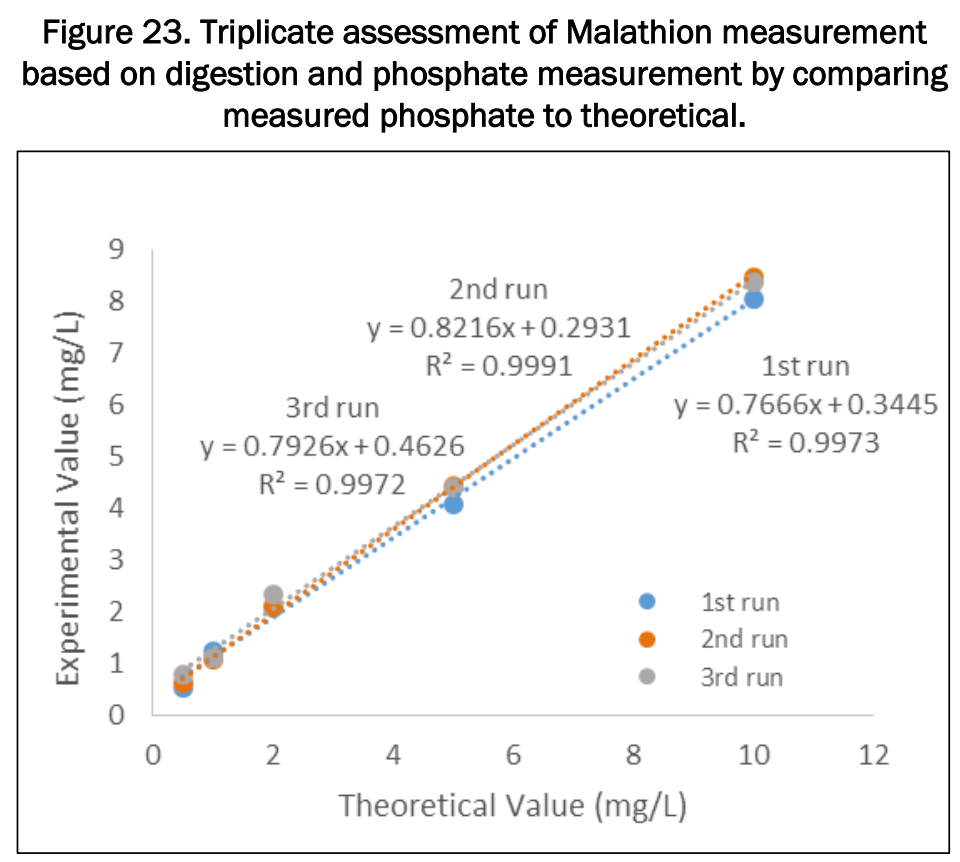

\subsection{Chlorine}

Chlorine analysis was performed with a Hach DR 2700 colorimeter. The Hach method 10070 was uses a total chlorine method with a reporting range of $0.1-10.0 \mathrm{mg} / \mathrm{L}$. This procedure is equivalent to USEPA and Standard Method 4500-Cl G for drinking water and wastewater. 


\section{Background Testing}

Several background experiments contributed to the design of the DETS and provided a framework. Key background experiments are provided below.

\subsection{Evaluation of treatment approaches that were not included in the pilot-scale DETS design}

In designing the system, experiments were conducted to study interesting treatment approaches, some of which were determined not necessary for the final design. However, these results were interesting and are presented to provide information for future treatment system designs.

\subsubsection{Surfactant skimmer testing}

The ERDC team conducted assessment of a foam fractionation approach. A Bashsea protein skimmer was adapted to create foaming of dissolved surfactant in water and then to skim it off as foam (Figure 24). Figure 26 shows the results of a 17 hour fractionation study. The results show that rapid removal of the surfactant was affected within one hour, dropping an initial surfactant concentration of $270 \mathrm{mg} / \mathrm{L}$ to about $70 \mathrm{mg} / \mathrm{L}$ within 45 minutes (Figure 25). Subsequent removal slowed, leveling off at about 20 $\mathrm{mg} / \mathrm{L}$. The process was promising, but other experiments indicated that activated carbon removal would achieve the surfactant removal goals, making the skimmer unnecessary. A video of the skimmer in action can be found at https://www.youtube.com/watch?v=dHvA-usTieE.

Figure 24. Picture of the foam separation skimmer.

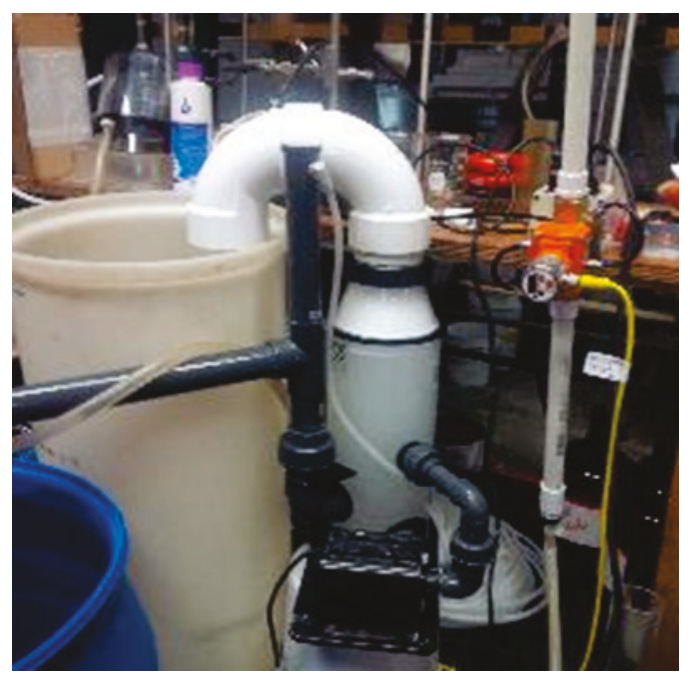


Figure 25. Results of a foam skimming test.

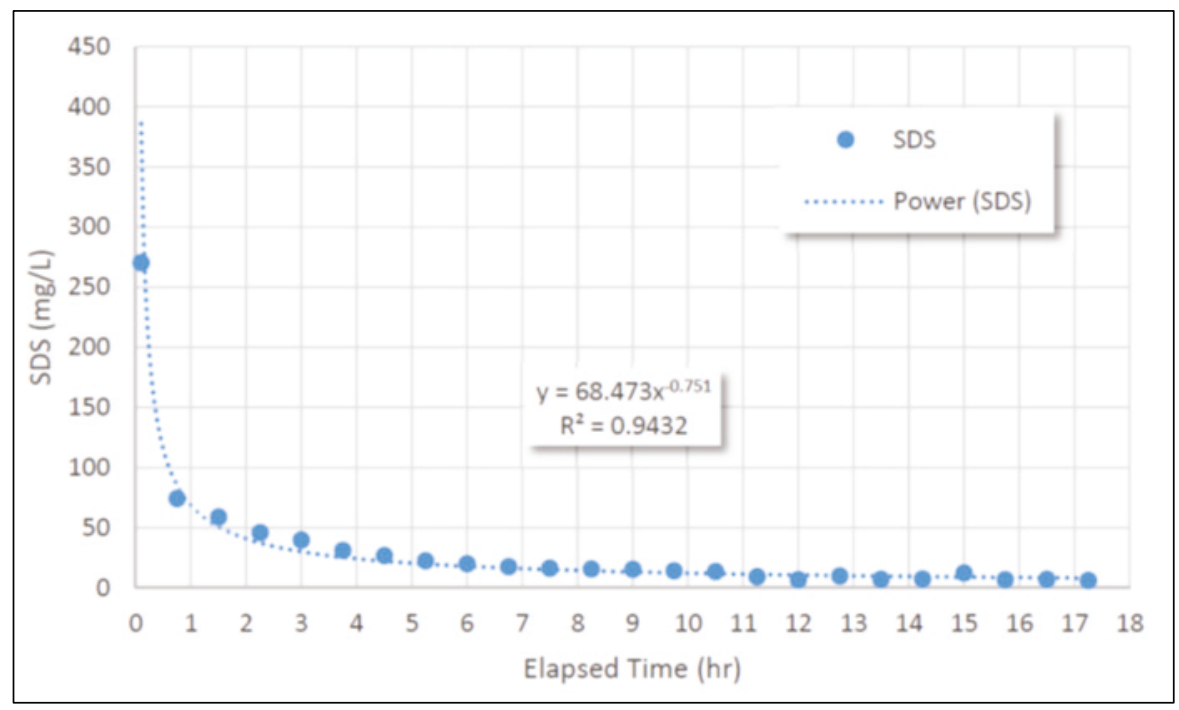

\subsubsection{Chemical degradation of bleach}

It is well established that bleach ( $\mathrm{NaOCl}$ ) (Figure 26) can be degraded in a chemical reaction with sodium thiosulfate (Na2S2O3), as follows:

$$
\begin{gathered}
4 \mathrm{NaOCl}(\mathrm{aq})+\mathrm{Na} 2 \mathrm{~S} 2 \mathrm{O} 3(\mathrm{aq})+2 \mathrm{NaOH}(\mathrm{aq}) \\
2 \mathrm{Na} 2 \mathrm{SO} 4(\mathrm{aq})+4 \mathrm{NaCl}(\mathrm{aq})+\mathrm{H} 2 \mathrm{O}(\mathrm{I})+\text { heat }
\end{gathered}
$$

This reaction is commonly used to remove active chlorine from tap water so water can be safely used in aquariums or for other applications in which chlorine is undesirable. A titration system was set up to evaluate sodium thiosulfate dosing on water spiked with $34 \mathrm{mM} \mathrm{NaOCl}$. This corresponds to an initial concentration of $2,515 \mathrm{mg} / \mathrm{L}$, which is about 1,000 times higher than levels typically found in tap water (which typically ranges from 0.5 to $2 \mathrm{mg} / \mathrm{L})$.

Figure 26. Sodium Thiosulfate. Chemical formula and powder form.

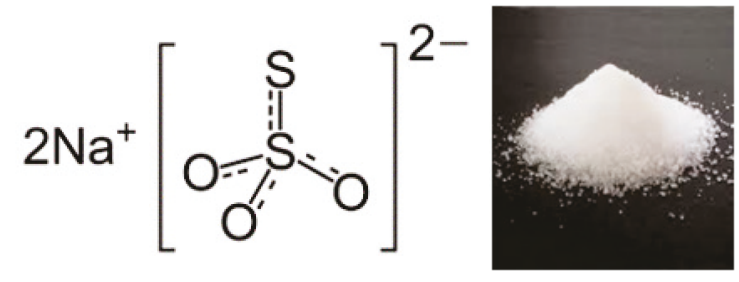


Figure 27 shows the result of the titration. The results indicate that thiosulfate does result in the degradation of hypochlorite. However, a high thiosulfate dosage was required, the molar ratio was 0.65. Furthermore, temperature increased by nearly $15^{\circ} \mathrm{C}\left(59^{\circ} \mathrm{F}\right)$ and $\mathrm{pH}$ dropped from 12 to less than 2, which were both undesirable effects. The potential of high levels of bleach (perhaps up to 5\%) makes sodium thiosulfate treatment untenable due to temperature increase and $\mathrm{pH}$ depression. However, this chemical treatment could be useful as a polishing step if coupled with another approach that can reduce the initial hypochlorite concentration.

Another option for chemical degradation of hypochlorite is sodium bisulfite, which is a strong reductant. The sodium bisulfite reaction is similar to that of thiosulfate, and the team anticipate it could have similar issues in treating very high hypochlorite concentrations to thiosulfate (increase temperatures and gas release).

Figure 27. Results of the bleach titration using sodium thiosulfate at an initial bleach concentration of $34 \mathrm{mM}$

$(2,516 \mathrm{mg} / \mathrm{L})$.

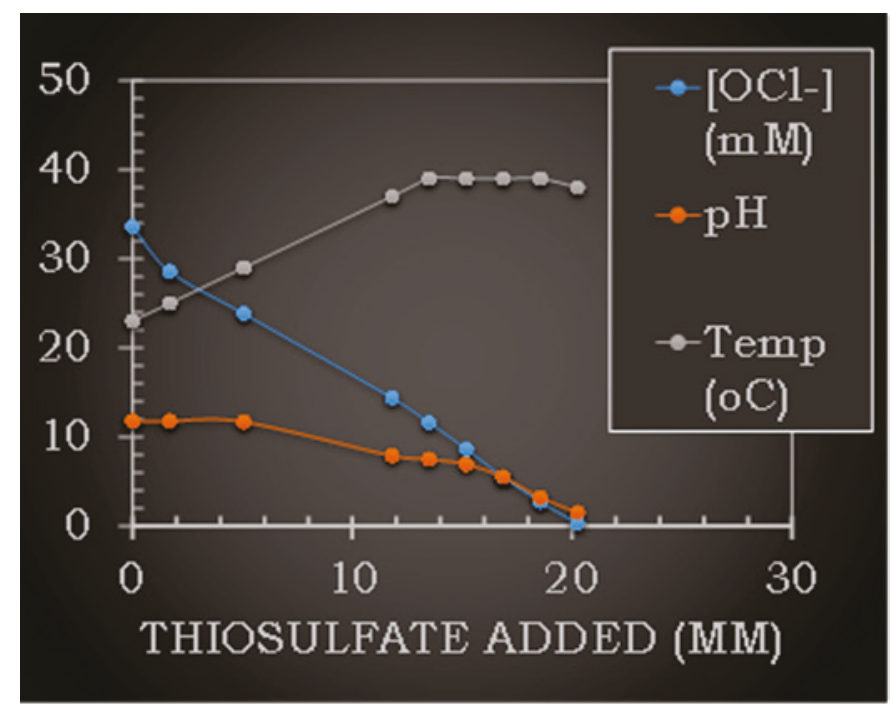

\subsubsection{Ultraviolet degradation of bleach}

Another means of degrading bleach is reaction by ultraviolet (UV) light. Reaction for hypochlorite degradation in the presence of UV light is:

$$
\begin{aligned}
& \mathrm{OCl}+\mathrm{hv}(\mathrm{UV}) \rightarrow \cdot \mathrm{O}-+\cdot \mathrm{Cl} \\
& \mathrm{O}-+\mathrm{H} 2 \mathrm{O} \rightarrow \cdot \mathrm{OH}+\mathrm{OH}-
\end{aligned}
$$


Figure 28 is the UV treatment cell. Collimated beam reactor experiments were performed to measure the change in hypochlorite concentration, $\mathrm{pH}$, and temperature as a function of UV dose. The study tested UVC, UVB, and UVA light sources for the treatment of $0.5 \%$ sodium hypochlorite solution.

Figure 28. UV treatment cell.

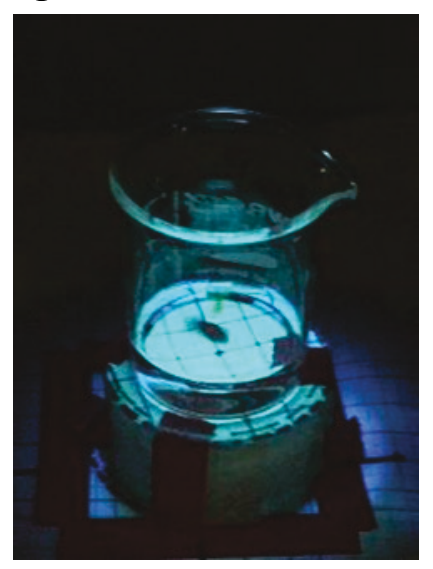

The UV treatment studies indicated that UV-C was the most effective radiation. Figure 29 summarized UV-C study results. Actual data are shown by the blue dots and a quantum yield model is shown by brown dots. These limited results showed that UV treatment hypochlorite would require a lot of energy, so the experiments were discontinued.

Figure 29. Hypochlorite degradation by LP-UV radiation.

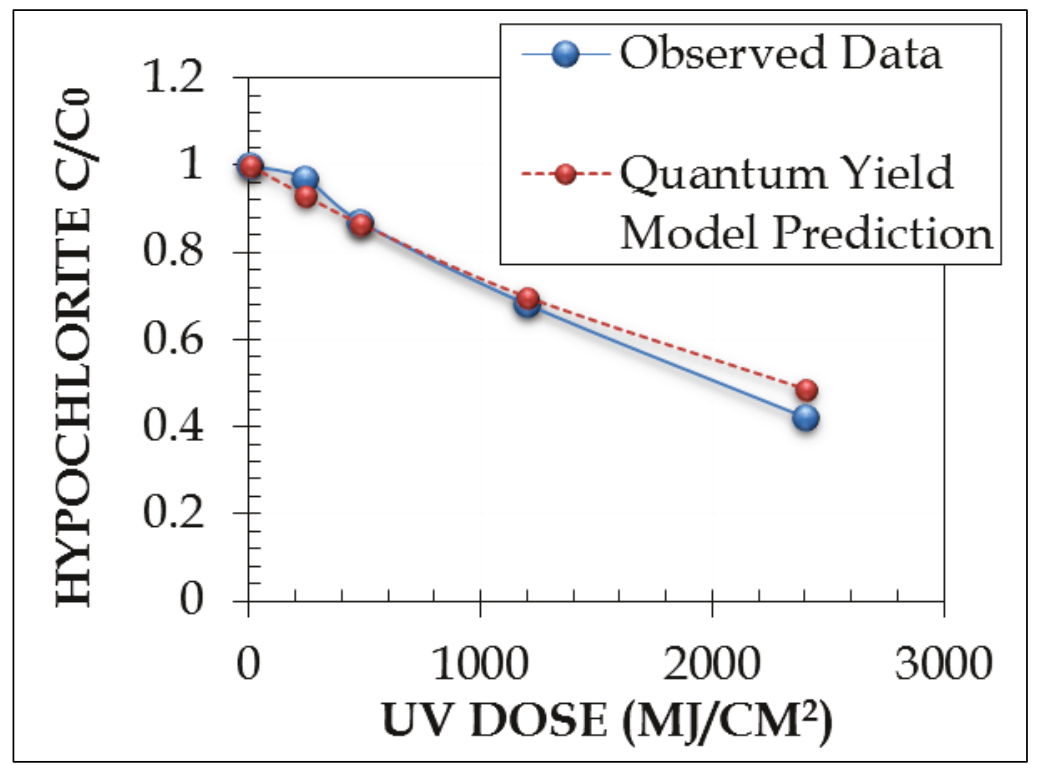


In summary, bleach can be destroyed by UV light, but the process is very slow. Bleach is highly UV absorbent, making light penetration difficult. Ultimately, a photocatalyst may be needed. Therefore, adsorption was chosen as the primarily means of bleach removal. However, UV reactions would likely create byproduct radicals that may aid CWA agent destruction.

\subsubsection{Ultrafiltration}

Figure 30 shows a two-stage, Applied Systems WMF-24A-116 ultrafiltration (UF) system that was tested for treatment of cesium (influent concentration approximately $10 \mathrm{mg} / \mathrm{L}$ ), and Malathion (influent concentrations ranging from 8 to $9 \mathrm{mg} / \mathrm{L}$ ). The system was sized for a flow rate of $10-12 \mathrm{gpm}$. The system was ineffective at treating either contaminant and testing was discontinued.

Figure 30. Ultrafiltration columns tested for treatment of cesium and Malathion.

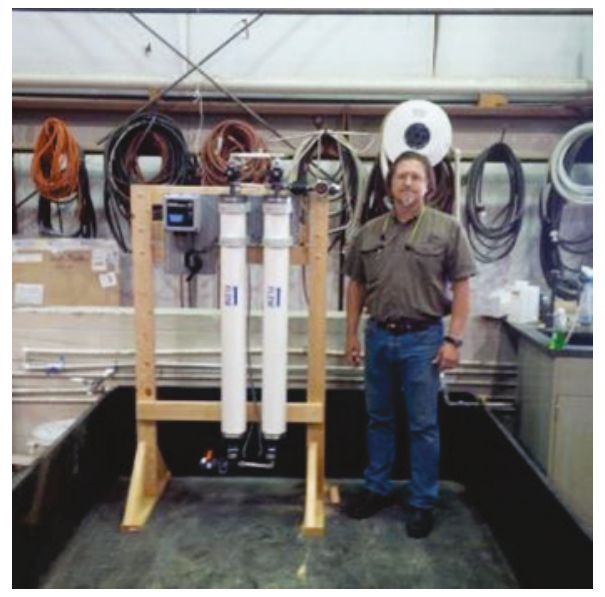

\subsection{Testing of settling tank}

A 2,500 gallon collapsible settling tank is an optional component to the DETS. The capacity of the settling tank was too large for the field evaluation, so it was not included. However, the tank has undergone background testing.

The first testing focused on the tank setup. A two man team was able to set up the tank within twenty minutes. Next, the tank was set up near a creek at WES observed to have high turbidity following rainstorms (Figure 31). Results from two rainstorms were monitored. The tank had water pumped in and out at the target $10 \mathrm{gpm}$, giving a residence time of 250 minutes. 
Influent and effluent concentrations were monitored (Table 5). The first event (14 February 2017) had relative low values of suspended solids (average $6.67 \mathrm{mg} / \mathrm{L}$ ) and the sedimentation tank averaged 61.5\% removal. The second event (7 March 2017) had much higher suspended solids (average $619 \mathrm{mg} / \mathrm{L}$ ), and removal averaged 82.9\%.

Figure 31. Pictures of the 2,500 gallon sedimentation tank setup for sediment removal testing near creek at WES and picture inside tank showing sediment colored water.

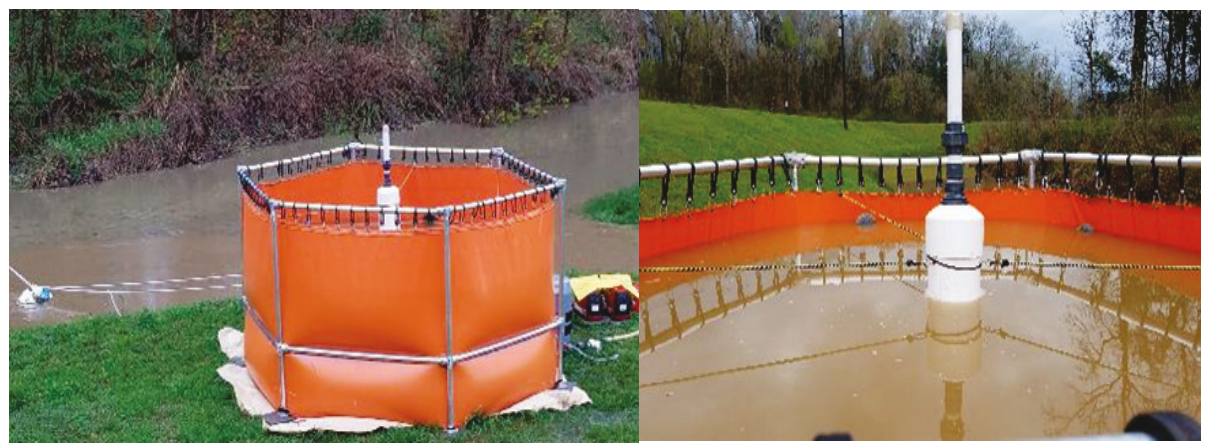

Table 5. Evaluation of suspended solids removal using 2,500 gallon collapsible setting tank with 250 minute residence time.

\begin{tabular}{|l|l|l|l|l|l|}
\hline Date & $\begin{array}{l}\text { Length of } \\
\text { test }(\mathrm{hr})\end{array}$ & $\begin{array}{l}\text { Number of } \\
\text { Samples }\end{array}$ & $\begin{array}{l}\text { Influent } \\
\text { Concentration } \\
(\mathrm{mg} / \mathrm{L})\end{array}$ & $\begin{array}{l}\text { Effluent } \\
\text { Concentration } \\
(\mathrm{mg} / \mathrm{L})\end{array}$ & Removal \\
\hline $02 / 14 / 2017$ & 5 & 5 & $6.67 \pm 2.07$ & $2.57 \pm 2.96$ & $61.5 \%$ \\
\hline $03 / 07 / 2017$ & 6 & 6 & $619 \pm 595$ & $106 \pm 48$ & $82.9 \%$ \\
\hline
\end{tabular}

\subsection{Testing of unit processes}

The team conducted a study to assess the performance of key unit processes, these are presented below.

\subsubsection{Scaled column testing of the media filters}

A series of column testing was conducted to evaluate the effectiveness of the media tank systems (Figure 32). These tests will be presented in detail in an upcoming journal article, however, a brief summary is presented here. Small diameter columns $(2.54 \mathrm{~cm}$ diameter by $90 \mathrm{~cm}$ length $[1 \mathrm{in} . \mathrm{x}$ 36 in.]) were sized to allow comparison to full-scale media tanks, with a direct linear scale of 1:1. The flow scaled to match Darcian velocity of the full-scale tanks, so the retention time and loading scale were also 1:1. 
Figure 32. Picture of column testing setup.

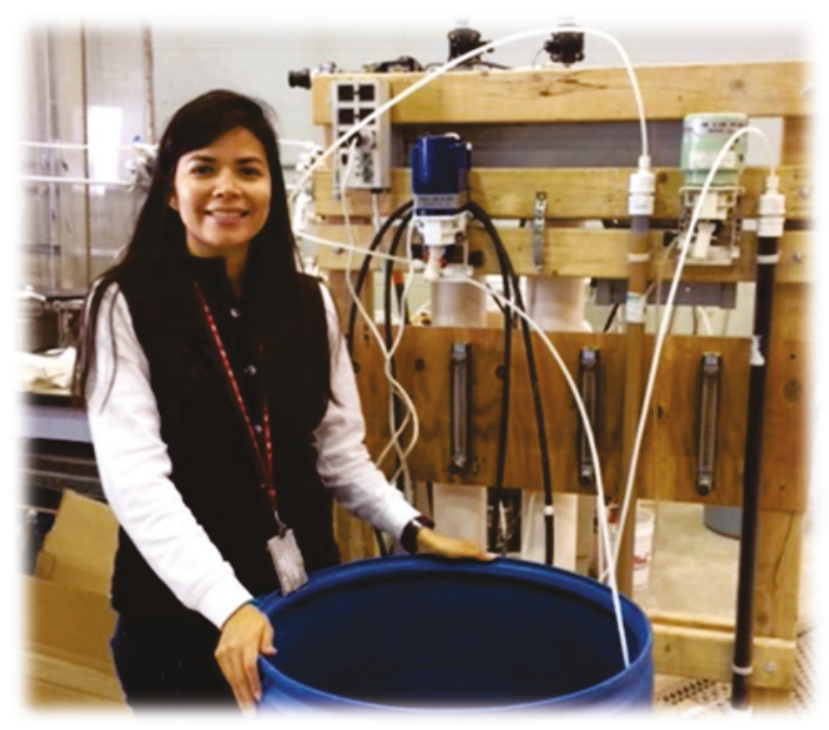

Testing was conducted to evaluate removal of surfactants at a flow rate of $148 \mathrm{~mL} / \mathrm{min}$. There was no retention by the sand column. Figure 33 shows treatment using the GAC column. Inlet concentrations varied from 10 to $15 \mathrm{mg} / \mathrm{L}$ as LAS. As discussed above, the goal was to have successful treatment for at least 3 days of continuous operation. The column study indicated that breakthrough did not occur until after 72 hours. From 72 to 120 hours, the breakthrough curve leveled off giving a final effluent concentration of $8.7 \mathrm{mg} / \mathrm{L}$. However, this concentration remained lower than that of the initial concentration, at that point ranged from 12 to $15 \mathrm{mg} / \mathrm{L}$, with the system having 27.5 to $42.0 \%$ removal. This suggests that there is either a destructive element of removal of the surfactant or more likely that there were multiple layers of surfactant adsorption on the GAC.

Studies with Malathion used a commercial insecticide blend called Drexel Malathion $5 \mathrm{EC}$ (Drexel Chemical Company, Memphis, TN), this contains $57 \%$ Malathion ( $5 \mathrm{lb} / \mathrm{gal}, 570 \mathrm{~g} / \mathrm{L}$ ). It also contains petroleum distillates and unspecified surfactants (measured as $18,000 \mathrm{mg} / \mathrm{L}$ as LAS). This was diluted with water for testing to give a target Malathion concentration of $10 \mathrm{mg} / \mathrm{L}$, leaving a surfactant concentration of $0.31 \mathrm{mg} / \mathrm{L}$ ).

Figure 34 summarizes the treatment of Malathion by the GAC material used in the media filter. Influent concentrations ranged from 8.1 to $10 \mathrm{mg} / \mathrm{L}$. Effluent concentrations started at $2 \mathrm{mg} / \mathrm{L}$. A breakthrough curve started at about 80 hours of operation, meeting the goal of 72 hours of operation. The final concentration leveled off at approximately $5 \mathrm{mg} / \mathrm{L}$, 
about $1 / 2$ the influent concentration. This also suggests that there is a degradation component of the Malathion. The mechanism could be simply hydrolysis of the Malathion.

Figure 33. Adsorptive removal of surfactant by GAC column.

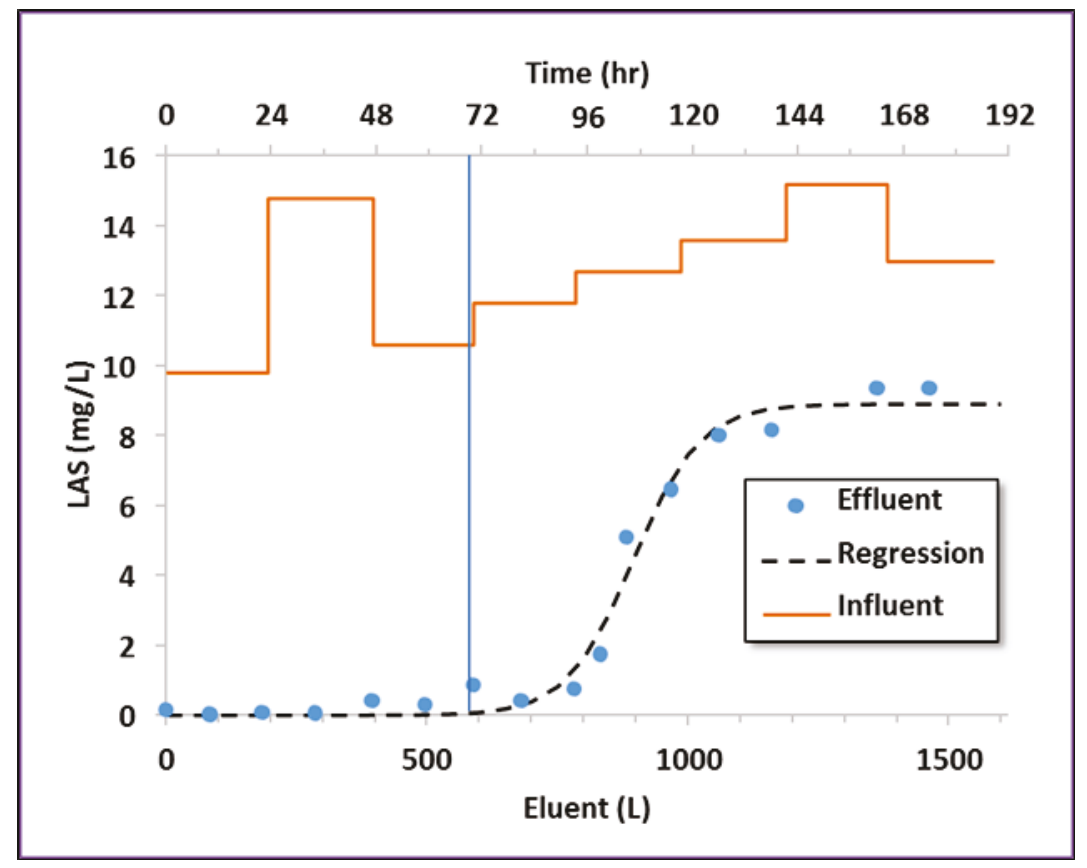

Figure 34. Treatment of Malathion by activated carbon.

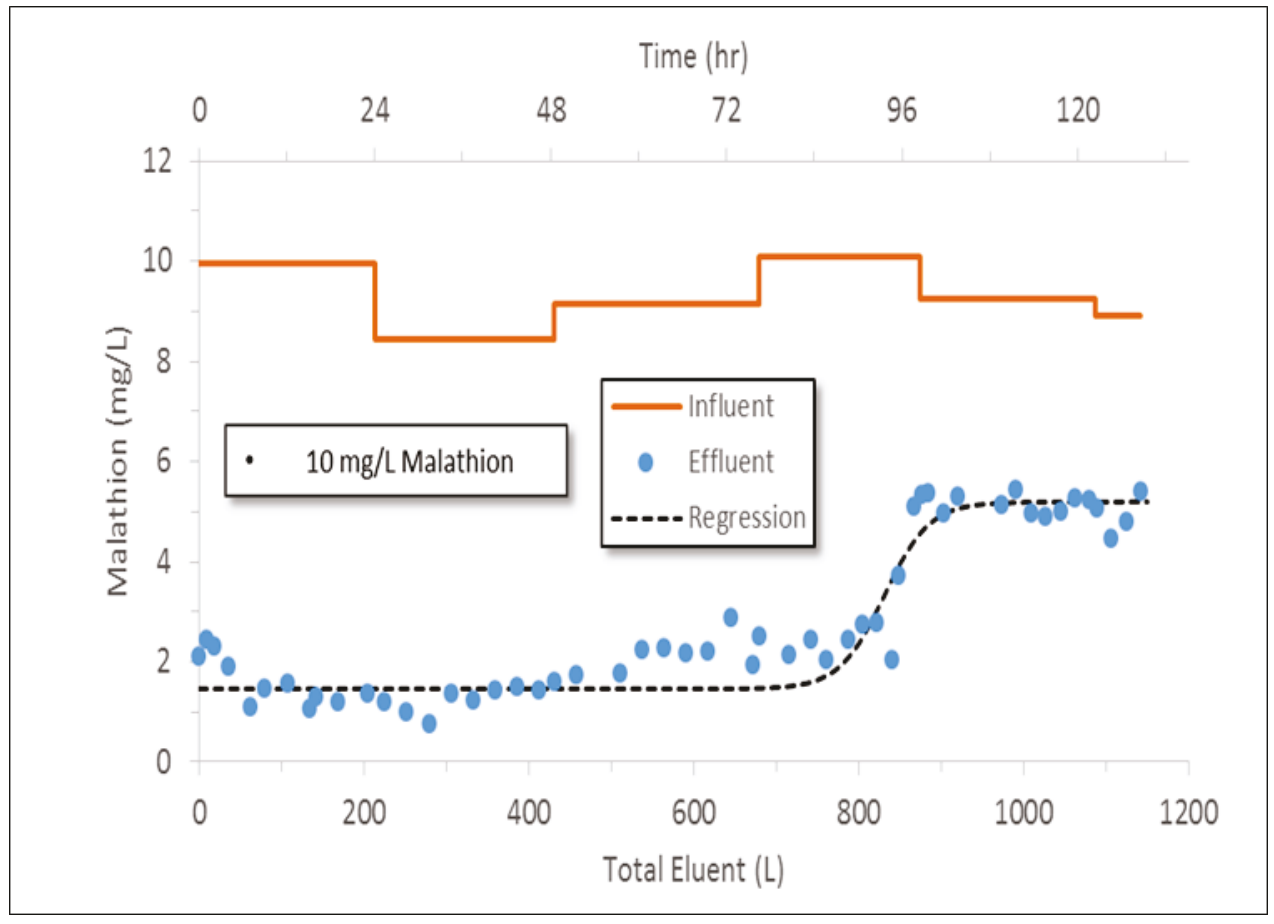


Figure 35 shows Malathion results for a mixture of $10 \mathrm{mg} / \mathrm{L}$ surfactant as LAS. Breakthrough began just after 24 hours of operation. Influent Malathion concentrations ranged from 8 to $9.1 \mathrm{mg} / \mathrm{L}$. At 72 hours, the effluent concentration was approximately $5 \mathrm{mg} / \mathrm{L}$, and removal was about $37 \%$. A final concentration of $7 \mathrm{mg} / \mathrm{L}$ was reached, and the breakthrough curve fit predicted that the concentration would eventually approach that of the influent concentration. Therefore, removal of a combination of surfactant and Malathion can accelerate breakthrough and increase the final concentration of the Malathion. The surfactant may hamper the adsorption process and the faster break through may leave less time for hydrolysis to occur.

Figure 35. Treatment of Malathion with $10 \mathrm{mg} / \mathrm{L}$ LAS surfactant by activated carbon.

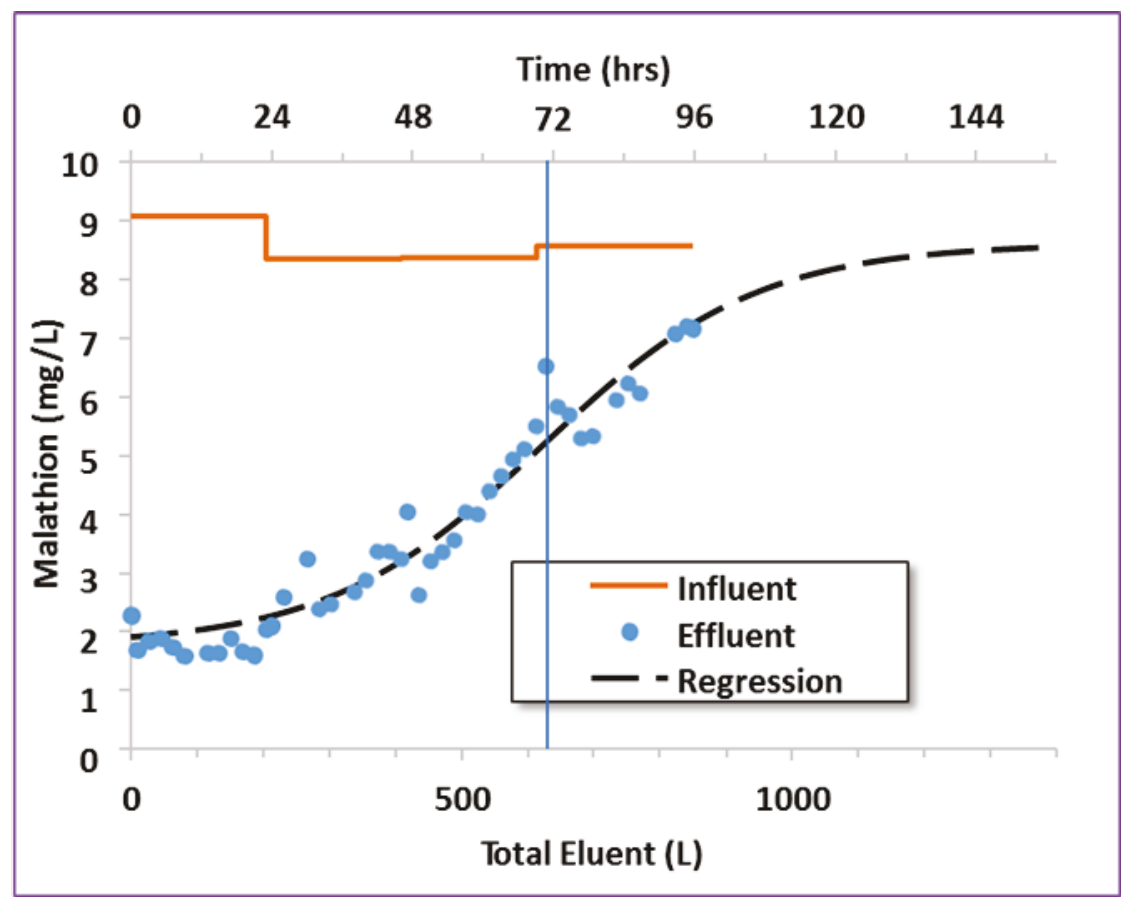

Studies were finally conducted on the removal of dissolved cesium by both the sand and the GAC media beds. $\mathrm{CsCl}$ was used to create a solution with $10 \mathrm{mg} \mathrm{L}$ of Cs. Cs was not removed to any appreciable amount either by the sand or the GAC media.

\subsubsection{Flat plate reactor evaluation of reverse osmosis}

A series of flat plate reactor studies were carried out to evaluate RO treatment for the target simulants of cesium chloride and Malathion. An Osmonics system flat plate RO system at the CERL laboratory was used 
(Figure 36). This system can test a wide range of RO swatches (7.5 in. $\mathrm{x}$ 5.5 in. [19.05 $\mathrm{cm} \mathrm{x} 13.97 \mathrm{~cm}])$ and can test pressures up to $1000 \mathrm{psi}$ $(6,895 \mathrm{kPa})$. The membrane cell is made of gold plated stainless steel to resist corrosion and buildup of contaminants.

Figure 36. Pictures and schematic of the Osmonics Flat Plate RO system used in this study. Left is the feed solution.
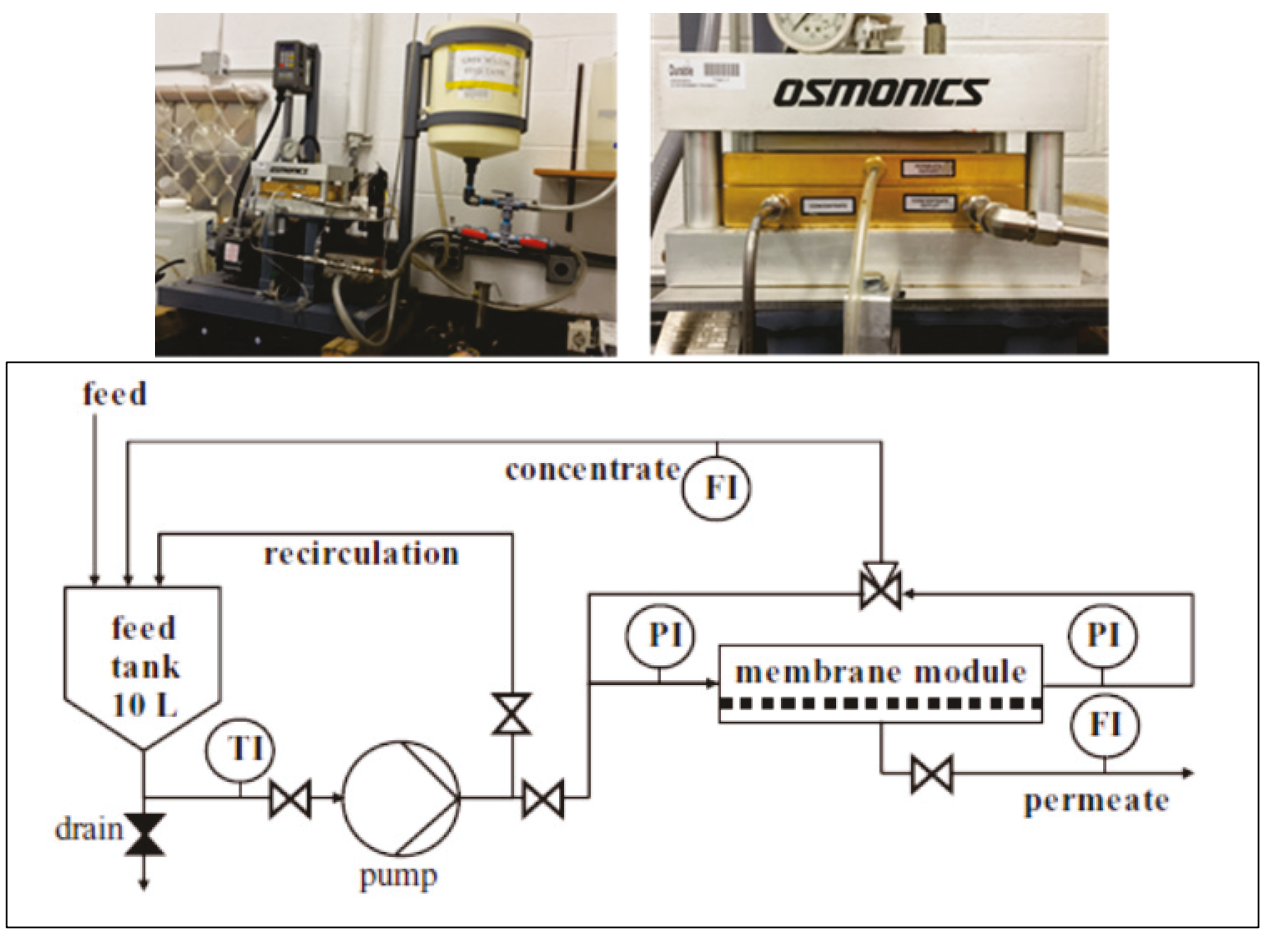

Table 6 summarized the three RO membranes that were tested in this study. These included two low energy membranes from DOW and General Electric (GE). The TriSep x210 is a conventional high rejection membrane. Figure 37 is a scanning electron microscopy (SEM) micrograph of a cross section of one of the membranes, the DOW BW3OLE.

Table 6. Three RO Membranes used in the laboratory test.

\begin{tabular}{lccc}
\multicolumn{1}{c}{ Product Name } & Size $(\mathrm{mm})$ & Material & Type \\
\hline \hline DOW BW30LE & $190 \times 140$ & Polyamide & Fouling Resistant \\
GE Osmonics TF RO SG & $190 \times 140$ & Thin Film & Chlorine Resistant \\
TriSep $\times 210$ & $190 \times 140$ & Polyamide-urea & Fouling Resistant \\
\hline
\end{tabular}


Figure 37. Scanning electron microscopy of the DOW membrane.

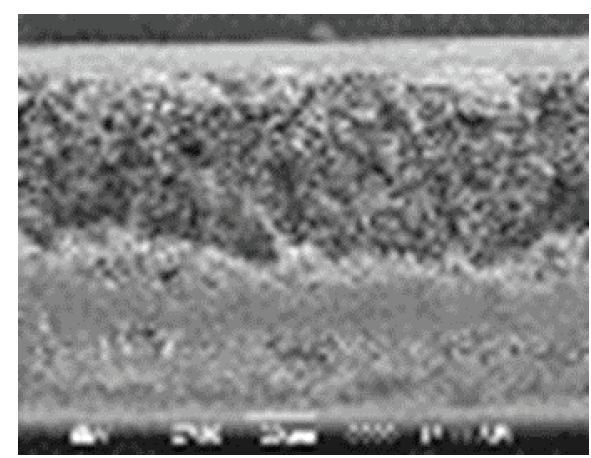

Figure 38 shows the pressure/flux performance of the three membranes tested. The DOW and GE membranes performed similarly, with the GE membrane having a somewhat higher flux for each pressure tested. The TriSep membrane, which is a conventional membrane, had progressively lower flux per unit pressure. The results indicate that low energy membranes can reduce energy requirements close to $50 \%$ at higher pressures and fluxes.

Figure 38. Pressure vs. flux for the three membranes studied.

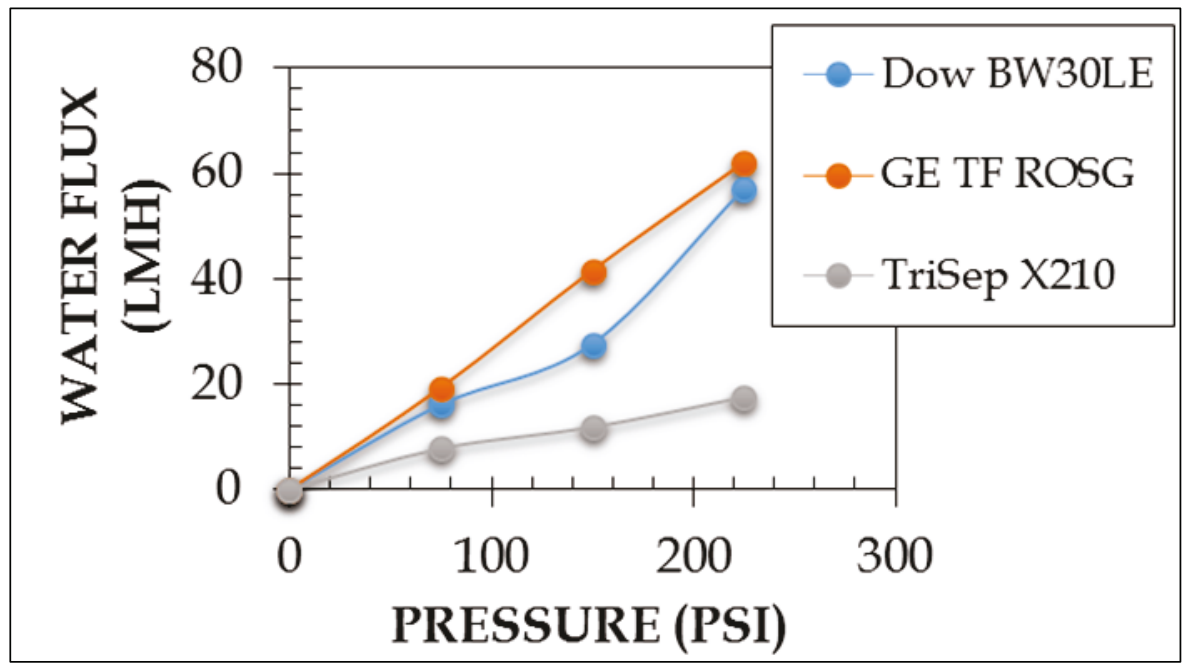

Figure 39 summarizes rejection of $10 \mathrm{mg} / \mathrm{L}$ of cesium chloride vs. operating pressure for the three membranes. The DOW and TriSep membranes had similar performance, and the DOW membrane had slightly higher removal. Removal of cesium was up to $95 \%$. 
Figure 39. Osmonics study of removal of Cesium using three RO membranes (Table 6).

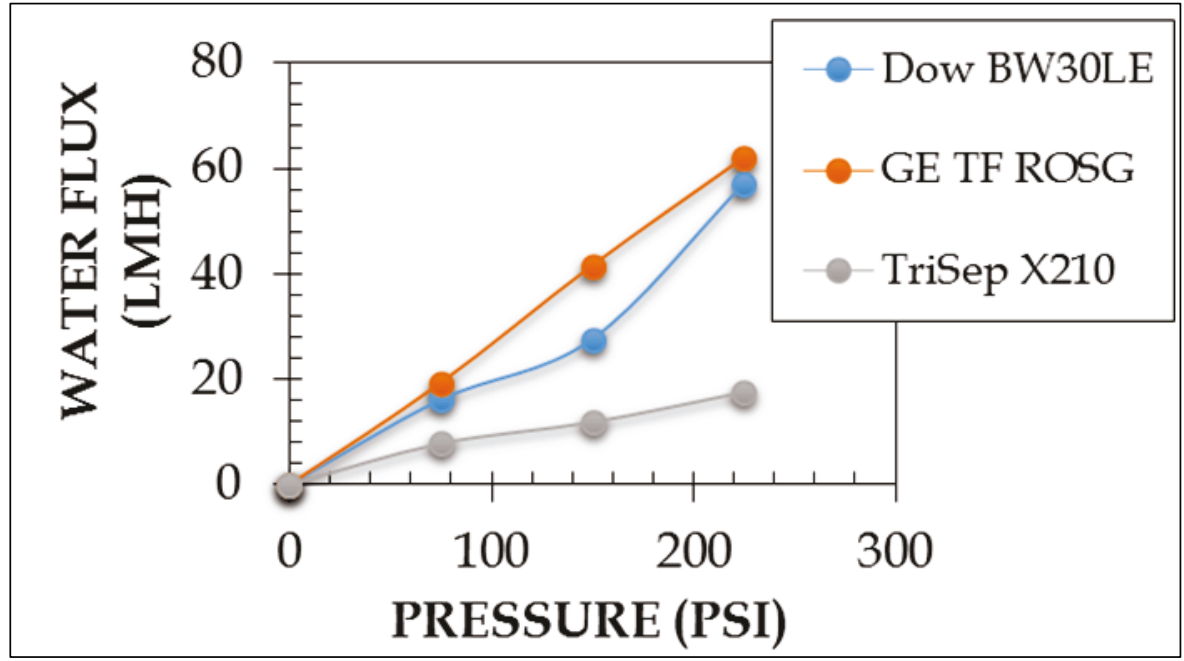

\subsubsection{RO System}

The six-stage Applied Membranes Inc. RO system (Figure 40), described section 2.8.3, was studied for its effectiveness for the removal of Malathion and of cesium. The system operated at a product flow rate of ten gpm (38 L/min) at a pressure of 93 psi and had 83\% water recovery. Figure 41 summarizes Malathion removal. For the first data point, the Malathion removal was 93.7\%. Afterwards, the Malathion removal exceeded 98\%, averaging $99.21 \%$.

Figure 40. The Applied Membranes Inc. six-stage RO system.

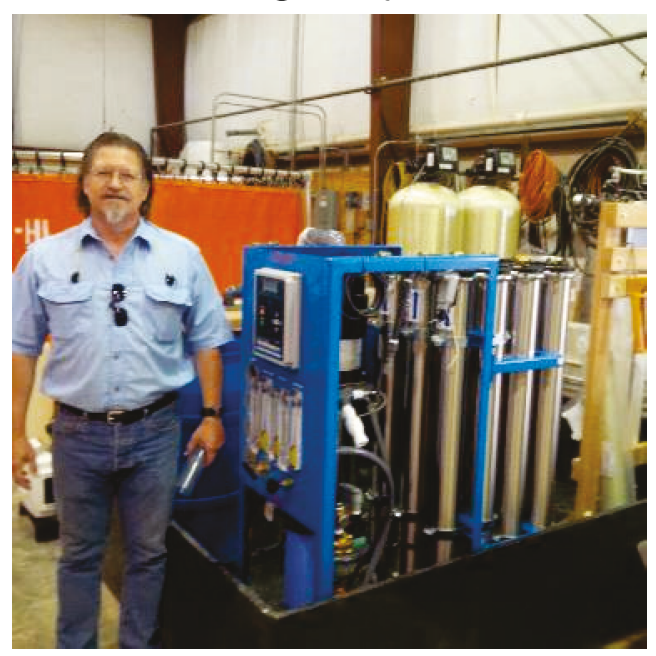


Figure 41. Treatment of Malathion ( 8 to $9 \mathrm{mg} / \mathrm{L}$ ) by the six-stage RO system.

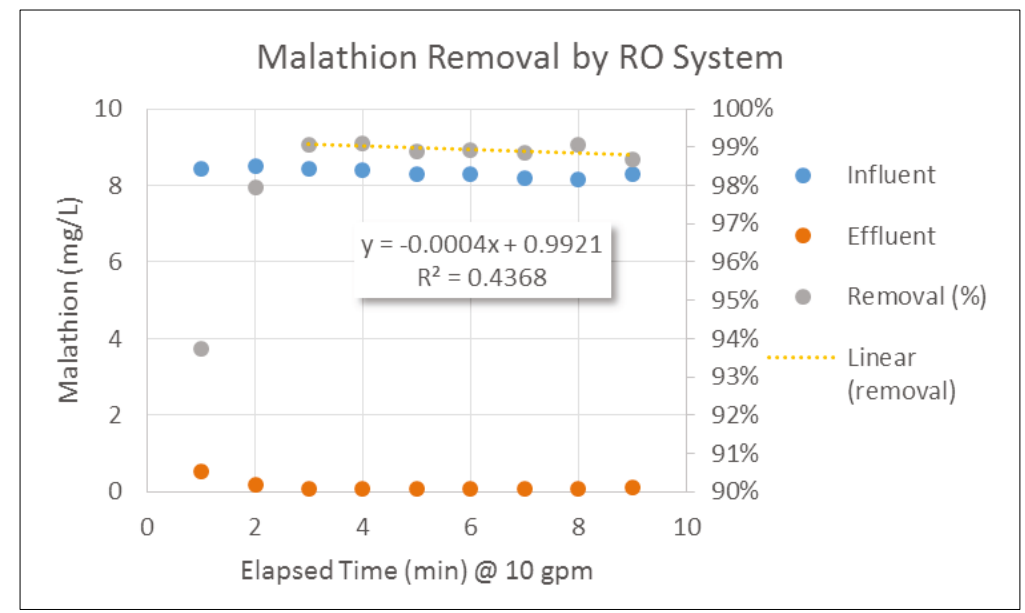

\subsection{Laboratory testing of complete system}

A laboratory test was conducted six weeks prior to the field evaluation, on 24 April 2017. The system was used to treat approximately 50 gallons of water contaminated with surfactant, bleach, clay, and cesium at a flow rate of $12 \mathrm{gpm}$ ( $45 \mathrm{~L} / \mathrm{min}$ ). The result was $>99 \%$ removal of each constituent. Figure 42 shows a comparison of the influent and the effluent from this test. The test revealed some shortcomings in the pumping and control systems that were used and these were modified prior to the field evaluation.

Figure 42. Comparison of reactor influent and effluent of a laboratory test conducted on 24 April 2017.

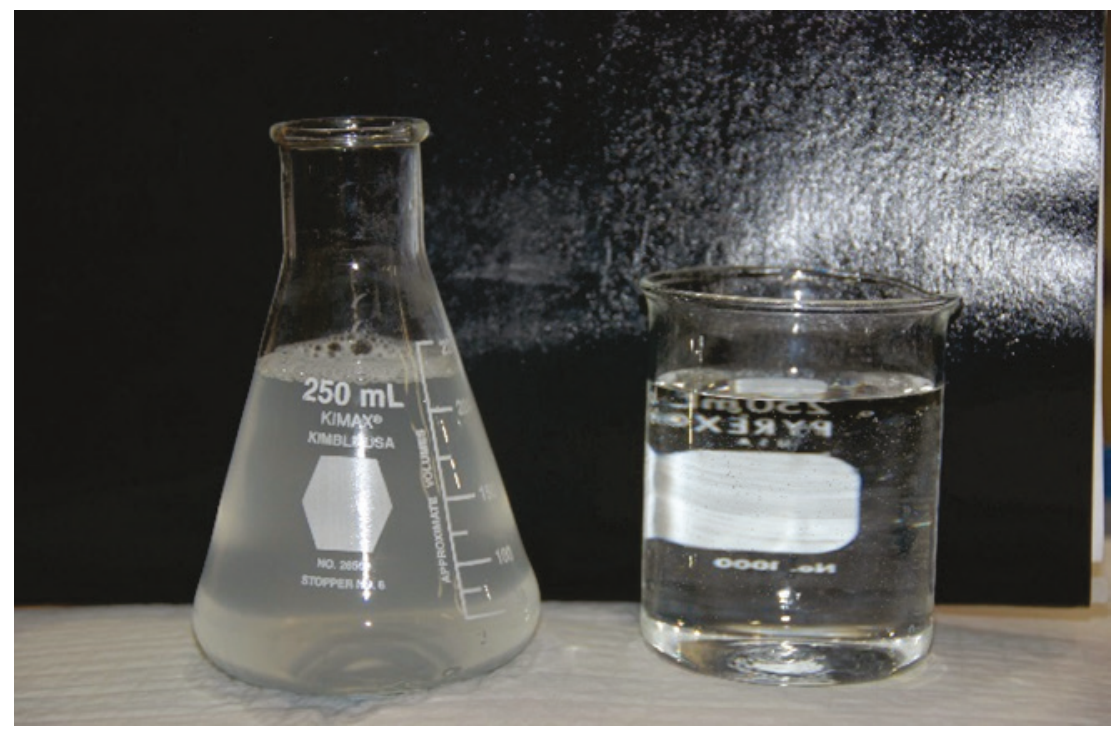




\section{Results of the Field Evaluation}

\subsection{Assessment of the simulated decontamination effort}

The decontamination effort appeared to provide a suitable simulation of vehicle decontamination. Vehicle washing was thorough, and generated an influent with high turbidity and soap. The method of collecting the wash water using the drainage vault proved to be easy to set up and very effective. The team could not put agents on the vehicles or use bleach in the wash water. Instead, these were added into the influent tank. This probably resulted in higher levels than would be expected. However, this was an effective means of testing the system.

\subsection{Assessment of DETS operation}

\subsubsection{Set up}

The setup of the system was fast and easy. It was easily driven into place, the hose reels allowed for the DETS to be quickly attached to influent and concentrate tanks, and to the effluent discharge. Once electrical connections were complete, the pump, control system, and RO system were easily started. Most of the set up was conducted by two people, but it is feasible to accomplish it with one.

\subsubsection{Operation}

The overall system performance was deemed very successful. The system operated for two hours and showed no signs for performance degradation. There was one leak from a coupling from the hose reel to the influent tank that occurred after one-hour of use, however, this was quickly addressed, repaired, and the operation continued.

Operating pressures were monitored at the inlet of the media tank and at the inlet of the RO system. At the inlet of the media tank, the operating pressure was $80 \mathrm{psi}\left(55^{2} \mathrm{kPa}\right), \pm 5 \mathrm{psi}(34 \mathrm{kPa})$. This was well below maximum allowable pressure for the media tanks of $120 \mathrm{psi}(827 \mathrm{kPa})$. Pressure at the inlet of the RO system was kept at $43 \mathrm{psi}(296 \mathrm{kPa}), \pm 2 \mathrm{psi}$ (14 kPa). This was just above the minimum feed pressure of $40 \mathrm{psi}$ $(276 \mathrm{kPa})$. Maintaining these pressures required that the pump speed be monitored and corrected. For the field evaluation, this was done manually. The effort was not excessive, but it did require a dedicated operator. 
The RO system operated at a pressure ranging from 120 to $150 \mathrm{psi}$ ( 827 to $1,034 \mathrm{kPa})$. The system is rated at $77^{\circ} \mathrm{F}\left(25^{\circ} \mathrm{C}\right)$ using $1,000 \mathrm{ppm}$ sodium chloride solution operating at 200 psi pressure. However, the dissolved solids concentrations in this study were much lower, resulting in the lower pressures.

Near the two hour mark, the system pressure of the RO unit climbed by about $20 \mathrm{psi}$. This resulted from sediment buildup in the $5 \mu \mathrm{m}$ pre-filter cartridge in the entry point of the RO system (Figure 43). The system was stopped for a few minutes and the cartridge was quickly changed out.

Figure 43. Cartridge Filter protecting the RO system from fine

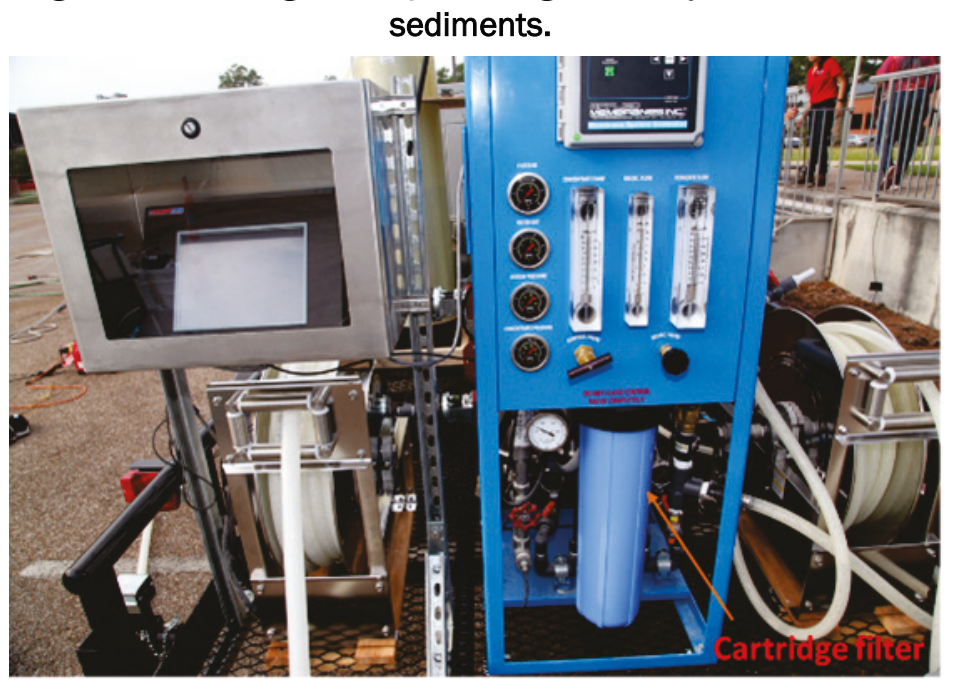

\subsubsection{Problems}

One of the goals of the study was to identify issues that need to be addressed. Several issues were identified, but none appear to be unsolvable.

\subsubsection{Trailer issues}

Since the pilot evaluation took place at the ERDC facility, the trailer could be moved slowly and carefully. Knowing this, and because of time constraints, the unit processes were secured sufficiently for this test, but not sufficiently for long distance travel on public roads and highways. Securing consisted of bolting the units to the trailer floor and bracing with wooden braces (Figure 44). After the field evaluation, the unit processes were modified to be held in place with upgraded metal braces mounted to the trailer frame. 
Figure 44. Wood bracing used for unit processes in this study. The wood bracing was replaced by welded metal bracing (Figure 61).

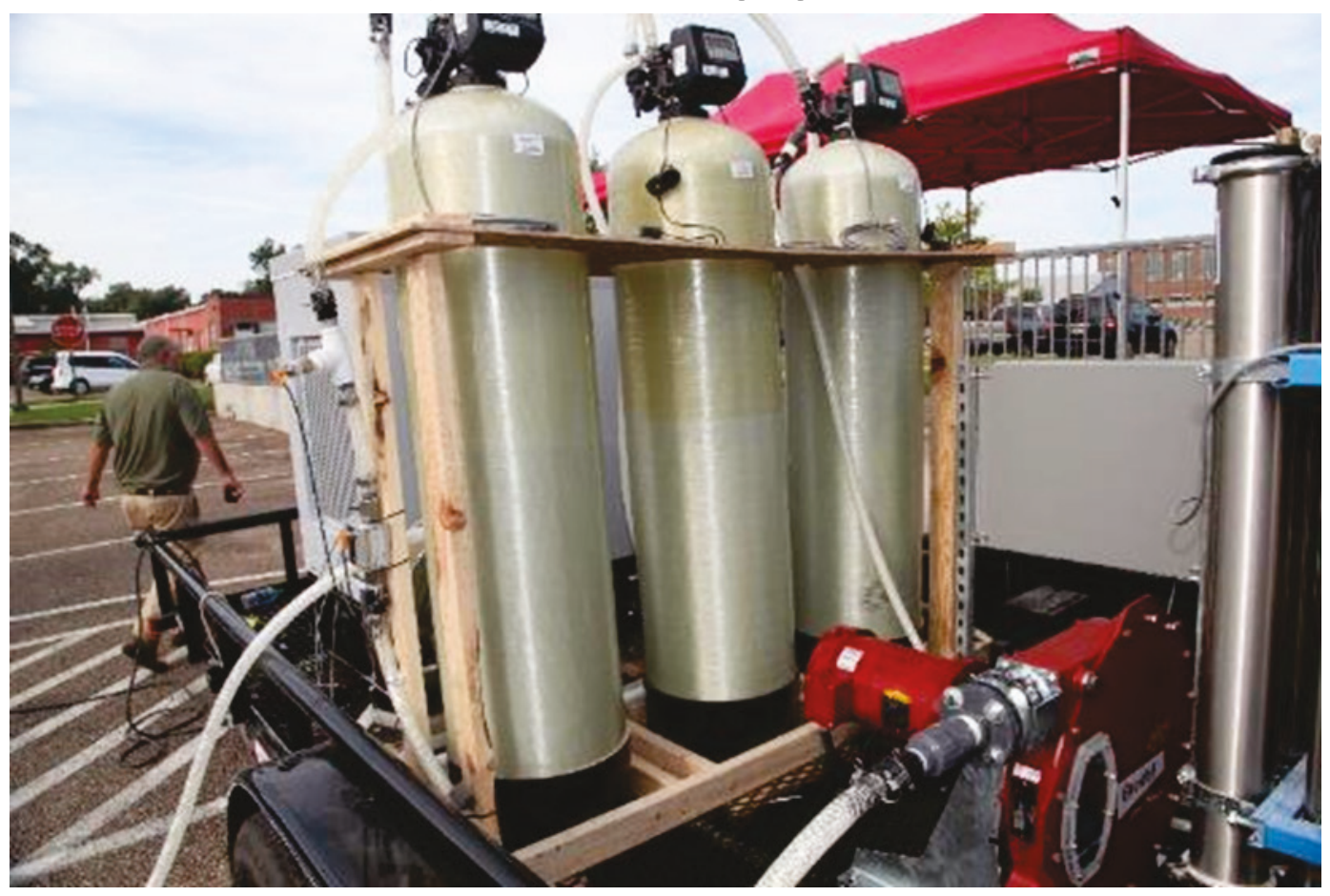

The trailer was selected to provide sufficient support for the weights of the various unit processes when dry, or with water. However, there was some bowing on the trailer and wheels, and some sag in the frame under the generator unit. Therefore, it was necessary to strengthen the trailer. The trailer was upgraded in September 2017 at a cost of $\$ 1,800$. The upgrade included adding additional bracing material under the trailer bed and on the tongue for the generator, and the axles were changed from 4,00o lb to $5,000 \mathrm{lb}$ capacity axels. Swing-down jack stands were also added to the front corners of the trailer to go along with the two swing-down jacks at the back corners of the trailer.

\subsubsection{Deficiency in generator power for startup}

The generator proved to be insufficient in power during the startup. Supporting power calculations had determined that the generator would be sufficient for simultaneous maximum loads of all system components during system operation. The generator could successfully start the pump, but a power surge associated with the startup of the RO unit caused a large draw on the current and caused a voltage drop that tripped the mechanical phase converter and shut down the main pump. The mechanical phase converter was added to the system because the one-phase to three-phase 
variable frequency drive (VFD) that came with the pump was not able to start the pump after it had been sitting idle for a several minutes. The power shutdown necessitated the use of a supplementary generator during the field evaluation (Figure 45).

Figure 45. Supplemental generator used in this study to address amperage surge associated with the mechanical phase converter.

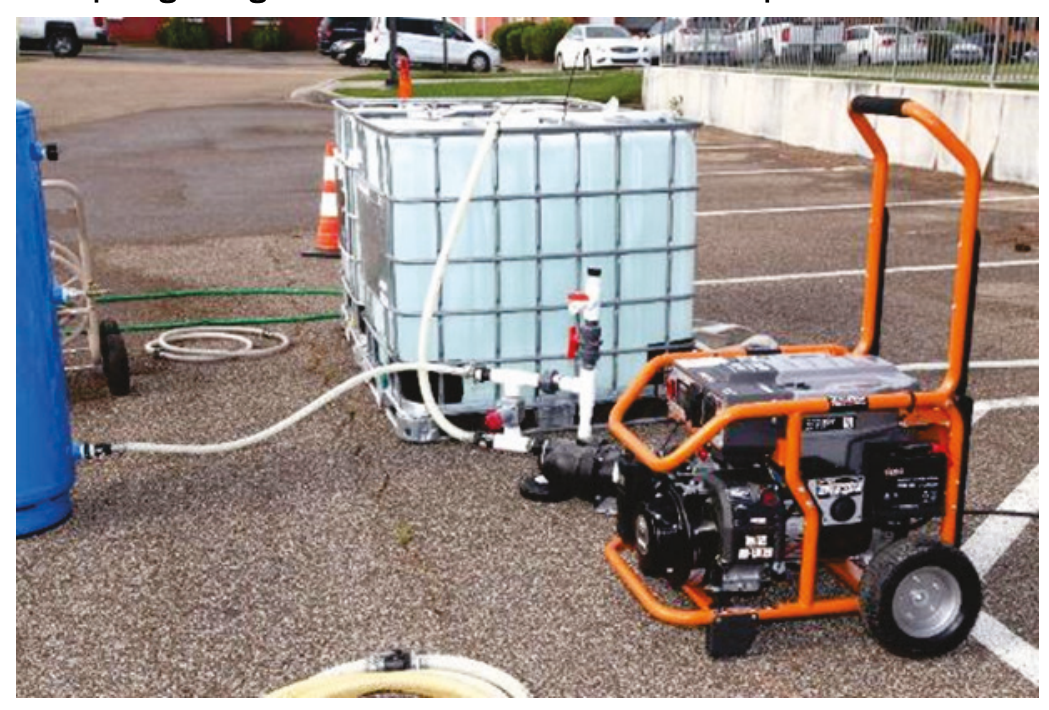

Requiring a second generator to operate the system is not a desirable long term solution. The team corrected this issue in September 2017 by correcting settings in the single to three-phase VFD supplied by the pump manufacturer. This allowed for the elimination of the mechanical phase converter. However, the team is also considering further upgrades to the electrical system to maintain voltage during the startup of the RO booster pump.

\subsection{Analytical results of influent and treated water}

\subsubsection{Washed off components from vehicles}

\subsubsection{Turbidity and suspended solids}

Figure 46 shows a comparison of samples collected from the system influent and effluent. The influent is brown and opaque. The effluent is very clear. The effective performance of the system for turbidity and suspended solids removal was obvious. 
Figure 46. Comparison of samples collected from the system influent (left) and effluent (right).

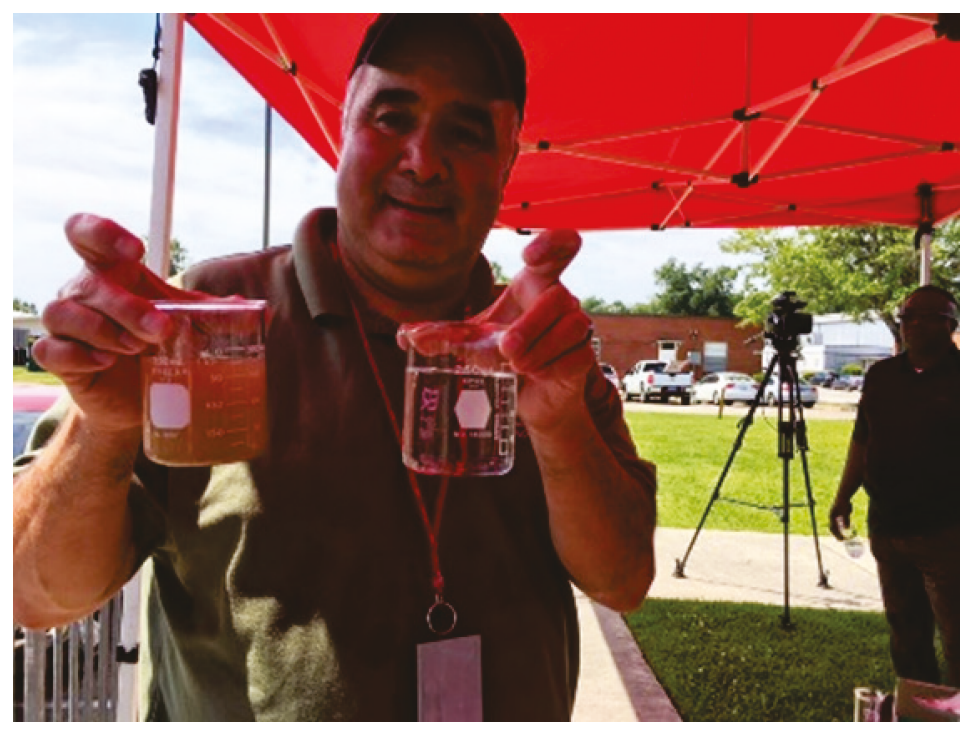

Figure 47 summarizes the turbidity measurements taken during the experiment. Except for sample 7, all of the influent samples exceeded the upper detection limit of 4,200 NTU. Effluent turbidity levels ranged from 0.55 to $3.4 \mathrm{NTU}$. This means that the turbidity reduction is three to four orders of magnitude.

Figure 47. Turbidity (influent and effluent) during the course of the field evaluation.

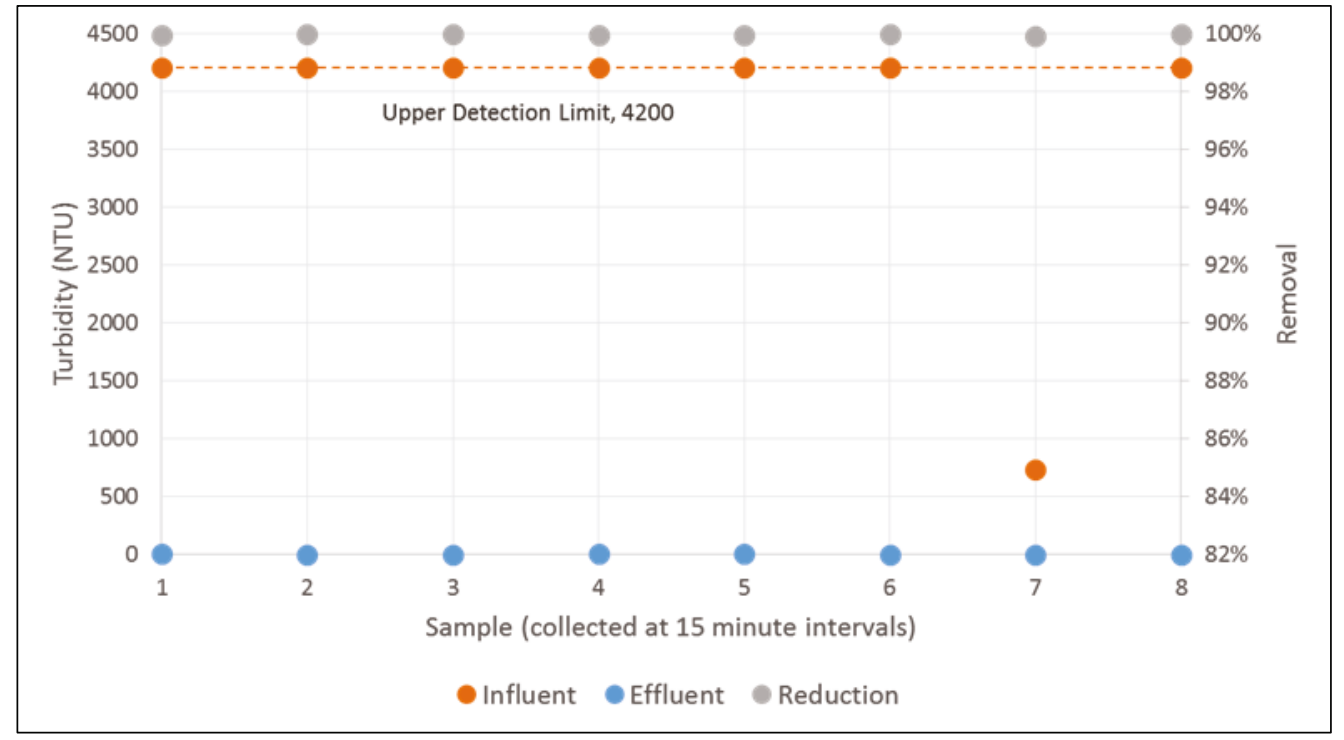

Figure 48 shows the treatment of total suspended solids. Influent concentrations ranged from 1,623 to $6,439 \mathrm{mg} / \mathrm{L}$ and treated effluent ranged from 1.5 to $8.0 \mathrm{mg} / \mathrm{L}$. Removal ranged from 99.7 to $99.9 \%$. 
Figure 48. Total suspended solids (influent and effluent) during the course of the field evaluation.

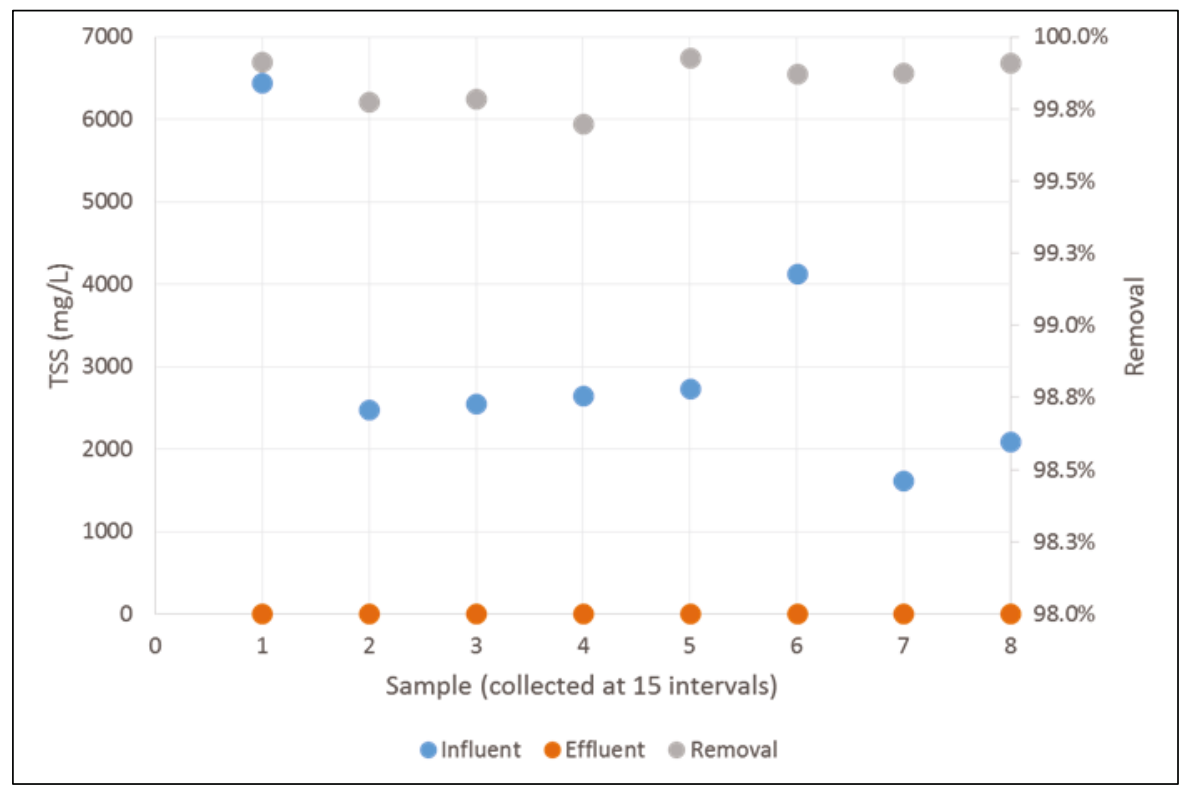

Figure 49 is a picture of rotometers showing key flows in the RO system, it is clear that although turbidity and suspended solids removal was overall effective, substantial turbidity was entering the RO unit, this is not desirable. As discussed above, a cartridge filter replacement had to be conducted. This suggests that the pretreatments may not have been as effective as planned. Ideas to improve pretreatment are presented in the discussion.

Figure 49. Rotometers to RO system, with the two on the left showing high turbidity in the system, and product flow on the right.

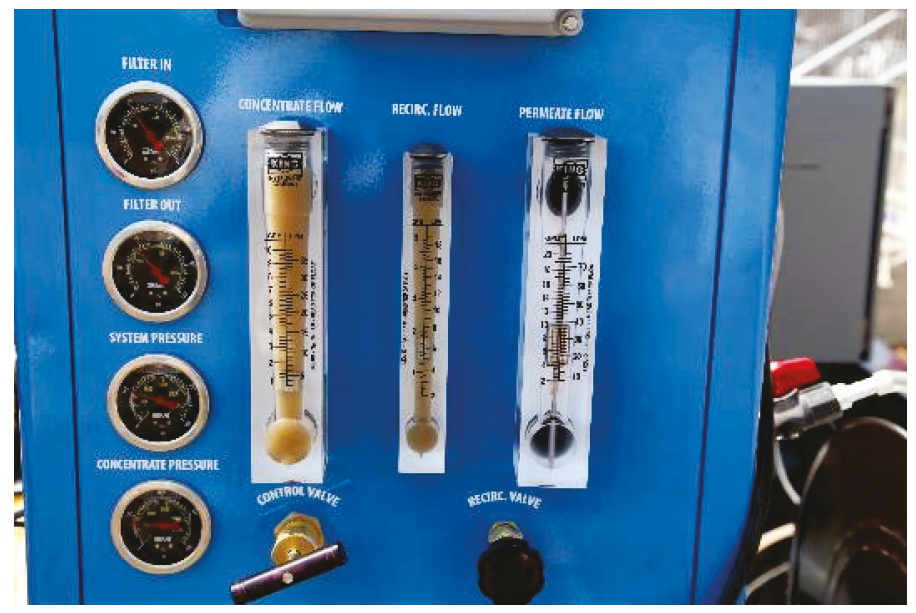




\subsubsection{Conductivity and hardness}

Figure 50 summarizes conductivity measurements. Influent conductivity ranged from $161-540 \mu \mathrm{S} / \mathrm{cm}$. Effluent ranged from 13.0 to $16.0 \mu \mathrm{S} / \mathrm{cm}$. Reduction ranged from 90.7 to $97.6 \%$. Influent hardness concentrations ranged from 18 to $153 \mathrm{mg} / \mathrm{L}$. Hardness was completely removed in the system effluent.

Figure 50. Conductivity measurements (influent and effluent) during the course of the field evaluation.

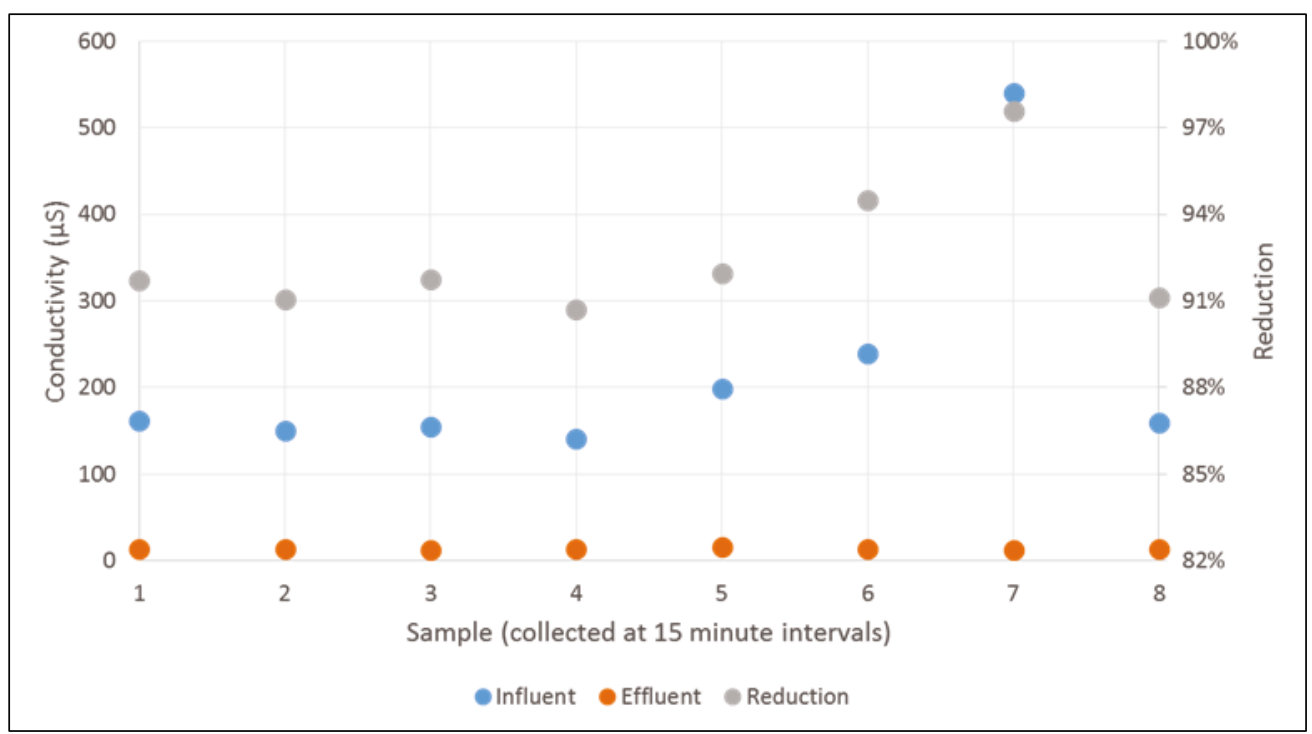

\subsubsection{Total organic carbon (TOC)}

Figure 51 summarizes data on TOC during the DETS operation. Influent TOC concentrations ranged from $27.3-61.4 \mathrm{mg} / \mathrm{L}$. Effluent concentrations ranged from $\mathrm{o}-2.02 \mathrm{mg} / \mathrm{L}$. Removal ranged from 94.7 to $100 \%$. Malathion (see section below) made up a substantial portion of the organic carbon, on the order of $50 \%$. 
Figure 51. TOC measurements (influent and effluent) during the course of the field evaluation.

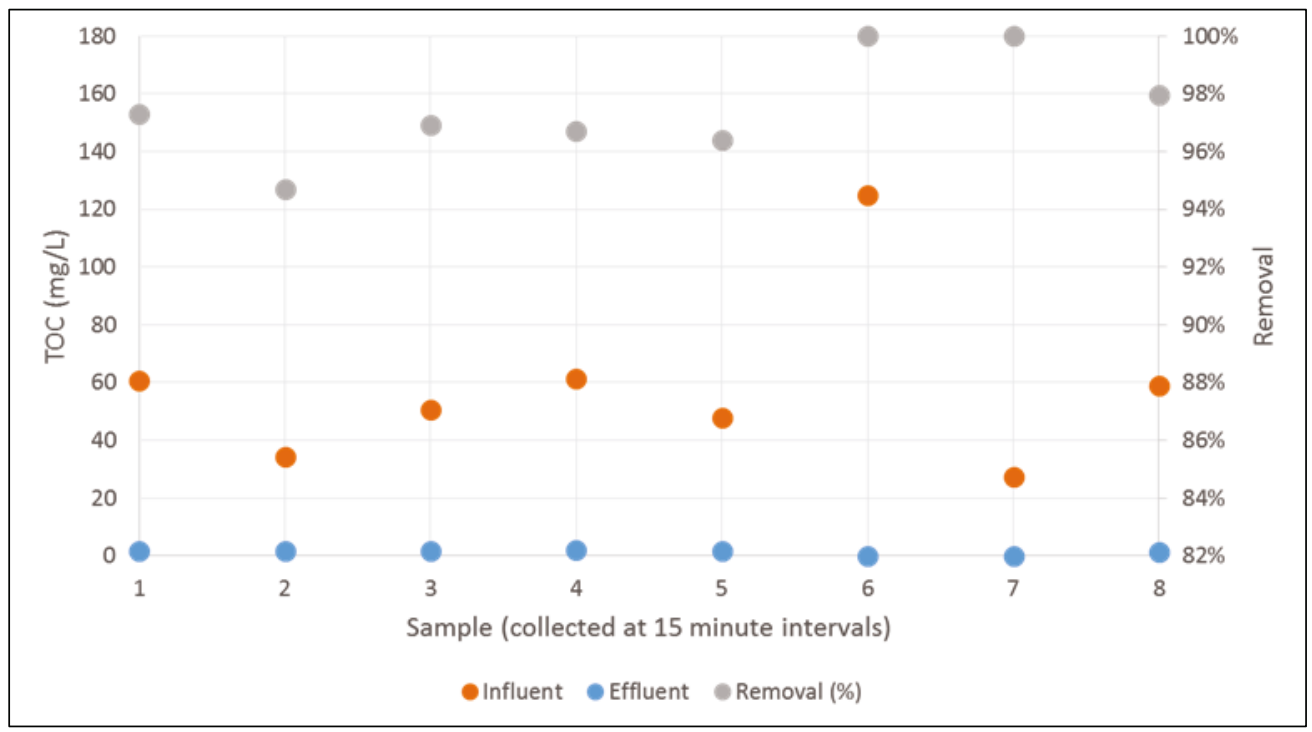

\subsubsection{Treatment chemicals}

\subsubsection{Surfactants}

Figure 52 summarizes the treatment of surfactants by the reactor. Surfactant concentrations ranged from 0.73 to $1.93 \mathrm{mg} / \mathrm{L}$ as LAS. Effluent concentrations ranged from non-detect to $0.05 \mathrm{mg} / \mathrm{L}$ as LAS.

Figure 52. Reduction of surfactant concentrations during the experiment.

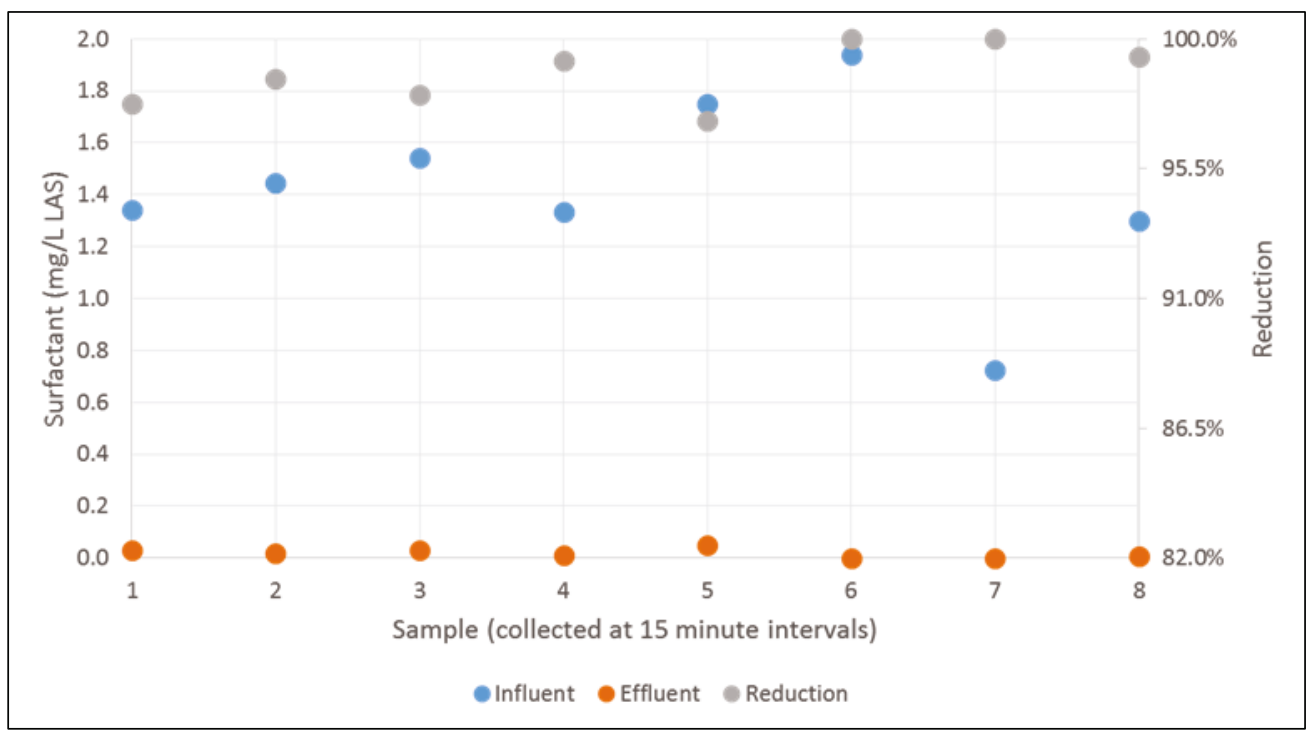




\subsubsection{Available chlorine (bleach)}

Total chlorine is a colormetric method, and field collected samples showed dramatic differences in influent vs. effluent samples (Figure 53). Influent bleach concentrations ranged from $0.4-0.2 \mathrm{mg} / \mathrm{L}$ total chlorine (Figure 54). Effluent concentrations were non-detect, with a method reporting limit of $0.1 \mathrm{mg} / \mathrm{L}$. Concentrations in the concentrate were $0.2 \mathrm{mg} / \mathrm{L}$ at the midpoint and $0.2 \mathrm{mg} / \mathrm{L}$ at the end of the experiment.

Figure 53. Colorimetric results for total chlorine. Sample on the left is the influent sample and has red color indicating high total chlorine concentration. The sample on the right is from the effluent and has no color, as chlorine is largely removed.

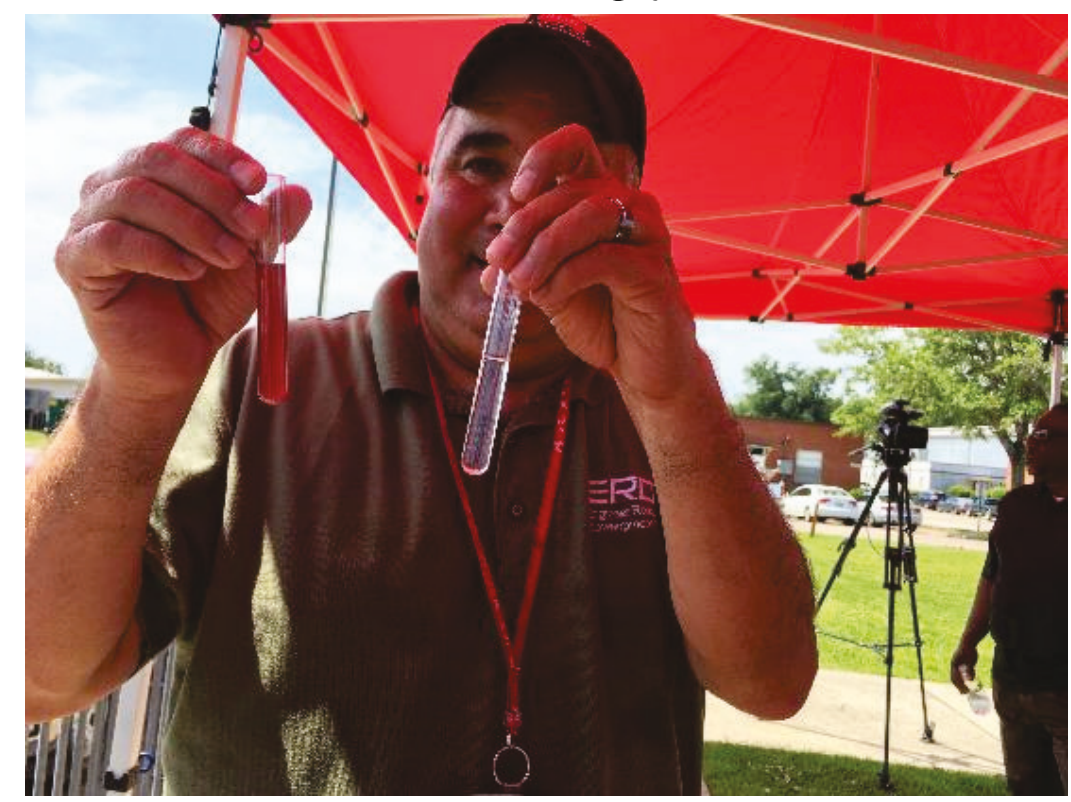


Figure 54. Bleach measured as available chlorine for samples collected during the field evaluation.

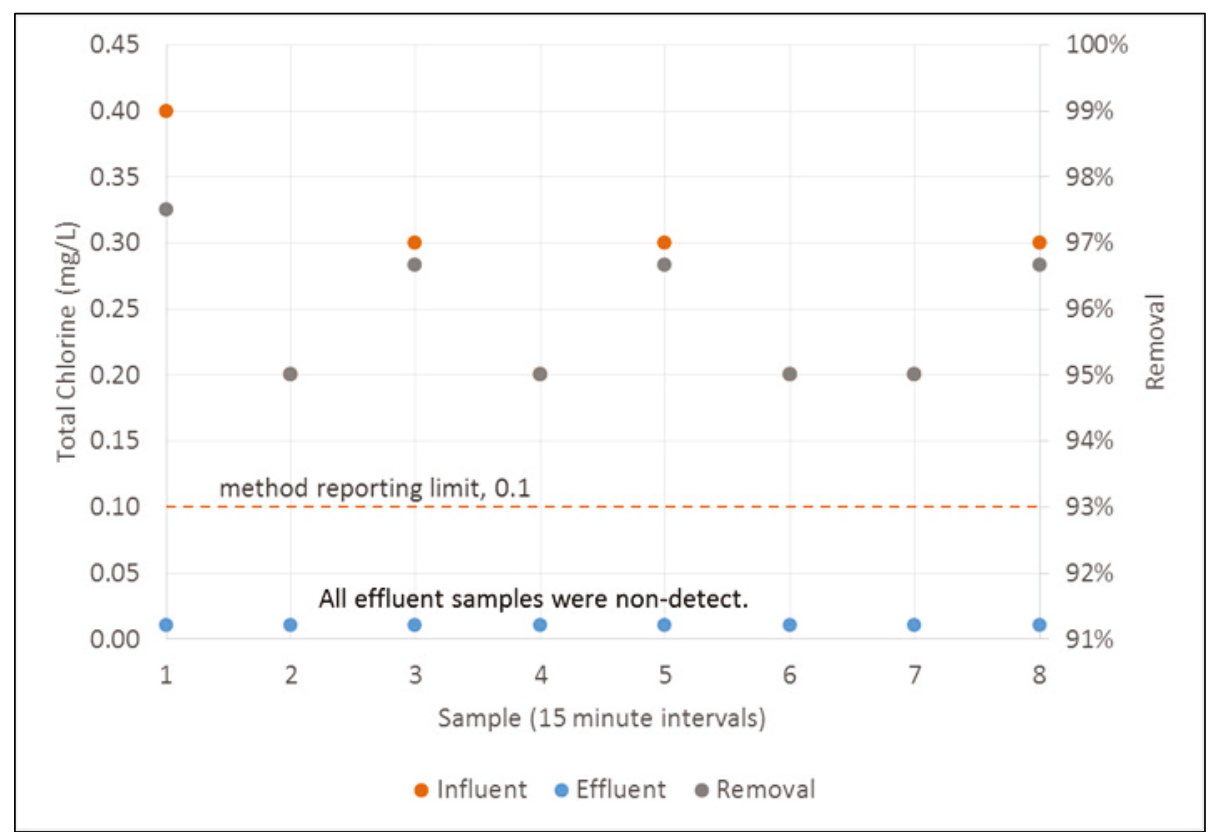

\subsubsection{Contaminants}

\subsubsection{Cesium}

Figure 55 shows cesium concentrations in the samples collected during the two hour operation of the DETS. Influent cesium concentrations ranged from non-detect to $10.5 \mathrm{mg} / \mathrm{L}$. The team is not completely sure why there were several non-detect influent samples, but it may be due to a malfunction in the dosing pump. All effluent concentrations were nondetect. Removal was $100 \%$. Concentrations in the concentrate were $0.0555 \mathrm{mg} / \mathrm{L}$ at the halfway point (sample 4), and $0.0819 \mathrm{mg} / \mathrm{L}$ at the conclusion. 
Figure 55. Cesium concentrations for samples collected during the field evaluation.

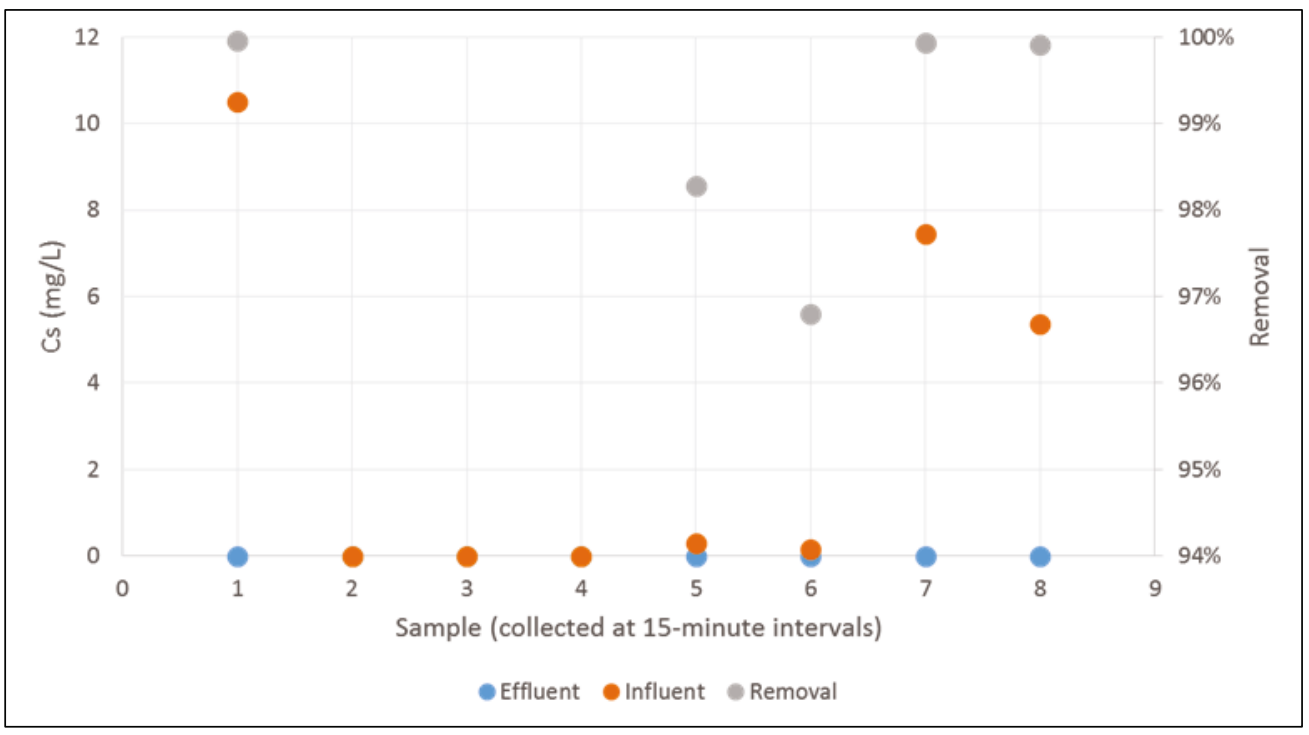

\subsubsection{Malathion}

Figure 56 shows the results of Malathion analysis using phosphate digestion and analysis on influent and effluent samples collected during the treatment study. Influent samples ranged from $13.75-53.35 \mathrm{mg} / \mathrm{L}$. Effluent ranged from 0.01 - $0.08 \mathrm{mg} / \mathrm{L}$. Removal ranged from $99.4-$ 99.9\%. Reject concentrations were 19.08 and $19.85 \mathrm{mg} / \mathrm{L}$. These were actually lower than the influent concentrations, except for the number seven sample. This is an indication that a large fraction of the Malathion was adsorbed by the GAC media before it reached the RO system.

Figure 56. Malathion concentrations in the course of the field evaluation as measured by counting phosphorus using IC.

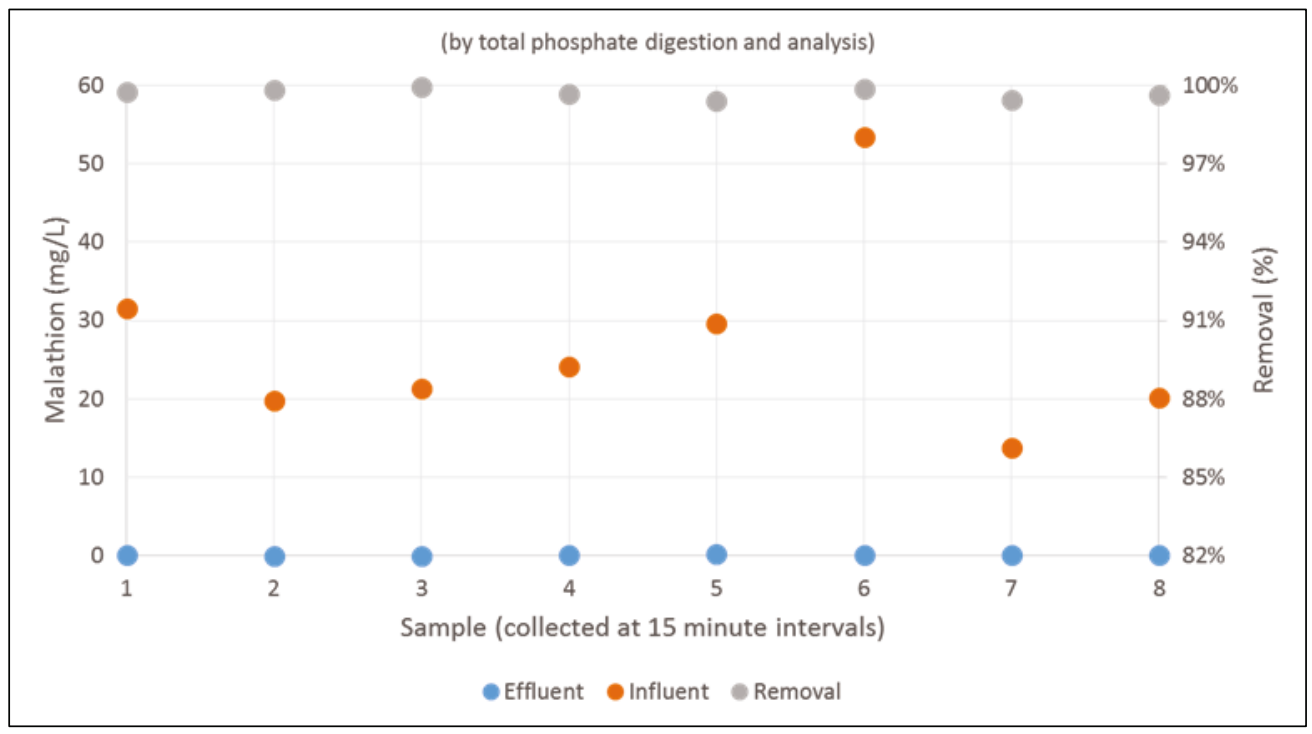


Figure 56 documents that the system achieves a high degree of contaminant removal. However, the effluent concentrations were as high as $80 \mu \mathrm{g} / \mathrm{L}$. For many chemical warfare agents, this level might be considered still hazardous. However, the analytical method focusing on digested phosphorus can produce false positive, or higher than actual concentrations. To evaluate the extent to which the phosphorus method may have overestimated Malathion concentrations, three samples (collected at sample interval four) were reanalyzed by Gas Chromatography/Nitrogen Phosphorus Detector (GC/NPD) following USEPA Method 8141A. These results are presented in Table 7, and indicate that nearly 100\% removal was achieved. This indicated that some Malathion degradation occurred resulting in a small amount of phosphorus leaching through the RO system.

Table 7. Malathion measurements of sample four conducted by GC/NPD (USEPA 8141A) in comparison to the same sample measured by the phosphorus counting method.

\begin{tabular}{|l|l|l|}
\hline Sample & Concentration by USEPA 8141 & $\begin{array}{l}\text { Concentration by phosphorus } \\
\text { counting method }\end{array}$ \\
\hline Influent & $24.7 \mathrm{mg} / \mathrm{L}$ & $24.17 \mathrm{mg} / \mathrm{L}$ \\
\hline Effluent & $0.000097 \mathrm{mg} / \mathrm{L}$ & $0.80 \mathrm{mg} / \mathrm{L}$ \\
\hline Reject & $0.0025 \mathrm{mg} / \mathrm{L}$ & Not measured \\
\hline Removal & $\sim 100 \%$ & \\
\hline
\end{tabular}

\subsubsection{Treatment summary}

Table 8 is a summary of treatment of key constituents by the DETS. Turbidity, hardness, total chlorine, and cesium were nearly $100 \%$ removed. Surfactants and total organic carbon were 98.7 and $98.0 \%$ removed, respectively. Malathion was measured using two methods. Using a phosphorus balance method, Malathion removal was $98.7 \%$. Using the USEPA 8141A method, (gas chromatograph with electron capture detector), removal was essentially $100 \%$. All measurements indicate that the DETS accomplished at least 98\% removal of key contaminants, was often higher, and is highly effective treating constituents found in decontamination wash water. 
Table 8. Summary of treatment of key constituents by the DETS field evaluation.

\begin{tabular}{|l|l|l|l|}
\hline Constituent & Influent Concentration & Effluent Concentration & \%Removal \\
\hline Turbidity & $>4200 \mathrm{NTU}$ & $1.825 \pm 1.145 \mathrm{mg} / \mathrm{L}$ & $100.0 \%$ \\
\hline Hardness & $82.36 \pm 40.79 \mathrm{mg} / \mathrm{L}$ & $0 \mathrm{mg} / \mathrm{L}$ & $100.0 \%$ \\
\hline Total Chlorine & $0.26 \pm 0.07 \mathrm{mg} / \mathrm{L}$ & $0 \mathrm{mg} / \mathrm{L}$ & $100.0 \%$ \\
\hline Surfactants & $1.422 \pm 0.359 \mathrm{mg} / \mathrm{L}$ & $0.019 \pm 0.017 \mathrm{mg} / \mathrm{L}$ & $98.7 \%$ \\
\hline Total Organic Carbon & $58.23 \pm 29.7 \mathrm{mg} / \mathrm{L}$ & $1.18 \pm 0.84 \mathrm{mg} / \mathrm{L}$ & $98.0 \%$ \\
\hline Malathion (P balance) & $26.71 \pm 12.16 \mathrm{mg} / \mathrm{L}$ & $0.08 \pm 0.05 \mathrm{mg} / \mathrm{L}$ & $99.7 \%$ \\
\hline Malathion (USEPA 8141A) & $24.7 \mathrm{mg} / \mathrm{L}$ & $0.000097 \mathrm{mg} / \mathrm{L}$ & $100.0 \%$ \\
\hline Cesium & $2.97 \pm 4.21 \mathrm{mg} / \mathrm{L}$ & $0 \mathrm{mg} / \mathrm{L}$ & $100.0 \%$ \\
\hline
\end{tabular}

\subsubsection{Concentrate}

Samples were collected from the concentrate midway through the experiment and at the end. Comparing to the initial concentrations, the concentrate concentration tended to be somewhat lower, with the exception of conductivity (Table 9). This is an indication that the media tanks were removing a significant amount of these constituents as expected.

Table 9. Concentrations of constituents in collected concentrate and comparison to initial concentrations.

\begin{tabular}{|l|l|l|l|}
\hline Constituent & $\begin{array}{l}\text { Average Initial } \\
\text { Concentration }\end{array}$ & $\begin{array}{l}\text { Concentration in } \\
\text { Concentrate at midpoint } \\
\text { of evaluation }\end{array}$ & $\begin{array}{l}\text { Concentration in } \\
\text { Concentrate at end of the } \\
\text { evaluation }\end{array}$ \\
\hline Turbidity & $>4,200 \mathrm{NTU}$ & $827 \mathrm{NTU}$ & $859 \mathrm{NTU}$ \\
\hline $\begin{array}{l}\text { Total Suspended Solids } \\
\text { (TSS) }\end{array}$ & $3,088 \pm 1,532 \mathrm{mg} / \mathrm{L}$ & $1,192 \mathrm{mg} / \mathrm{L}$ & $756 \mathrm{mg} / \mathrm{L}$ \\
\hline $\begin{array}{l}\text { Total Organic Carbon } \\
\text { (TOC) }\end{array}$ & $58.2 \pm 29.7 \mathrm{mg} / \mathrm{L}$ & $35.9 \mathrm{mg} / \mathrm{L}$ & $41.4 \mathrm{mg} / \mathrm{L}$ \\
\hline Conductivity & $218 \pm 134 \mu \mathrm{S} / \mathrm{cm}$ & $592 \mu \mathrm{S} / \mathrm{com}$ & $689 \mu \mathrm{S} / \mathrm{cm}$ \\
\hline Hardness & $82.4 \pm 40.8 \mathrm{mg} / \mathrm{L}$ & $40.7 \mathrm{mg} / \mathrm{L}$ & $32.1 \mathrm{mg} / \mathrm{L}$ \\
\hline Surfactant & $1.42 \pm 0.36 \mathrm{mg} / \mathrm{L} \mathrm{LAS}$ & $0.80 \mathrm{mg} / \mathrm{L} \mathrm{LAS}$ & $0.82 \mathrm{mg} / \mathrm{L} \mathrm{LAS}$ \\
\hline Free Chlorine & $0.26 \pm 0.07 \mathrm{mg} / \mathrm{L}$ & $0.20 \mathrm{mg} / \mathrm{L}$ & $0.20 \mathrm{mg} / \mathrm{L}$ \\
\hline Malathion & $26.71 \pm 12.16 \mathrm{mg} / \mathrm{L}$ & $19.08 \mathrm{mg} / \mathrm{L}$ & $19.85 \mathrm{mg} / \mathrm{L}$ \\
\hline Cesium & $2.96 \pm 4.2 \mathrm{mg} / \mathrm{L}$ & $0.06 \mathrm{mg} / \mathrm{L}$ & $0.08 \mathrm{mg} / \mathrm{L}$ \\
\hline
\end{tabular}




\section{Discussion}

\subsection{Capture of decontamination wash water}

The DETS field evaluation study established the effectiveness of using the parking lot and drainage to effectively simulate the capture of wash water from decontamination activities. The process was relatively easy to implement in a paved area with well-established drainage vaults. Such a process could be implemented in urban or developed settings.

There may be other situations, particularly battlefield settings, where more effort may be required to capture the runoff water. Still, with the use of existing terrain coupled with some earthmoving, it seems that effective capture systems could be created.

\subsection{System set-up and operation}

System set-up was relatively easy and was largely accomplished by two people, with the exception of addressing some of the electrical issues discussed in section 6.2.3.2. With the electrical issue solved, it does appear that two people would be sufficient for setting up the system, and it could be done with one person if absolutely needed.

The DETS was operated by one individual. The system ran smoothly and there was one leak that was easy to correct. Monitoring operating pressure was an effective means of regulating system operation and it was used to regulate the speed of the main pump and determine when it was necessary to replace the RO unit's cartridge filter, this was easily accomplished by one person.

The system was operated for two hours and treated 1200 gallons. This involved the decontamination of twenty cars and trucks and ten large military vehicles, this was a substantial effort. However, for large events, it may be necessary for the system to operate for several days on the order of ten to twelve hours per day. Therefore, although the results were positive, the team realize the need to further stress the system.

The ease of operation was obviously a plus, but it does make assessing issues with system failure difficult. A future goal will be to develop tests of 
extreme conditions to intentionally cause failure, and assess and record what is needed for complete recovery.

\subsection{Treatment of constituents}

\subsubsection{Environmental constituents}

The system proved to be highly effective at treating environmental constituents.

\subsubsection{Sediments/particulates}

The influent concentration of suspended solids in the collected wash water averaged 3,088 $\pm 1,532 \mathrm{mg} / \mathrm{L}$. Brown (2002) studied suspended solids in commercial carwashes throughout various locations including Phoenix, Arizona, Florida, and Boston, Massachusetts, and found levels ranging from 6 to $117 \mathrm{mg} / \mathrm{L}$. The simulated decontamination had levels from 26 to almost 515 times higher than that found in commercial carwashes. Two factors played a key role. First, the military vehicles, which were driven through muddy parts of the ERDC station, collected high levels of mud and muck. Figure 19 shows large clods of mud and dirt that were left after washing the military vehicles, this contributed to the high levels of suspended solids. In addition, substantial solids could have been contributed by dirt and particulates on the asphalt driveway where the field evaluation took place. It was brought to our attention after the demonstration by Army personnel that standard decontamination operations include scraping gross contamination (e.g. caked on dirt) from vehicles before they enter the decontamination area. Doing so would have greatly reduced the level of suspended solids entering the system.

The vault where the wash water was collected, then pumped to the influent collection tote, is a natural settling basin. This would serve to reduce the suspended solids reaching the influent to the DETS. However, soils in Vicksburg tend to be fine grained, which allows for a higher amount of suspended materials, and the sump pump used is designed to draw water from the lowest point possible. The high suspended solids in the influent resulting in extremely high turbidity measurements, which exceeded 4,200 NTU in most measurements.

Both TSS and turbidity, measurements of suspended particulates were highly reduced by the treatment system. This is important because CBRN 
agents may be in the form of particulates. For example, radioactive agents are often in the form of particulates, such as uranium (Larson et al. 2012) and finely ground cesium powders. Also, contaminants can adsorb onto particulates. So, removal of the particulates could be a substantial means of reducing CBRN agents.

Removal of particulates is important for the operation of the key unit processes in the system. In particular, the particulates can foul and/or damage the membranes used in the RO system. The system was effective at removing particulates, and there was no evidence of any damage or fouling due to particulates. However, as discussed in the results section, high turbidity was measured entering the RO unit (Figure 50), and the protective cartridge filter leading to the RO system had to be changed once during the four hours of operation. For a long operational period, these change outs could compound operational complexity. Although the cartridge filter replacement was simple to do, the need to replace it suggests that the existing sediment pretreatments could be improved.

This field evaluation used a relatively small 250 gallon tote for inlet collection, and the water was withdrawn from the tote through a port near the bottom. This resulted in the vast majority of solids being transferred to the DETS unit. In CONUS systems, water is collected in 3,000 - 5,000 gallon blivets. The team designed the system with a 3,000 gallon collapsible tank, this can be used to reduce the solids load if blivets are not available. The 250 gallon tote was a factor of $10-20$ times smaller than either the collapsible tank or blivets. It is likely that using these systems would significantly reduce the level of particulates in the RO influent.

More aggressive means could be taken to reduce particulates prior to reaching the RO unit. A coagulant step could be also added. This might improve performance, but at the cost of added complexity. The sand in the multimedia sand filter can also be replaced with a finer grained garnet material, or an additional large-capacity cartridge filter could also be added to the system after the media tanks. The team will explore these options in FY-18.

\subsubsection{TOC}

Existing in many forms, TOC can be particulates, others may be adsorbed to particulates, and some may be dissolved. The processes to remove TOC depend on its form. Particulate TOC forms would be removed by settling 
and by sand media filtration. Most dissolved forms of TOC would be removed by GAC adsorption and $\mathrm{RO}$ would remove the smallest dissolved organic materials.

In this case, TOC removal was effective, ranging from $96.4-100 \%$. The influent levels of TOC ranged from $27.3-125 \mathrm{mg} / \mathrm{L}$, and this could be caused by a number of sources. Some of the TOC could be from organic CWAs. In this case, Malathion was used as a CWA simulant. Levels were as high as $53.35 \mathrm{mg} / \mathrm{L}$, corresponding to a TOC measurement of $2.76 \mathrm{mg} / \mathrm{L}$, this accounts for $2.2-8.3 \%$ of the total TOC.

The remaining portion of TOC was likely from natural organic materials and oils and greases washed off the vehicles. Brown (2002) found oil and grease levels ranged from $6.7-60 \mathrm{mg} / \mathrm{L}$ in car washes throughout the U.S. Plant and animal (such as insects) material, as well as organic acids in soils, also contribute to TOC. In the case of human decontamination, dead skin, hair, and clothing material would also contribute to TOC. Even innocuous organic matter could serve as sorption sites for CWAs, therefore, its removal is vital.

\subsubsection{Conductivity}

Conductivity is caused by dissolved ions in the water. Influent conductivity levels ranged from 141 to $540 \mu \mathrm{S} / \mathrm{cm}$, and removal ranged from 91.07 to $97.59 \%$. With a few exceptions, these ions tend to be monovalent or divalent. In general, monovalent are considered much more difficult to remove. Hardness focuses on divalent cations, particularly magnesium and calcium. STB contains calcium oxide (quick lime) as a stabilizing agent (Smart 2002). When dissolved in water, this additive results in a large source of hardness. In laboratory experiments hardness adversely affect the GAC media by leaving scaling deposits. To address this, a water softening unit was added containing ion exchange resin resulting in $100 \%$ removal of hardness in this study.

Surfactants can also increase conductivity (Hattiangdi et al. 1949). Since surfactants are added at high concentrations, it is likely that these could be a significant source of conductivity in some cases. However, surfactant measurements in this study indicate that surfactant removal approaches were effective. 
The $100 \%$ removal of hardness indicates that only monovalent cations penetrated the treatment. Some monovalent ions will always penetrate the treatment system in relatively small amounts. Of particular concern are monovalent radioactive isotopes such as cesium. This evaluation showed that cesium was removed to non-detectible levels by the DETS.

Conductivity was the only water quality measurement to increase in the concentrate. This is due to the approximately ten-fold increase of conductivity in the RO concentrate associated with the greater than $90 \%$ reduction of conductivity in the product water. It is likely that if the concentrate itself is treated, the conductivity of the effluent would still be low, but the conductivity of the new concentrate would further increase by a factor of 10. Eventually, this parameter could limit the number of time the reject water from the system can be recycled.

\subsubsection{Decontamination chemicals}

The study indicated $100 \%$ removal of bleach (measured as total chlorine) and surfactants. This is a promising result since both chemicals can be detrimental to the performance of the RO membranes. Bleach is important because it can damage membranes and seals through oxidation, and surfactants can coat the RO membranes and result in fouling. During the study, there was no evidence of RO performance degradation. However, future tests need to sample between the filter media reactors and the RO system in order to assess if the media filters are successfully protecting the RO unit.

\subsubsection{Chemical warfare simulants}

\subsubsection{Removal of Cesium 133}

Removal of chemical warfare simulants was very effective and met expectations. Cesium is a monovalent ion that is very soluble and hygroscopic. The team considered it one of the most challenging constituents to remove. The removal of cesium was $100 \%$. The form of Cesium used in the experiments was as a salt $(\mathrm{CsCl})$. However, Cesium could also be applied as a particle. In fact, a dirty bomb would most likely use Cesium in a fine powdered from. Particulates would likely be easier to remove in the various media filter steps in the DETS. So, the ionic form used in this field evaluation was a worst case scenario. 


\subsubsection{Removal of Malathion}

Malathion is a relatively unstable compound that can undergo hydrolysis reaction and oxidation with bleach. Because of this, a high spiking level of Malathion was used, probably higher than expected during most decontamination scenarios. Influent concentrations were ranged from 20 to $50 \mathrm{mg} / \mathrm{L}$ using the phosphate digestion method and over $24 \mathrm{mg} / \mathrm{L}$ using USEPA Method 8141A (using sample 4). Analysis of the effluent using the phosphate digestion method gave an average of $0.091 \mathrm{mg} / \mathrm{L}$ remaining, which was a massive reduction in concentration, ranging from 99.4 to 99.9\% removal. The analysis of sample 4 using USEPA $8141 \mathrm{~A}$ have a similar influent concentration to the phosphate counting method (24.7 vs. 24.17). However, the effluent concentration was much lower (0.00097 $\mathrm{mg} / \mathrm{L}$ vs $0.08 \mathrm{mg} / \mathrm{L}$ ). This suggests that there was some breakdown of the Malathion resulting in phosphorus penetrating the RO system, but that actual Malathion breakthrough was extremely small, less than $1 \mu \mathrm{g} / \mathrm{L}$.

The high degree of Malathion removal in sample 4 analysis demonstrated a highly effective treatment system. Various studies have indicated that while RO is generally very effective removing Malathion and other pesticides, $100 \%$ rejection is not always the case (Bhattacharya et al. 2006; Chian et al. 1975). Studies have indicated that Malathion removal by RO is largely due to adsorptive properties (Chain et al. 1975) that are prone to breakthrough and competitive interactions. Therefore, the team will also consider adding a final polishing step. This could include a second GAC filter or a graphene oxide adsorbent material. Another possibility could be using an UV oxidation process, this has been shown to be effective for organophosphorus CWAs, such as VX (Zuo et al. 2005).

The background GAC treatment studies indicated that there could be a degradative aspect regarding surfactants and Malathion. Degradation could be a key feature that greatly enhances treatment by allowing for larger treatment capacity that simple adsorption. SDS is an anionic surfactant, and these can be readily biodegraded. Activated carbon can often enhance biodegradation by concentrating contaminants and other nutrients.

Malathion can also be biodegraded, but as an organophosphate ester, it is also susceptible to hydrolysis (Watts 1997). Hydrolysis could be an effective means to removing Malathion and other organophosphate contaminants. Many CWA's are also organophosphate ester. Soman is a 
traditional OP ester that readily hydrolysizes. VX is a modified OP ester that is more resistant to hydrolysis, but can degrade at a slower rate (Groenewold 2010). Therefore, degradative process would likely extent to organophosphate CWAs. Columbus et al. (2006) studied gas filtration of VX using GAC, and found that $90 \%$ of the adsorbed VX was decomposed over time, presumably due to hydrolysis reactions. This degradation was consistent regardless of the phase from which the VX was loaded, the presence of metal impregnation, and the water content of the VX. Degradation of CWAs on activated carbon can also be conducted by a variety of treatments. These include metal inclusions like copper oxides (Fichtner et al. 2013), heated water (Osovsky et al. 2013), and hydrogen peroxide (Osovsky et al. 2014).

\subsection{Concentrate}

The concentrate numbers, summarized in Table 9, indicate that the reject generated by the RO system had concentrations less than the influent to the DETS system in most cases. The one exception to this pattern was conductivity, which was elevated on the order of $2-3$ fold.

Studying the concentrate provides some idea of how the system is working. The $\mathrm{RO}$ will result in increased contaminant concentrations in the reject stream relative to the influent to the RO system. In this case, with the unit achieving approximately $85 \%$ recovery, the contaminants should be concentrated by about 6.7 times (calculated based on inlet/reject volume), assuming no degradation or adsorption. The only way that the concentrate concentration of a given constituent can be lower is if substantial removal occurred before the RO unit. The bulk of the constituents had concentrations lower than the DETS influent, indicating that the pre-RO processes resulted in substantial removal.

Conductivity was an exception to this pattern. Conductivity levels were about $2-3$ times higher in the concentrate versus the initial concentration. This, however, is lower than the expected 6.7 fold concentration increase expected from $\mathrm{RO}$ alone. Therefore, there is still significant removal of conductivity in the pre-RO processes. Hardness was lower in the concentrate compared to initial concentrations, this indicates that the bulk of the conductivity concentration was due to monovalent ions. Cesium, which is a monovalent ion, was also much lower in the concentrate than the initial concentration. We speculate that sodium and chloride are the species causing most of the conductivity making it to the RO unit. 
The level of concentrations also suggests that the concentrate could be rerun through the system to achieve recovery levels higher than $85 \%$. Treating the concentrate could increase water recovery to level of 95 to $99 \%$, which would also significantly decrease the volume of water requiring regulated disposal. Conductivity could end up being the constituent limiting the number of times the concentrate can be retreated.

\subsection{Monitoring}

The system tested in this first evaluation had limited monitoring capabilities. In terms of operational monitoring, pressure is a very useful parameter to measure because it can reveal if there are leaks (which would result in a decrease in pressure), and fouling and clogging in the system (which would result in increases in pressure). Pressure gauges on the inlet of the sand media tank, and on the RO system provided data on the system operation. The RO system also had dial pressure gauges that provided operational data. For the purpose of the evaluation, this was adequate, but for a fully operational system, having to watch these gauges would be an inefficient use of manpower. Fortunately, this can be easily modified by adding additional pressure monitoring devises in the system and attaching them electronically to the control system. It would then be possible to view graphs of the pressure performance to see trends (particularly steady or growing increases in operating pressure) that could indicate potential problems. And the control system can include alarms to alert operators of problems. Additional pressure sensors will be incorporated in FY-18 (October 2017 through September 2018).

A conductivity monitoring system on the RO provided data on contaminant removal for the influent/effluent of the RO system. Particulate removal can also be monitored by looking at the water clarity of the influent and effluent, which had dramatic differences. In this project, grab samples were taken to monitor contaminant removal, however, it took several days for the results to return.

There are several on line technologies that can be added to monitor for water quality parameters. These include $\mathrm{pH}$, oxidation/reduction potential, dissolved oxygen, and turbidity. The program will explore which sensors make the most sense to incorporate in the DETS and incorporate those in FY-18. 
Continually monitoring for contaminant removal can be more challenging, primarily because of the range of potential agents. Radioisotopes may actually be the easiest to monitor for. Radiation detectors and monitors are well developed and should be easily adaptable for the treatment system. The most common systems detect gamma radiation, this radiation is the form that is easiest to detect because it is highly penetrating and difficult to shield. Alpha and beta detectors are also available, but these tend to not be as sensitive. One possible candidate for this use is the NEXBETA-ABG (Figure 57), which is advertised to provide real time, in-line, continuous detection of alpha, beta and gamma radiation in a water line. Two sources for this detector were found but no price was advertised.

Figure 57. NEXT-BETA-ABG radiological detector that could be adapted for the DETS.

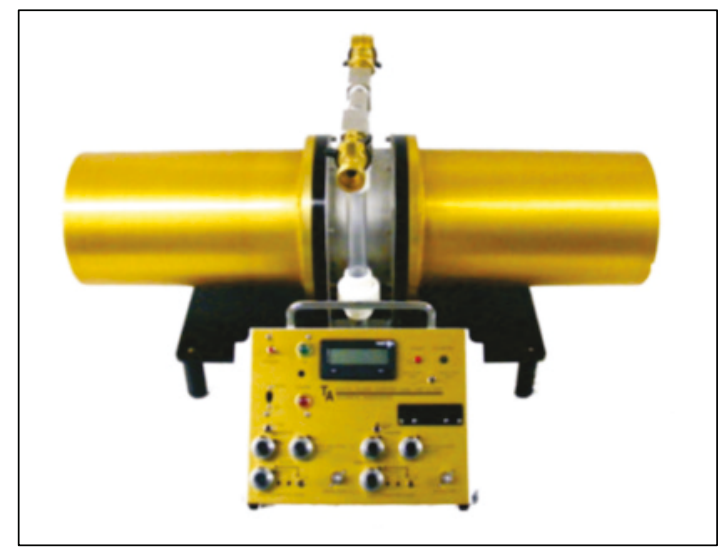

Chemical agents are more challenging from a monitoring perspective, but there are some options. Visible/UV spectrophotometry could be monitored on line and most organic chemicals have ideal absorbance at a given wavelength. This could be used to quantify a known chemical. However, identification of most chemical warfare agents is not possible solely by UV absorbance spectra (Rewick et al. 1986). Total absorbance could be used as a general method to look for breakthrough. UV Raman detectors are being developed for monitoring purposes (Lochner et al. 2008), and these may be adaptable to water uses in the future. The Ocean Optics USB 4000 is a unit that could be possibly adapted for this purpose (Figure 58). 
Figure 58. A small, contained spectrophotometer that could be adapted for online monitoring.

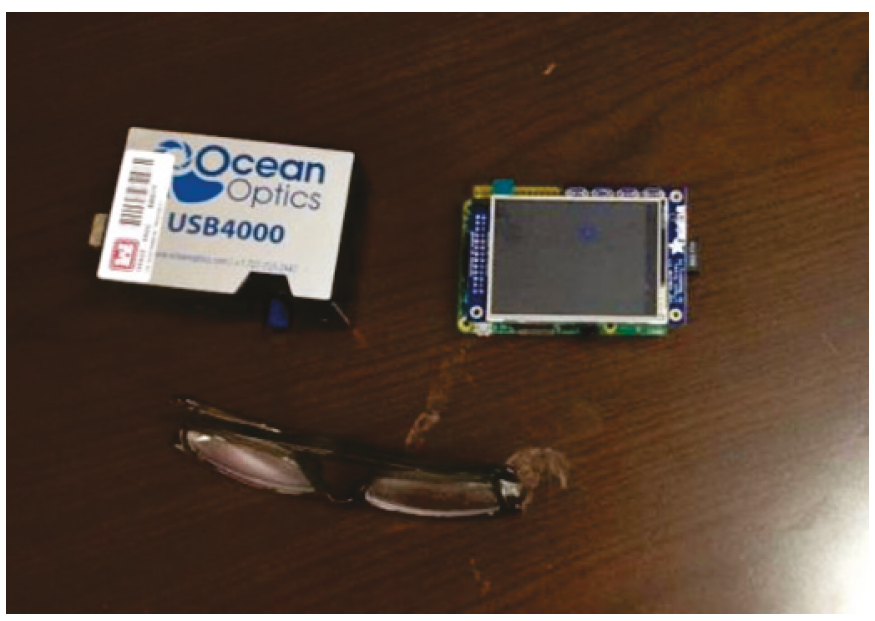

The team propose to explore the use of total organic carbon as a means of monitoring the effluent to look for gross breakthrough of organic chemicals through the RO system The GE Sievers M5310C online TOC (Figure 59) appears to be a robust system with an analog current output for monitoring using the existing control system. It has an advertised wide detection range ( 0.004 to $50 \mathrm{mg} / \mathrm{L}$ ), analysis time of four seconds, response time of 3.25 minutes, and an approximate cost of $\$ 30,000$.

Figure 59. GE Sievers online TOC analyzer.

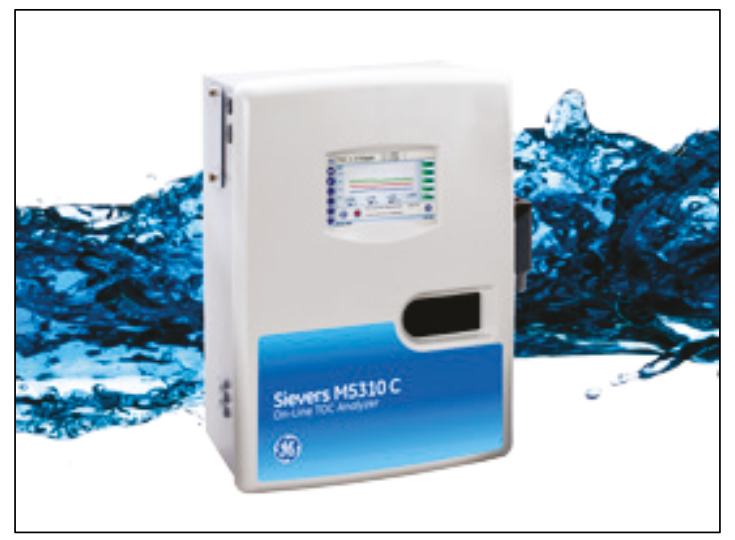

The DETS would most likely be used in association with chemical units. These units have mobile instrumentation that allows for rapid analyses of samples. This could be taken advantage of in terms of monitoring DETS performance. Periodic samples could be taken, or samples could be taken if breakthrough is found on a TOC or UV/Visible light spectrophotometer. Samples could also be taken on the treated effluent to confirm water is safe for reuse or discharge. 
Monitoring for specific biological agents is even more challenging. It would probably be necessary to rely on laboratory testing. However, particulate monitoring, such as turbidity, could be an effective surrogate measure. This could, once again, be coupled with grab sample analysis from mobile, onsite laboratories. Due to the physical size of most biological agents, it is unlikely that any would be capable of penetrating an RO membrane unless there is a physical failure of the membrane. A physical failure of the membrane would be indicated by a rapid and significant increase in conductivity in the product water from the RO system.

Biological monitoring could be a direct method of assessing performance. The treatment system at the Old "O" Field uses a biological system in which eight Blue Gill fish are monitored for breathing rate, depth, gill purge rate, and body movement (as communicated by Mr Howard Beardsley, Joint Program Executive Office Chem/Bio Defense (JPEOCBD)). Irregularities in the fish health suggest that the system performance is degrading. Biological monitoring is good because it can account for a wide range of constituents. However, it is not precise in terms of what is causing performance deterioration. And it does require that live fish can rather quickly be implemented into the monitoring system, which may not be practical for a deployable system.

\subsubsection{Discharge and reuse}

The chemical analyses from the study indicated that Cs were completely removed from solution by the DETS system. Further, Table 7 indicates that Malathion was nearly 100\% removed, and the remaining concentration was less than $1 \mu \mathrm{g} / \mathrm{L}$. Bleach and surfactants were removed at high levels. These treatment levels discharge requirements for OCONUS operation based on OEGBD criteria. They would also exceed any expected requirement for discharge for CONUS operations, including discharge into storm drains or into sanitary sewers leading to WWTP. Furthermore, the water would be suitable for reuse for decontamination.

\subsubsection{Analysis of wash water reuse}

Horne (2016) describes the need to conserve water during decontamination. In the article, it is discussed that operating environments are frequently in areas with stressed water conditions, and that decontamination operations can use a substantial amount of water. Even if sufficient water is available, usage may stress local water resources 
and adversely affect friendly or neutral populations. Further, there is a significant risk that a WMD attack will result in loss of water pressure in the local distribution system or contamination of the local water supply. The DETS has the ability to both treat local water sources and make water resources go substantially further.

As discussed above, the treated water would be suitable for reuse in decontamination operations. Figure 60 demonstrates the advantage of water reuse, based on a scenario of $85 \%$ water recovery (which has been achieved with the DETS), and with an initial water volume of 600 gallons. The scenario assumes that $100 \%$ of the wash water is captured. The solid lines show the scenario where the treated water is reused for decontamination and the concentrate is simply collected. In this scenario, the 600 gallons can act like 4000 gallons for decontamination (solid blue line, Figure 60). The total collected concentrate would be 600 gallons (solid grey line, Figure 60).

However, data on the concentrate indicates that it was similar in concentration to that of the original source water (Table 9). It could therefore be treated and reused as well (dashed blue line, Figure 60). If this is done after 18 cycles/reuses of the water product water, then the 550 gallons of concentrate can be reused, resulting in a total volume of just over 7000 gallons of recycled water. The total collected concentrate (dashed grey line, Figure 60) would be just over 550 gallons. In either case, treatment and reuse of the wash water can greatly extend water resources. Furthermore, it is likely that the concentrate could be treated and reused more than once. 
Figure 60 . Total usable water volume and reject generated volume based on an initial 600 gallons of decontamination water and $85 \%$ recovery for two scenarios, one with no treatment of concentrate $(\mathrm{r} 1)$ and the second with a single treatment of the concentrate.

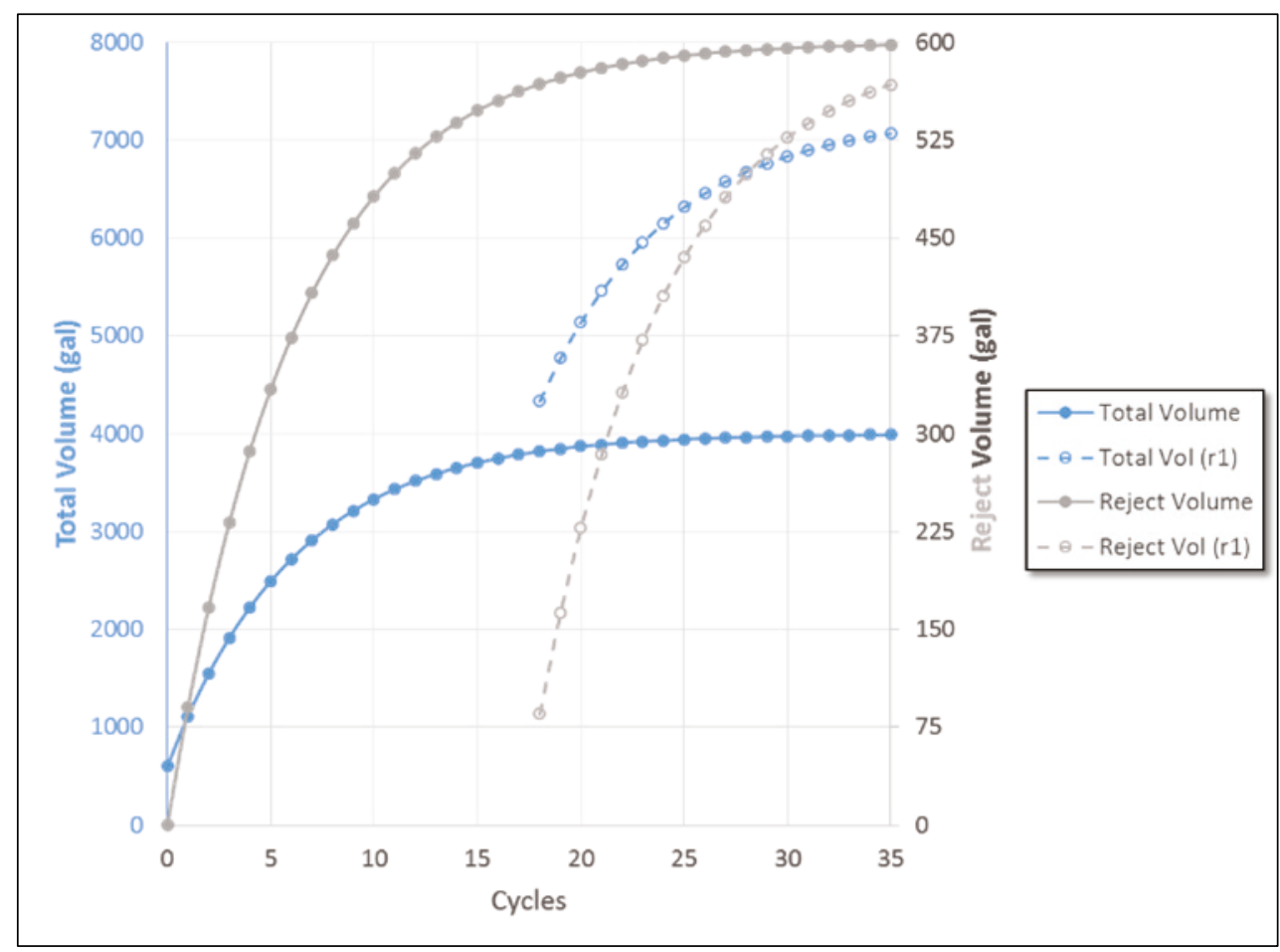

\subsection{DETS Transportation}

The DETS was designed to be towed on its own trailer. Although the trailer was sized for this application, some signs of deformation were found. Consequently, the trailer bed and suspension were upgraded in September 2017. In November, additional bracing was added to better support the generator, the trailer axels were upgraded, and a metal frame was fabricated to brace the media tanks, which now allows the trailer to be towed safely at highway speeds or on rough roads (Figure 61). At this time, the team expects that the trailer can be safely taken on highways and the U.S. Interstate system. It may be necessary to limit the towing speed due to poor aerodynamics of the trailer. However, a future design could include a removable shell to improve aerodynamics and allow higher driving speeds. Although the DETS is not certified, it is within size and weight for air transport. Road worthiness testing is planned in future studies (see section 8). 
Figure 61. Bracing added to trailer to enhance support for system components (30 November 2017).

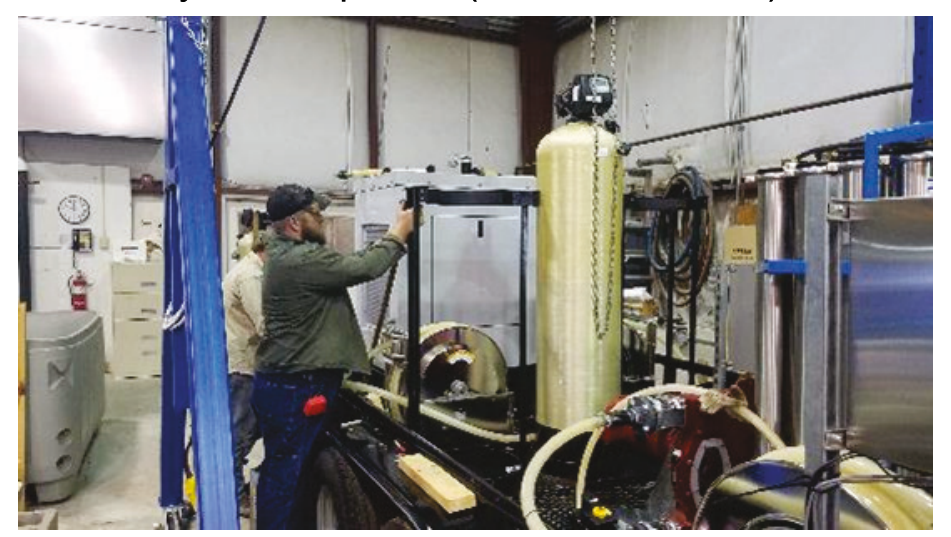

\subsection{Feedback from invited stakeholders}

Stakeholders with interests in water availability associated with CBRN decontamination attended the field evaluation. Appendix G contains a list of these stakeholders. After the evaluation, a meeting was held to gain impressions from these stakeholders. Appendix $\mathrm{H}$ contains notes from the meeting collected by Dr. Jon Brame and supplemented by Dr. Victor Medina. In addition, a trip report prepared by Howard Beardsley of Joint Program Executive Office Chem/Bio Defense (JPEOCBD) is provided in Appendix I. A video of the field evaluation is available on YouTube (https://youtu.be/d9TZuYZUMno).

Key points discussed include:

- The size of the system (company level) appears to be a good size for military applications.

- Technology Readiness Level (TRL) level six is need for transition.

- Vessel materials need to be checked for sorption of chemical agents. There was a particular concern expressed of the spun fiber used in the granular media tanks.

- Could the system be optimized by other material choices? Recommend testing of alternatives for sand media, GAC, and RO membranes.

- The Old "O" Field is a groundwater remediation site contaminated with CWAs and other contaminants. This could be a good place to conduct a test of DETS using real CWAs.

- Another possibility would be to tie into live agent training and testing that is planned by Joint Program Manager-Protection (JPM-P) in the Czech Republic. This is under negotiation, but is likely to occur in FY 18-19. 
- NORTHCOM conducts large scale exercises that involved CBRN events. Teaming with one of these exercises could be valuable.

- Collection of water could be a challenge in some cases, particularly in OCONUS operations.

- The greatest advantage in the short-term is for CONUS applications. Also, the system would have great value in urban environments, both CONUS and OCONUS.

- Sacrificing a team member solely to run the system is not desirable. It would be advantageous to have the system performance report to a cell phone or personal device, so that the operator can do other things to support the CBRN mission. Remote operation could be advantageous as well, particularly to allow problem solving.

- Cesium is a good surrogate for radioisotopes. It's high solubility and radioactivity $(137 \mathrm{Cs})$ makes it a worse case. Technetium was also suggested as a radioisotope.

- Could enough radioactivity be accumulated to make the DETS "hot"? Professional opinion was "probably not", but testing or calculations recommended.

- The decontamination simulation was an excellent simulation. However, there are some changes that could be incorporated to increase realism. The M26 decontamination sprayer is generally used instead of fire hoses. There is commonly a dry removal step using brooms. Be aware that CBRN agents and contaminants can become entrained in water mists and these can spread contamination and recontaminate cleaned vehicles.

- All stakeholders requested we continue to inform them on the progress of the project. 


\section{Future Evaluations of the DETS}

The research plan is to conduct future evaluations of the DETS. These include the following:

- A road worthiness evaluation

- The team will conduct a series of videotaped driving tests to document that the system can be effectively transported by trailer.

- A mass personnel decontamination

- This will simulate human decontamination by using a waste stream of spiked water collected from shower activities or using a simulant.

- This will also include a stress test, with the goal of operating the system until failure.

- The test may be conducted at Camp Shelby, Mississippi, or onsite at ERDC Vicksburg.

- Final Study

- A final study of a finalized unit.

- Coordinate and integrate into a training with a National Guard CBRNE Enhance Response Force (CERF) Unit

- Both mass personnel and vehicle decontamination 


\section{Conclusions}

Based on this study, the following conclusions can be derived:

- DETS is a low cost treatment system, the first of its kind to treat and recycle decontamination effluent.

- An effective means of capturing wash water from vehicle decontamination was demonstrated.

- The process was effective at $99 \%$ removal of all constituents tested.

- The system was relatively easy to use and performed reliably.

- Several areas for improvement were identified. 


\section{References}

Baghel, A., B. Singh, P. Pandey, R. K. Dhaked, A. K. Gupta, K. Ganeshan, and K. Sekhar. 2006. Removal of water poisons from contaminated water by adsorbents. Journal of Hazardous Materials 137(1):396-400.

Baghel, A., and B. Singh. 2016. Kinetic study on removal of sulphur mustard on granular activated carbon from aqueous solution. Defence Life Science Journal. 1(2):167170. doi: 10.14429/dlsj.1.10738.

Balling, F. O. 2009. Army portable water treatment units. Presentation slides. U.S. Army RDECOM TARDEC. https://www.michigan.gov/documents/deq/deq-wb-wws-wss09pres3_284554_7.pdf.

Bhattacharya, A., P. Ray, H. Brahmbhatt, K. N. Vyas, S. V. Joshi, C. V. Devmuarai, and J. J. Trivedi. 2006. Pesticides removal by low-pressure reverse osmosis membranes. Journal of Applied Polymer Science. 102(4):3575-3579.

Bibby, K., L. Casson, C. N. Haas, and T. Rycroft. 2016. Risks from Ebola discharge from hospitals to sewer workers. Alexandria, VA: Water Environment Research Foundation.

Boone, C. M. 2007. Present state of CBRN decontamination technologies. TNO-DV 2007 A028. Rijswijk, The Netherlands.

Brame, J., V. F. Medina, I. Smith, and L. Procell. 2016. Composition of CBRN decontamination effluent and development of surrogate mixtures for testing effluent treatment technologies. ERDC/EL-SR-16-2. Vicksburg. MS: U.S. Army Engineer Research and Development Center. http://hdl.handle.net/11681/20268.

Brown, C. 2002. Water effluent and solid wastes characteristics in the professional carwash industry. International Carwash Association.

Chian, E. S. K., W. N. Bruce, and H. H. P. Fang. 1975, Removal of pesticides by reverse osmosis. Environmental Science \& Technology. 9(1):52-59.

Columbus, I., D. Waysbort, L. Shmueli, I. Nir, and D. Kaplan. 2006. Decomposition of adsorbed VX on activated carbons studied by 31P MAS MMR. Environmental Science and Technology 40(12): 3952-3958. doi:10.1021/es052226d.

Czekaj, P., F. Lopez, and C. Guell. 2001. Membrane fouling by turbidity constituents of beer and wine: Characterization and prevention by means of infrasonic pulsing. Journal of Food Engineering 49(1):25-36. https://doi.org/10.1016/S02608774(00)00181-3.

Do, V. T., C. Y. Tang, M. Reinhard, and J. O. Leckie. Degradation of polyamide nanofiltration and reverse osmosis membranes by hypochlorite. Environmental Science and Technology 46(2):852-859. 
Ernst, H., R. Phillips, and M. Magnuson. 2016. The "what" and "how" of biocontaminated water management. USEPA Office of Research and Development, Homeland Security Research Program. Presentation Slides. Water Environment Federation Technical Exhibit and Conference. New Orleans, LA.

Fitch, J. P., E. Raber, and D. R. Imbro. 2015. Technology challenges in responding to biological or chemical attacks in the civilian sector. Science 302(5649):13501354. doi: 10.1126/science.1085922.

Fichtner, S, J. Hofmann, A. Möller, C. Schrage, J. M. Giebelhausen, B. Böhringer, R. Gläser. 2013. Decomposition of 2-chloroethylethylsulfide on copper oxides to detoxify polymer-based spherical activated carbons from chemical warfare agents. Journal of Hazardous Materials 262:789-795. https://doi.org/10.1016/i.jhazmat.2013.09.052.

Fulazzaky, M. A., and R. Omar. 2012. Removal of oil and grease contamination from stream water using the granular activated carbon block filter. Clean Technologies and Environmental Policy 14(5):965-971.

Groenewold, G. S. 2010. Degradation kinetics of VX. Main Group Chemistry 9(3):221224. doi 10.3233/MGC20100037.

Hattiangdi, G. S., W. W. Walton, and J. I. Hoffman. 1949. Some physical chemical properties of aqueous solutions of soaps and soapless detergents. Journal of Research of the National Bureau of Standards 42(4):361-368.

Herman, B. D., J. O. Eberly, C. M. Jung, and V. F. Medina. 2017. Review and evaluation of reservoir management strategies for harmful algal blooms. ERDC/EL TR-1711. Vicksburg. MS: U.S. Army Engineer Research and Development Center.

Horne, W. H. 2015. The need to conserve water during CBRN decontamination. Army Chemical Review. Summer: 27-30.

Hwang S-C., R. A. Larson, and V. L. Snoeyink. 1990. Reactions of free chlorine with substituted anlines in aqueous solution and on granular activated carbon. Water Research 24(4):427-432.

Jackson, D. E., R. A. Larson, and V. L. Snoeyink. 1987. Reactions of chlorine and chlorine dioxide with resorcinol in aqueous solution and adsorbed on granular activated carbon. Water Research 21(7):849-857. https://doi.org/10.1016/0043$\underline{1354(87) 90162-X .}$.

Jagauribe, E. F., L. L. Medeiros, C. S. Barreto, and L. P. Araujo. 2005. The performance of activated carbons from sugarcane bagasse, babassu, and coconut shells in removing residual chlorine. Brazilian Journal of Chemical Engineering 22(1):41-47.

Jegatheesan, V., S. H. Kim, C. K. Joo, and G. Baoyu. 2009. Evaluating the effects of granular and membrane filtrations on chlorine demand in drinking water. Journal of Environmental Sciences 21(1):23-29. https://doi.org/10.1016/S10010742(09)60006-1. 
Karnib, M., A. Kabbani, H. Holail, and Z. Olama. 2014. Heavy metals removal using activated carbon, silica, silica activated carbon composite. Energy Procedia 50:113-120. https://doi.org/10.1016/j.egypro.2014.06.014.

Kingery, A. F., and H. E. Allen. 1995. The environmental fate of organophosphorus nerve agents: A review. Toxicological and Environmental Chemistry 47(3-4):155-184. doi: 10.1080/02772249509358137.

Kloos, R. 2015. Measuring “LAS” based surfactants with Hach Barcode Cuvette Testing TNTPlus 874. Application Note. Loveland, CO: Hach Company.

Larson, S. L., V. F. Medina, J. Ballard, C. Griggs, M. Wynter, D. Mackie, B. King, and C. Nester. 2012. Large-scale physical separation of depleted uranium from soil. ERDC/EL TR-12-25. Vicksburg. MS: U.S. Army Engineer Research and Development Center Report.

Lee, Y., and Y. N. Lee. 2015. Solid-phase extraction of sulfur mustard metabolites using an activated carbon fiber sorbent. Journal of Analytical Toxicology 40(1)64-71. doi: 10.1093/jat/bkv112.

Lochner, J. M, A. M. Hyre, S. D. Christesen, and K. R. Gonser. 2008. Quantitative UV absorbance specta of chemical agents and simulants. ECBC-TR-611. Aberdeen, MD: U.S. Army Edgewood Chemical and Biological Center.

Medina, V. F. 1994. Development of biological filters using granular activated carbon as the packing material. Ph.D. Dissertation. Department of Civil and Environmental Engineering. Los Angeles, CA: University of Southern California.

Medina, V. F., J. L. Johnson, S. A. Waisner, R. Wade, J. Mattei-Sosa. 2015. Development of a treatment process for electrodialysis reversal reject with intermediate softening and secondary reverse osmosis. Journal of Environmental Engineering 141(7). doi: 10.1061/(ASCE)EE.1943-7870.0000929.

Medina, V. F., S. A. Waisner, E. Martinez-Guerra, and J. L. Johnson. 2018. Developing and testing the decontamination effluent treatment system. Army Chemical Review PB 3-18-1. 41-45.

Medina, V. F., C. S. Griggs, and C. Thomas. 2016. Evaluation of the destruction of the harmful cyanobacteria, microcystis aeruginosa, with a cavitation and superoxide generating water treatment reactor. Bulletin of Environmental Toxicology and Contamination. 96(6):791-796. doi: 10:1007/So0128-016-1742-6.

Munro, N. B., S. S. Talmage, G. D. Griffin, L. C. Waters, A. P. Watson, J. F. King, and V. Hauschild. 1999. The sources, fate, and toxicity of chemical warfare agent degradation products. Environmental Health Perspectives 107(12):933-974.

National Institute of Occupational Safety and Health (NIOSH). 2005. NIOSH Pocket Guide to Chemical Hazards. DHHS (NIOSH) Publication 2005-149.

Omar, H. A. and H. Moloukhia. 2008. Use of activated carbon in removal of some radioisotopes from their waste solutions. Journal of Hazardous Materials 157(12):242-246. https://doi.org/10.1016/i.jhazmat.2007.12.108. 
Osovsky, R., D. Kaplan, H. Rotter, I. Nir, and I. Columbus. 2013. Hydrothermal degradation of chemical warfare agents on activated carbon: Rapid chemical-free decontamination. Industrial Engineering and Chemical Research 52(28):97059708 .

Osovsky, R., D. Kaplan, I. Nir, H. Rotter, S. Elisha, and I. Columbus. 2014. Decontamination of absorbed chemical warfare agents on active carbon using hydrogen peroxide solution. Environmental Science and Technology 48(18):10912-10918.

Prentiss, A. M. 1937. Chemicals in war. New York, NY: McGraw Hill.

Rewick, R. T., M. L. Schumacher, and D. L. Hayes. 1986. The UV absorption spectra of chemical agents and simulants. Applied Spectroscopy 40(2):152-156.

Richardt, A., and M.-M. Blum. 2008. Decontamination of warfare agents. Enzymatic Methods for the Removal of B/C Weapons. John Wiley and Sons.

Ryan, M. A., H. T. Akinbi, A. G. Serrano, J. Perez-Gil, Huixing Wu, F. X. McCormack, and T. E. Weaver. 2006. Antimicrobial activity of native and synthetic surfactant protein B peptides. Journal of Immunology 176(1):416-425. https://doi.org/10.4049/iimmunol.176.1.416.

Smart, J. K. 2002. History of decontamination. Aberdeen Proving Ground, MD: U.S. Army Soldier and Biological Chemical Command (now Edgewood Chemical and Biological Command). http://ke.army.mil/bordeninstitute/published_volumes/chemwarfare/CHAP2_Pg_09-76.pdf.

Snoeyink, V. L., and D. Jenkins. 1980. Water chemistry. New York, NY: John Wiley and Sons.

Striano, E. 2011. Expert workshop on toxicity testing of water undergoing advanced oxidation processes prior to discharge. Workshop Summary Report. Alexandria, VA: Water Environment Research Foundation. Project Number WERF3W11.

United States Army Medical Research Institute of Infectious Diseases (USAMRIID). 2012. Quick bio-agents. Fort Detrick, MD.

United States Environmental Protection Agency (USEPA). 2013. Report on radionuclides in wastewater infrastructure resulting from emergency situations. EPA 600R13/159. Research Triangle Park, NC: Homeland Security Research Center.

United States Environmental Protection Agency (USEPA). 2014. Adsorption and desorption of chemical warfare agents on activated carbon: Impact of temperature and relative humidity. EPA 600R-14/261. Research Triangle Park, NC: Homeland Security Research Center.

United States Department of Defense (USDoD). 2007. Overseas environmental base-line guidance document. DoD 4715.05-G. Washington, DC: Office of the Under Secretary of Defense for Acquisition, Technology, and Logistics.

Warsinger, D. M., J. Swaminathan, E. Guillen-Burrieza, H. A. Arafat, and J. H. Lienhard. 2015. Scaling and fouling in membrane distillation for desalination applications: A review. Desalination 356:294-313. 
Watts, R. J. 1997. Hazardous wastes: Sources, pathways, receptors. New York, NY: Wiley.

Weinberg W. and N. Narkis. 1987. Physico-chemical treatments for the complete removal of non-ionic surfactants from effluents. Environmental Pollution 45(4):245-260. https://doi.org/10.1016/0269-7491(87)90100-X.

Wu, S. H., and P. Pendleton. 2001. Adsorption of anionic surfactant by activated carbon: Effect of surface chemistry, ionic strength, and hydrophobicity. Journal of Colloid and Interface Science 243:306-315. https://doi.org/10.1006/icis.2001.7905.

Xiao, J-X., Y. Zhang, C. Wang, J. Zhang, C-M. Wang, Y-X. Bao, Z-G. Zhao. 2005. Adsorption of cationic-anionic surfactant mixtures on activated carbon. Carbon 43:1032-1038. https://doi.org/10.1016/i.carbon.2004.11.039.

Ying, G-G. 2006. Fate, behavior, and effects of surfactants and their degradation products in the environment. Environment International 32:417-432. https://doi.org/10.1016/j.envint.2005.07.004.

Zuo, G-M, Z-X Cheng, G-W Li, L-Y Wang, and H Chen. 2005. Photo assisted reaction of chemical warfare agent VX droplets under UV light irradiation. Journal of Physical Chemistry A. 109(31):6912-6918. doi: 10.1021/jp051904f. 


\section{Appendix A: Public Affairs Storyboard Prepared on DETS Field Evaluation}

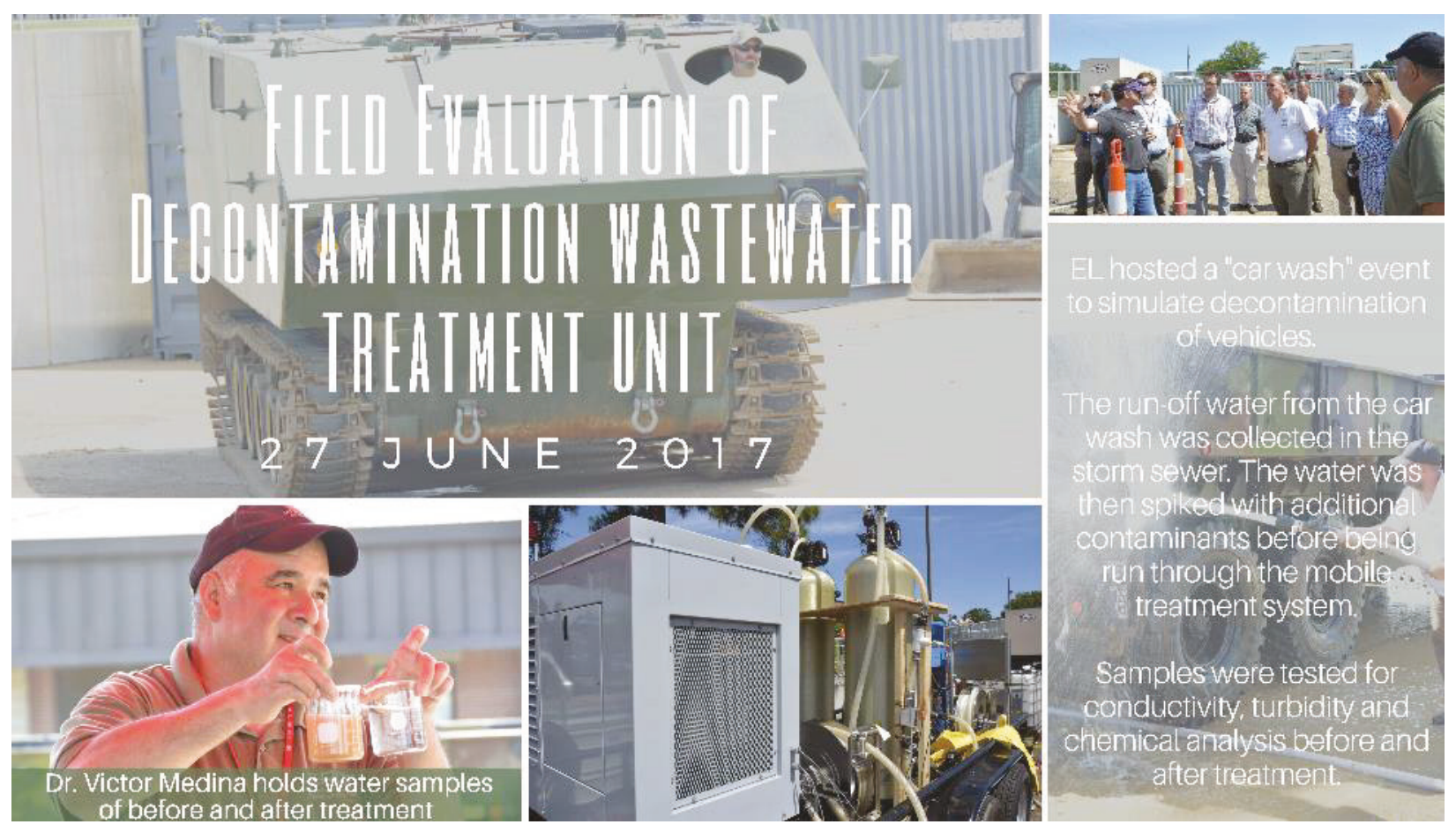




\section{Appendix B: Specification Sheets on the Bredel 40 Pump (no endorsement implied)}

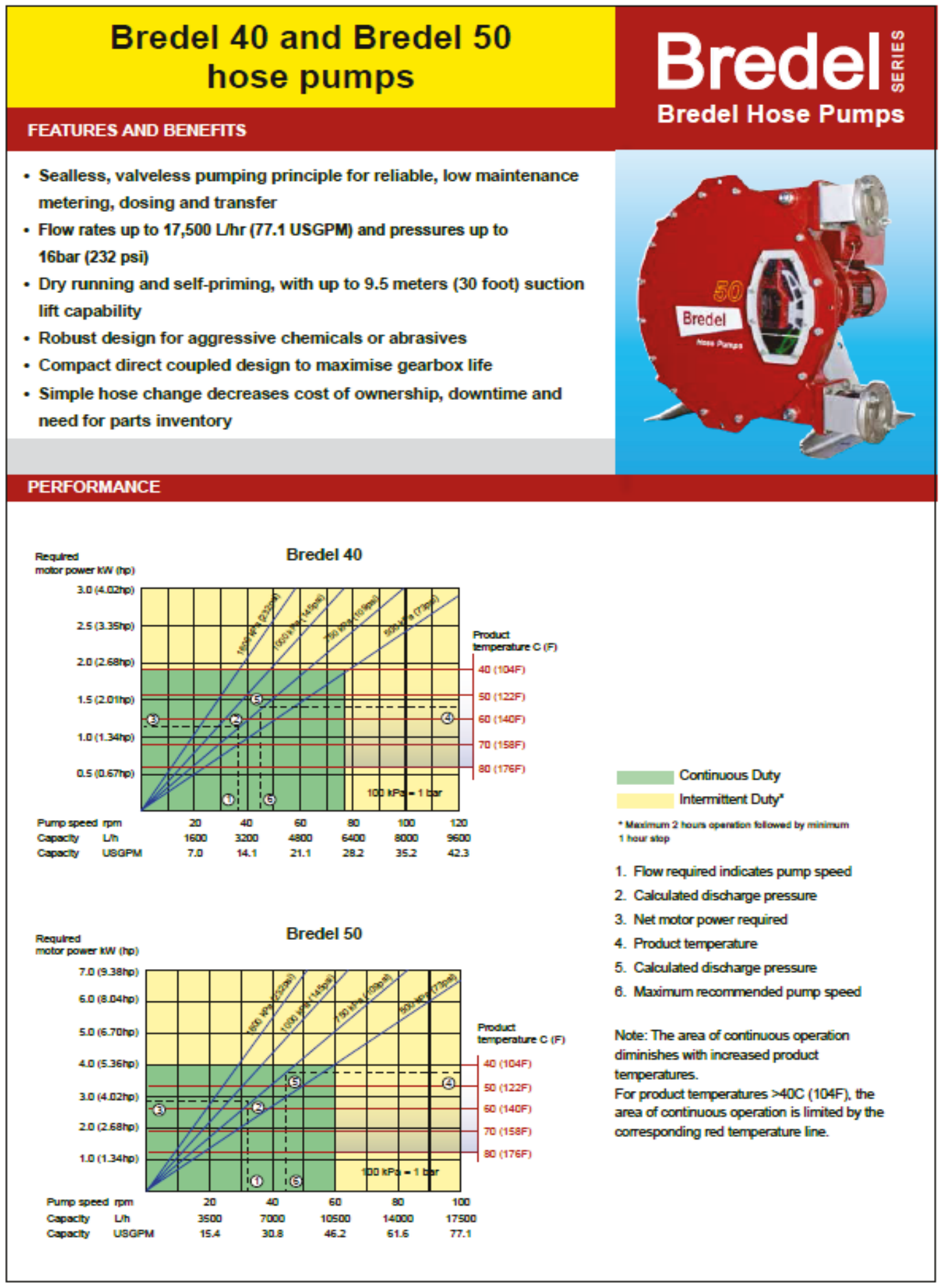




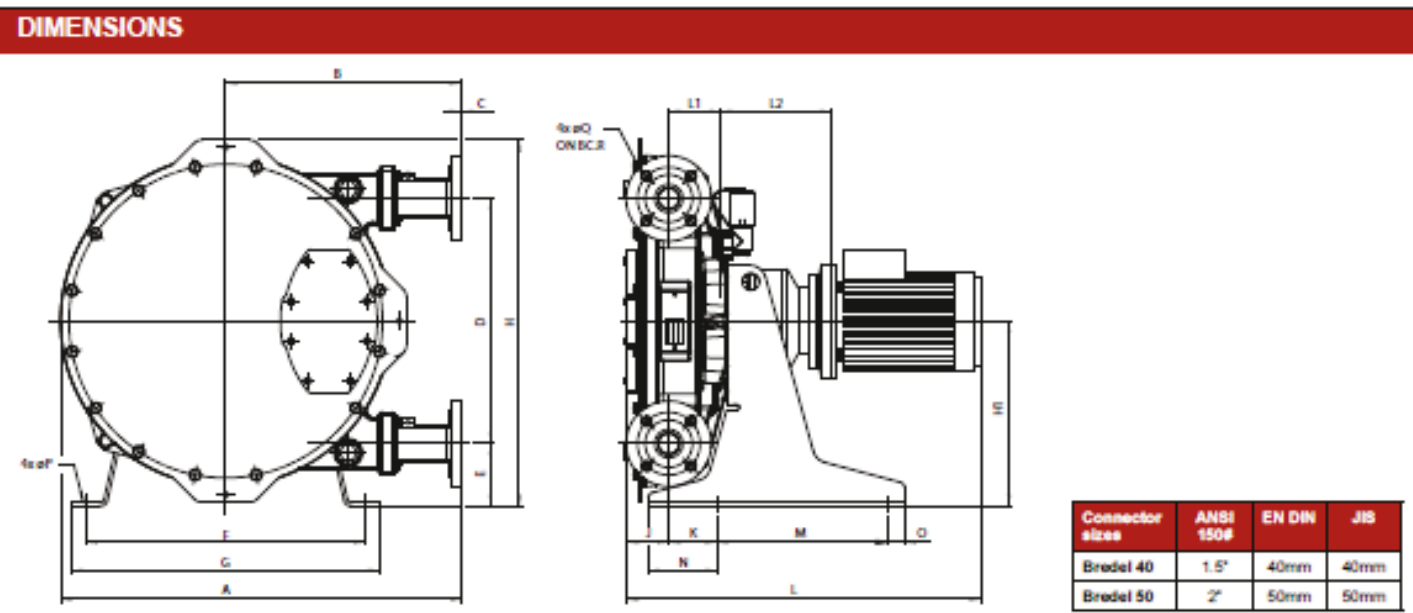

\begin{tabular}{|c|c|c|c|c|c|c|c|c|c|c|c|c|c|c|c|c|c|c|c|c|}
\hline Type & A & 8 & c & D & $\mathbf{E}$ & & 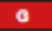 & H & MI & 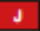 & K & $\max$ & LA & $\operatorname{Lanax}$ & M & N & 0 & $\infty$ & $s a$ & 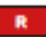 \\
\hline Brodel $40(\mathrm{~mm})$ & 705 & 412 & 25 & 430 & 110 & 400 & 540 & 643 & 325 & 73 & 84 & 100 & 91 & 301 & 300 & 120 & 30 & 18 & 18 & 110 \\
\hline Brobsel 40 (inches) & 27.8 & 162 & 0.00 & 16.9 & 4.3 & 10.3 & 21.3 & 25.3 & 128 & 29 & 39 & 95.7 & 98 & 110 & 11.8 & 4.7 & 12 & 0.71 & 0.71 & 4.3 \\
\hline Beosel 50 (mm) & 838 & 475 & 3 & 554 & 143 & 620 & 680 & 811 & 420 & 84 & 95 & 975 & 112 & 399 & 380 & 156 & 40 & 18 & 18 & 125 \\
\hline Brodel So (ibchea) & 20.0 & 18.7 & 0.12 & 21.8 & 5.8 & 24.4 & 20.8 & 31.0 & 16.5 & 39 & 9.7 & 38.4 & 4.4 & 13.9 & 15 & 8.1 & 1.8 & 0.71 & 0.71 & 4.9 \\
\hline
\end{tabular}

\section{TECHNICAL SPECIFICATIONS}

\begin{tabular}{|c|c|c|}
\hline & Bredel 40 & Bredel 50 \\
\hline Fow range & up to $9,600 \mathrm{~L} / \mathrm{hr}(2,536$ USGPM) & up to $17,500 \mathrm{Lhr}(4,623$ USGPM) \\
\hline Capacity & 1.33 Lirev (0.35 Girev) & 2.92 Lirev $(0.77$ Girev $)$ \\
\hline Minimum starting torque & $320 \mathrm{Nm}(2,832$ inch-lbs $)$ & $620 \mathrm{Nm}(5,487$ inch-lbs $)$ \\
\hline Hose lubricant required & 5 litres (1.32 USG) & 10 litres (264 USG) \\
\hline Pumpheas weight & $121 \mathrm{~kg}$ (287lbs) & $227 \mathrm{~kg}(500 \mathrm{bs})$ \\
\hline \multicolumn{3}{|l|}{ Common features } \\
\hline Max inlet pressure & \multicolumn{2}{|c|}{2.5 bar abs (38 psia) } \\
\hline Suction pressure & \multicolumn{2}{|c|}{0.05 bar abs (0.73 psia) } \\
\hline Maximum discharge pressure & \multicolumn{2}{|c|}{$1,600 \mathrm{kPa}$ (16 bar) $(232 \mathrm{psi})$} \\
\hline Product temperature range & \multicolumn{2}{|c|}{$-10 \mathrm{C}$ up to $80 \mathrm{C}$ ( $14 \mathrm{~F}$ up to $176 \mathrm{~F})$} \\
\hline Ambient temperature range" & \multicolumn{2}{|c|}{$-20 \mathrm{C}$ up to $45 \mathrm{C}$ (-4F up to $113 \mathrm{~F})$} \\
\hline
\end{tabular}

"Please consult your Bredel representative for lower or higher temperature operation.

"Alowable ambient temperature is based on pump capabilities and may be further limited by gearbox ambient capabilities

\section{MATERIALS OF CONSTRUCTION}

\begin{tabular}{|l|l|}
\hline Components & Materials \\
\hline Pump housing & Cast iron \\
\hline Rotor & Cast iron \\
\hline Pressing shoes & Aluminium or epoxy \\
\hline Cover & Mld steel \\
\hline Brackets & Galvanized steel or AISI 316 \\
\hline Flanges & Galvanized steel or AISI 316 \\
\hline Inserts & AlSI 316, PVC, PP, PVDF \\
\hline Support frame & Galvanized steel or AISI 316 \\
\hline Hose clamps & Galvanized steel or AISI 316 \\
\hline Shat & Aloy steel \\
\hline Seals & Neoprene or nitrile \\
\hline
\end{tabular}

\begin{tabular}{|l|l|}
\hline Options & Features \\
\hline Available hose materials & $\begin{array}{l}\text { NR, NR Endurance, NBR. F-NBR, } \\
\text { EPDM, CSM }\end{array}$ \\
\hline Available flanges & ANSI, EN DIN, JIS \\
\hline Available inserts & $\begin{array}{l}\text { Bredel standard or with sanitary } \\
\text { connectors }\end{array}$ \\
\hline High level float switch & $\begin{array}{l}\text { Max. 2A, 230 V ACIDC, max.40VA } \\
\text { ATEX- max. 50 mA, max. 28V ACIDC }\end{array}$ \\
\hline Low level float switch & Factory programmable from 12-80 Hz \\
\hline $\begin{array}{l}\text { Integrated FI for stand alone } \\
\text { speed control }\end{array}$ & $\begin{array}{l}\text { For maintenance intervals and /or } \\
\text { metering }\end{array}$ \\
\hline Revolution counter & $\begin{array}{l}\text { For difficult suction conditions and high } \\
\text { viscosity fluids }\end{array}$ \\
\hline $\begin{array}{l}\text { Vacuum assist } \\
\text { Cover lifting device }\end{array}$ & For one-man pump maintenance \\
\hline
\end{tabular}




\section{Appendix C: Specifications on Kubota Generator used in the study (no endorsement implied)}

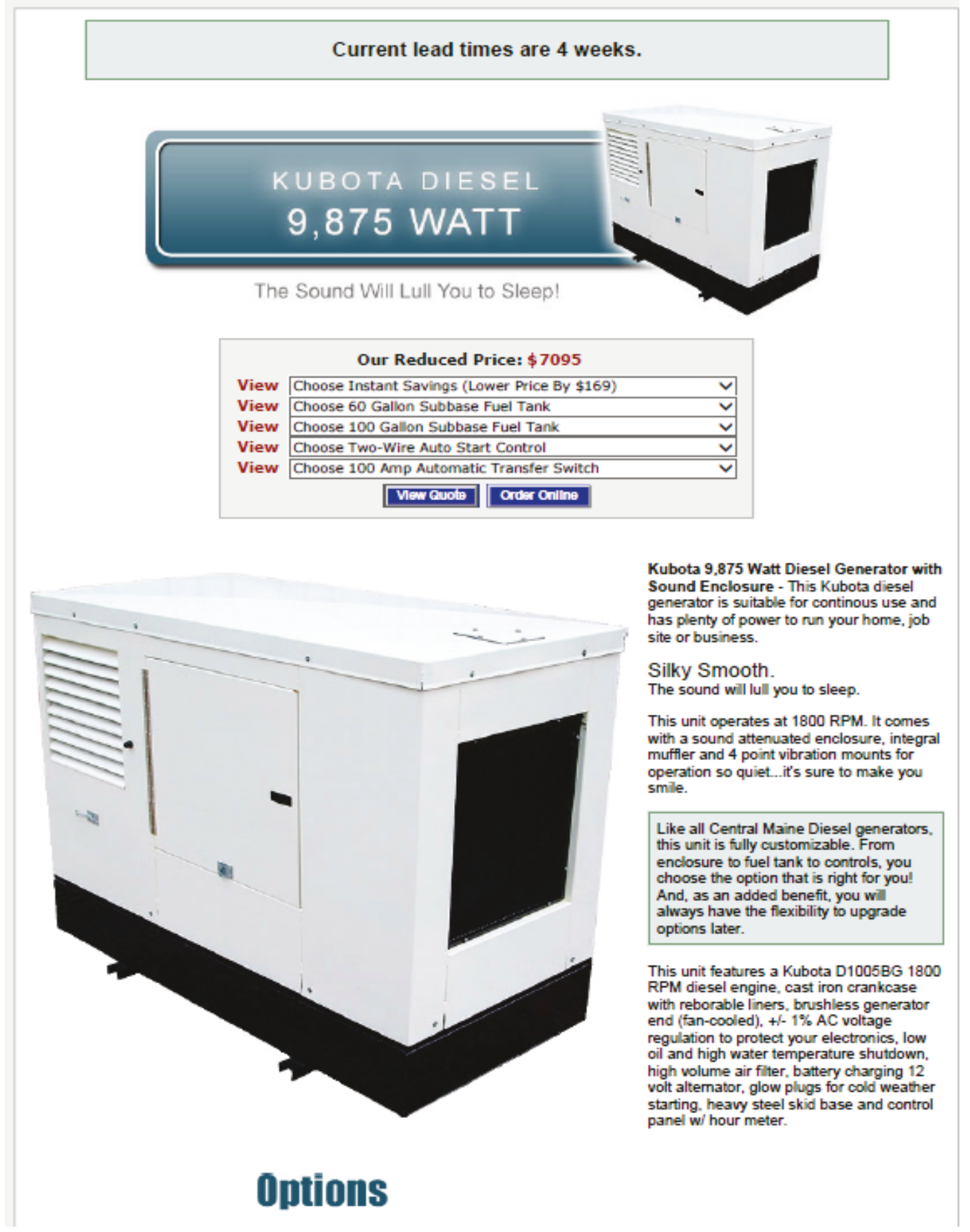




\begin{tabular}{|lc|}
\hline Options & Price \\
\hline 60 Gallon Subbase Fuel Tank & $+\$ 1,095$ \\
\hline 100 Gallon Subbase Fuel Tank & $+\$ 1,395$ \\
\hline Two-Wire Auto Start & $+\$ 495$ \\
\hline 100 Amp Automatic Transfer Switch & $+\$ 795$ \\
\hline
\end{tabular}

\section{Features/Benefits}

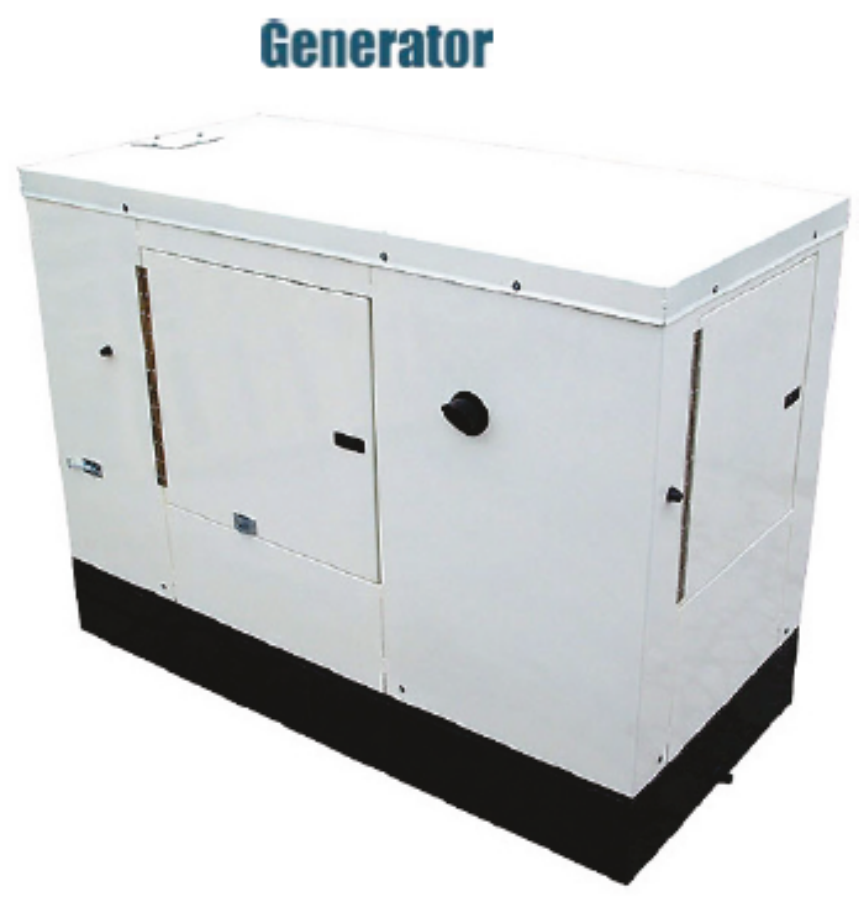

\begin{tabular}{|c|c|}
\hline \multicolumn{2}{|l|}{ Power Single-Phase } \\
\hline $\begin{array}{l}\text { Automatic Voltage } \\
\text { Regulation }\end{array}$ & Standard \\
\hline $\begin{array}{l}\text { Is this unit suitable for } \\
\text { powering sensitive } \\
\text { electronic equipment like a } \\
\text { laptop computer? }\end{array}$ & $\begin{array}{l}\text { Yes }-1 \% \\
\text { regulation from } \\
\text { ho load to full } \\
\text { oad. }\end{array}$ \\
\hline Maximum Output & 9,875 watts \\
\hline Continous Output & 8,750 watts \\
\hline \multicolumn{2}{|l|}{$\begin{array}{l}\text { Load Amperage at } 120 \\
\text { volts }\end{array}$} \\
\hline Maximum Load & 82 Amps \\
\hline Continous Load & $72.9 \mathrm{Amps}$ \\
\hline \multicolumn{2}{|l|}{$\begin{array}{l}\text { Load Amperage at } 240 \\
\text { volts }\end{array}$} \\
\hline Maximum Load & 41 Amps \\
\hline Continous Load & $36.5 \mathrm{Amps}$ \\
\hline $\begin{array}{l}\text { Sound Level @ } 23 \mathrm{ft}(7 \mathrm{~m}) \\
\text { at full load }\end{array}$ & $88 \mathrm{~dB}(\mathrm{~A})$ \\
\hline
\end{tabular}

\section{Engine}

\begin{tabular}{|l|l|}
\hline \multicolumn{2}{|l|}{} \\
\hline Model & Kubota D1005BG \\
\hline Type & 4 Cycle, Natura y Aspirated \\
\hline Cylinders & 3 \\
\hline Operating RPM & 1800 RPM \\
\hline Cylinder Block & Cast Iron Block w/ Cast Iron Sleeve \\
\hline Bore \& Stroke & $2.99^{*} \times 2.80^{*}$ \\
\hline Displacement & 1.3 Liters \\
\hline Air Cleaner & Heavy Duty Replaceable Dry Element \\
\hline & \\
\hline
\end{tabular}




\begin{tabular}{|l|l||}
\hline Oil Capacity (w/ Oil Filter) & 4.5 qts. \\
\hline Exhaust Outlet & $2^{\text {" OD Muffler Outlet }}$ \\
\hline Coolant Capacity & Approx.6.5 Qts \\
\hline Cold Weather Starting Aid & Glow Plugs \\
\hline Fuel & Diesel \\
\hline Starting System & Electric \\
\hline \hline
\end{tabular}

\section{Consumption}

\begin{tabular}{|c|c|}
\hline Consumption at $1 / 2$ load & $0.41 \mathrm{gal} / \mathrm{hr}$ \\
\hline Consumption at 3/4 load & $0.63 \mathrm{gal} / \mathrm{hr}$ \\
\hline Consumption at full load & $0.84 \mathrm{gal} / \mathrm{hr}$ \\
\hline
\end{tabular}

\section{Control Panel}

\begin{tabular}{|l|l|}
\hline \multicolumn{2}{|l|}{} \\
\hline Key Start & Standard \\
\hline Hourmeter & Standard \\
\hline Circuit Breaker & 10 Amps - Resetable \\
\hline
\end{tabular}

\section{Installation Data}

\begin{tabular}{|c|c|}
\hline Fuel Inlet Hose Size & $3 / 8^{n}$ \\
\hline Fuel Retum Hose Size & $5 / 16^{*}$ \\
\hline Minimum Power Lead Size & No. 4 AWG \\
\hline No. Power Lead Conductors & 4 \\
\hline Exhaust Outlet & 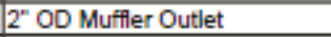 \\
\hline Coolant Recommendation & $\begin{array}{l}\text { Mixture: } 1 / 2 \text { Anti-Freeze } \& 1 / 2 \\
\text { Water }\end{array}$ \\
\hline $\begin{array}{l}\text { Radiator Dimensions } \\
(\mathrm{L} \times \mathrm{D} \times \mathrm{H})\end{array}$ & $22-3 / 4^{\prime \prime} \times 9-1 / 2^{\prime \prime} \times 24^{\prime \prime}$ \\
\hline $\begin{array}{l}\text { Fuel Inlet \& Retum Location } \\
\text { (Facing Radiator) }\end{array}$ & Left-Side \\
\hline $\begin{array}{l}\text { Exhaust Direction } \\
\text { (Facing Radiator) }\end{array}$ & Right-Side \\
\hline $\begin{array}{l}\text { Power Output Location (Facing } \\
\text { Radiator) }\end{array}$ & Back-Side \\
\hline $\begin{array}{l}\text { Service Points } \\
\text { (Facing Radiator) }\end{array}$ & $\begin{array}{l}\text { Oil Fill: Left-Side } \\
\text { Oil Drain:Left-Side } \\
\text { Air Filter: Back-Side } \\
\text { Oil Filter: Left-Side } \\
\text { Fuel Filter: Left-Side }\end{array}$ \\
\hline Battery Type & 12 VDC - 575 CCA \\
\hline Engine 01 Type & SAE $15 \mathrm{~W}-40$ \\
\hline
\end{tabular}

\section{Maintenance Schedule}

\begin{tabular}{|l|l|}
\hline Replace Oil Fiter & 500 hours $/ 12$ months \\
\hline Replace Fuel Filter & 500 hours $/ 12$ months \\
\hline Replace Air Filter & 500 Hours $/ 12$ months \\
\hline & \\
\hline
\end{tabular}




\begin{tabular}{|l|l||}
\hline Replace Engine Coolant & 500 Hours / 12 months \\
\hline Exercise Generator Under Load & Twice each month \\
\hline Change Oil & 500 hours / 12 months \\
\hline \hline
\end{tabular}

\section{Warranty}

\begin{tabular}{|l|l|}
\hline \multicolumn{2}{|l|}{} \\
\hline Engine Warranty & 3 Years \\
\hline Generator Warranty & 1 Year \\
\hline $100 \%$ Coverage for Parts \& Labor & Standard \\
\hline
\end{tabular}

\section{Dimensions}

\begin{tabular}{|l|l|}
\hline \multicolumn{2}{|l|}{} \\
\hline Length & $48^{\prime \prime}$ \\
\hline Width & $30.5^{\prime \prime}$ \\
\hline Height & $38^{\prime \prime}$ \\
\hline Dry weight & 825 lbs \\
\hline
\end{tabular}

\section{马 PRINTABLE VERSION}

Type Your Question(s) Here

E-Mail Address:

Send Question

Central Maine Diesel

29 Carey Circle

Hampden, ME 04444

Toll-Free: $1-888-89 \theta-0603$

Phone: 1-207-841-1188

Fax: 1-207-941-1189

E-Mail: sales/generatorsales.com

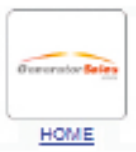




\section{Appendix D: Specification Sheet for Fold-a- Tank (no endorsement implied)}

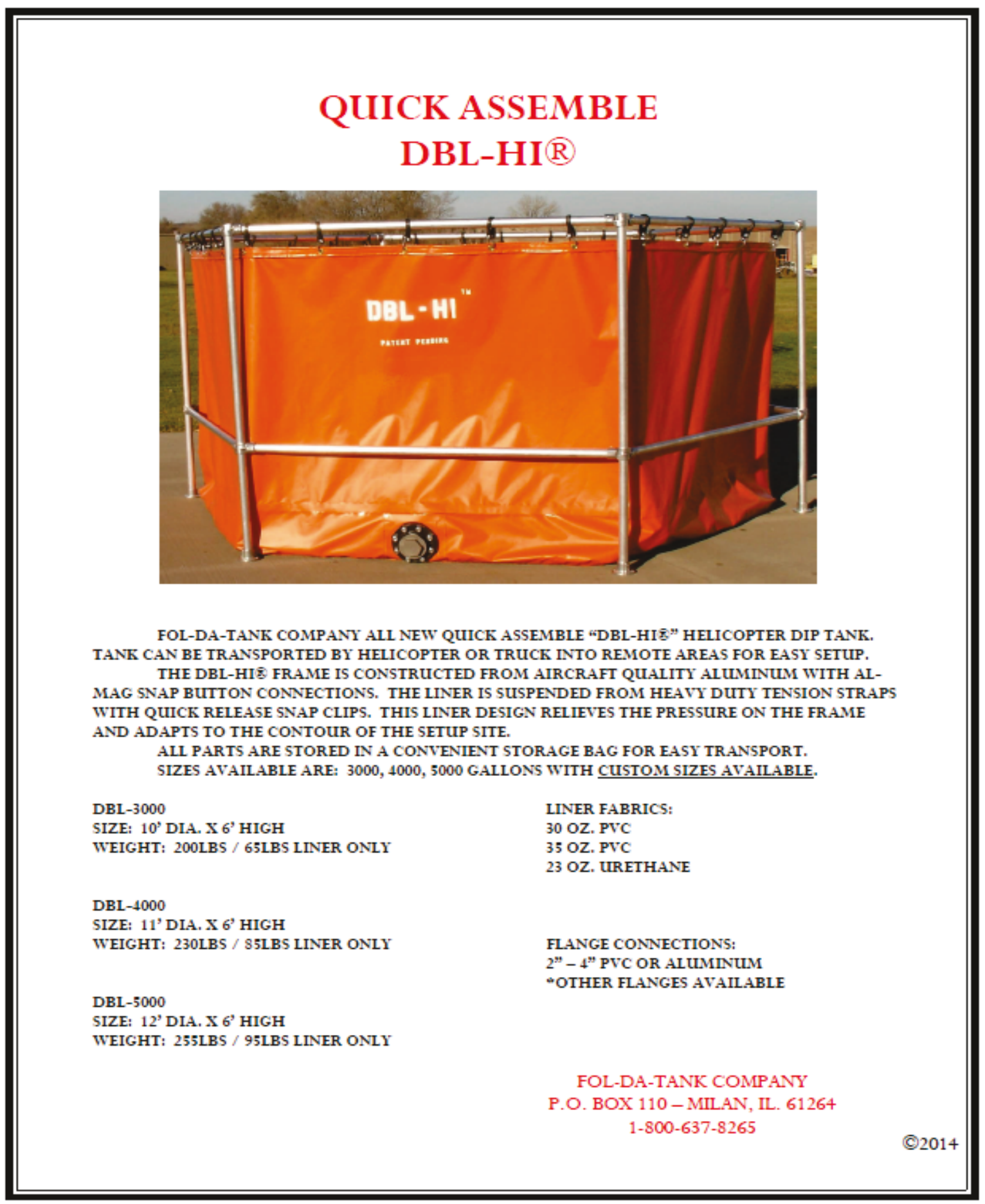




\section{Appendix E: Technical Specification Documents on Sand and Anthracite Used in Sand Media Bed (no endorsement implied)}

Highly spherical shape and uniform grading provide Clack Filter Sand and Gravel with reliable performance. Low soluable impurities limits undesirable mineral leaching into the process stream.

\section{Filter Sand and Gravel}

Clack Filter Sand and Gravel are naturally occurring, river washed, glacial deposit products. Their excellent chemical properties - high in silica content and low in soluable calcium, magnesium and iron compounds - meet AWWA-B100-96 specifications

Precision sizing and uniform grading to close limits meet the rigid specifications of professional engineers throughout the world.

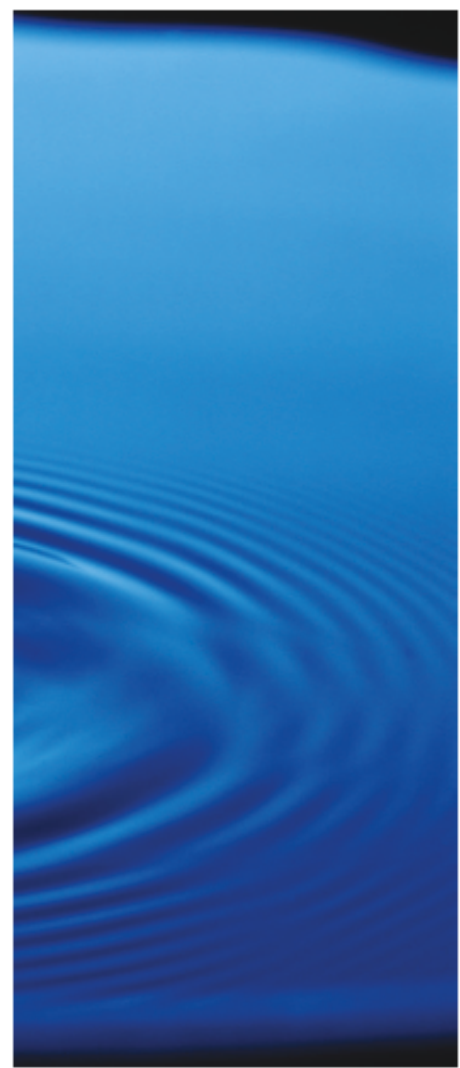

For over 80 years Clack Filter Sand and Gravel have been satisfying the requirements of industrial, municipal and residential users. These products have been specified and used nationally and internationally because of their high quality, desirable chemical properties, color, and wide range of precision sizing.

Processing and regular analysis of production are supervised by registered professional engineers.

Clack Filter Sand is graded specifically for water filtration plants. It can be used in municipal, industrial or residential applications for sediment filtration.

Clack uncrushed Gravel has a highly spherical shape that promotes good flow and even distribution in support beds. Gravel is low in soluable impurities and it will maintain the quality of the treated water, especially in softeners. Three inch layers are recommended in graded support beds.

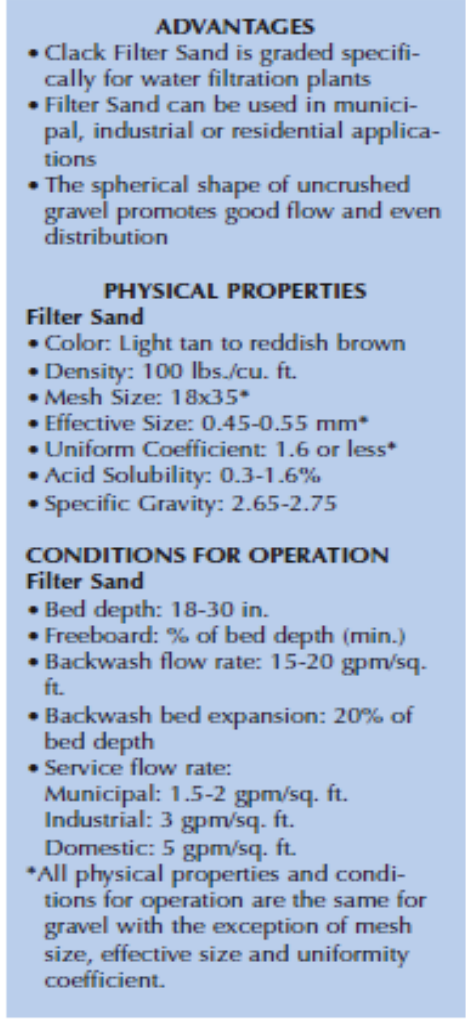




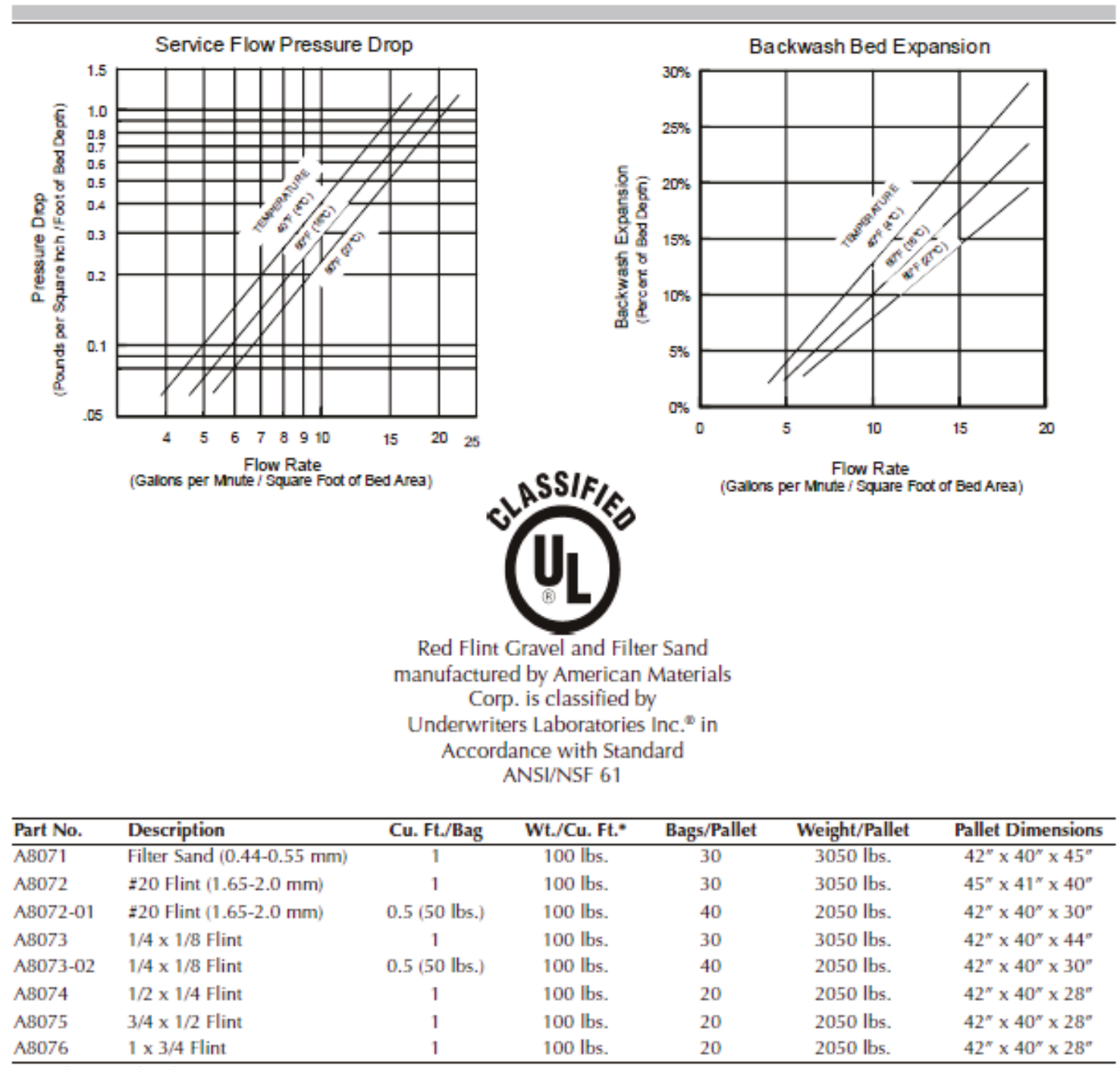

*Weight per cubic foot is approximate.

The information and recommendations in this publication are based on data we believe to be reliable. They are offered in good faith, but do not imply ary warranty or performance guarantee, as conditions and methods of use of our products are beyond our control. As such, Clack makes no express or implied warmanties of any kind with respect to this product, including but not limited to any implied warranty of merchantability or fitness for a panticular purpose. We recommend that the user determine whether the products and the information given are appropriate, and the suitability and performance of our products are appropriate, by testing with its own equipment. Specifications are subject to change without noxioe.

The information and recommendations given in this publication should not be understood as recommending the use of our products in violation of any patent or as a license to use any patents of the Clack Corporation.

The filter medias listed in this brochure do not rernove or kill bacteria. Do not use with water that is microbiologically unsafe or of unknown quality without adequate disinfection before or after the system.

Clack will not be liable under any circumstance for consequential or incidental darnages, including but not limited to, lost profits resulting from the use of our products. 
Clack Anthracite is a select coal, mined and processed for use in water filtration. It is ideal for single bed, dual bed or multi-media filtration systems.

\section{Anthracite}

\section{ADVANTAGES}

- Higher service flows and longer filter runs than equivalent sand filters

- Close attention to gradation, hardness and purity assures consistent and reliable performance

- Unique density allows Clack Anthracite to be combined with other filtration media in multi-media filters

- Lower uniformity coefficient has less oversized and undersized particles resulting in a highly uniform bed

\section{PHYSICAL PROPERTIES}

- Color: Black

- Bulk Density: 50 lbs./cu. ft.

- Hardness: 3.0-3.8 (Mohs scale)

- Effective Size:

$\$ 1$ Anthracite: $0.6-0.8 \mathrm{~mm}$ $\$ 1 \frac{1}{2}$ Anthracite: $0.85-0.95 \mathrm{~mm}$

\$2 Anthracite: $1.7-2.0 \mathrm{~mm}$

- Uniformity Coefficienty:

\#1 Anthracite: <1.7

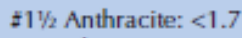

$\$ 2$ Anthracite: $<1.6$

- Mesh Size:

$\$ 1$ Anthracite: $14 \times 30$

\$1 $\frac{1}{2}$ Anthracite: $10 \times 20$

\$2 Anthracite: $4 \times 12$

- Acid Solubility: $\leq 1 \%$

- Caustic Solubility: $<1 \%$

- Apparent Specific Gravity: $1.6 \mathrm{gm} / \mathrm{cc}$

- Meets AWWA Standard B100-96

\section{CONDITIONS FOR OPERATION}

- Bed depth: 24-36 in., 10-18 in multibed filters

- Freeboard: 50\% of bed depth (min.)

- Service flow rate: $5 \mathrm{gpm} / \mathrm{sq}$. ft. or higher depending upon local conditions

- Backwash flow rate:

\$1 Anthracite: $12-18 \mathrm{gpm} / \mathrm{sq}$. ft. $\$ 1 \frac{1}{2}$ Anthracite: $18-25 \mathrm{gpm} / \mathrm{sq}$. ft.

\#2 Anthracite: use air scour

- Backwash bed expansion: 20-40\% of bed depth
Although its potential for water treatment has been recognized since ancient times, anthracite coal was not used for this purpose until the beginning of the 20th century. Crushed Anthracite makes an excellent medium density filtration media. Clack Anthracite is mined from the finest Pennsylvania coal. It is specifically selected for water treatment, and during its production goes through several sizing inspections. Representative samples are randomly chosen for a complete laboratory quality control analysis for effective size, uniformity coefficient, specific gravity, acid solubility and hardness.

Because of its angular shape, some of the sediment penetrates deeper into the bed. When compared to equivalent filter sands, this means longer filter runs and less head loss. Backwash rates are also reduced.

Because of its unique density, Clack Anthracite can be used in multi-media filters. At $50 \mathrm{lbs} / \mathrm{t}^{3}$, it will hydraulically classify and remain above heavier media such as Filter Sand or Manganese Greensand, providing a prefiltration layer.

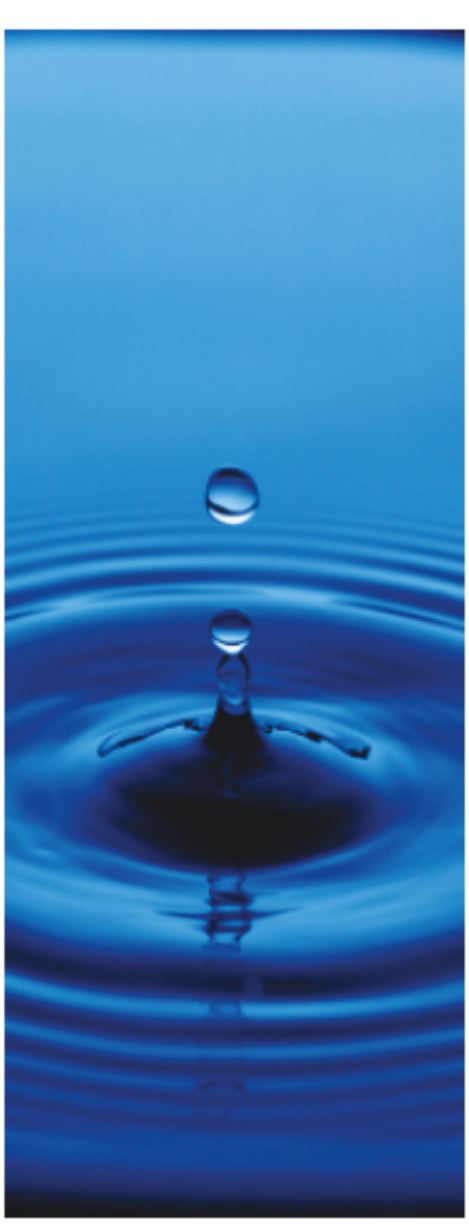



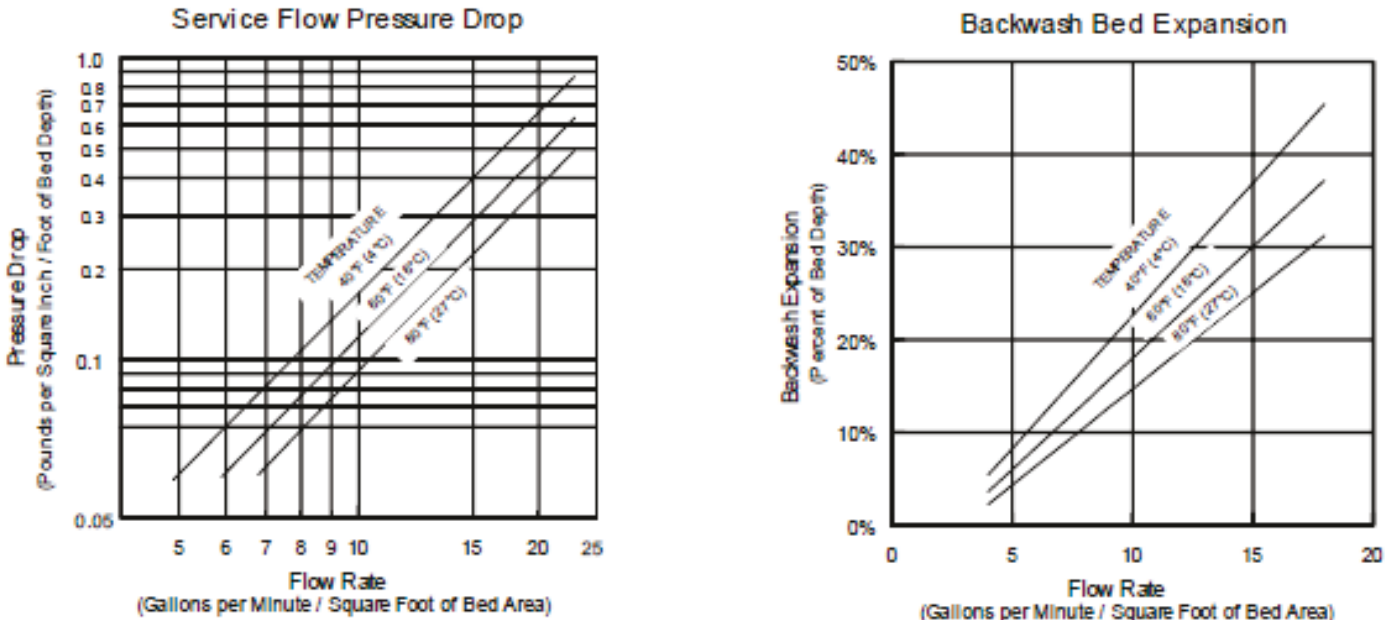

(Gallons per Minute/ Square Foot of Bed Area)

(Gallons per Minute / Square Foot of Bed Area)

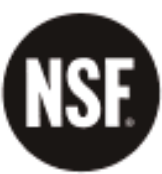

Certified to ANSI/NSF Standard 61

\begin{tabular}{llccccc}
\hline Part No. & Description & Cu. Ft./Bag & Wt./Cu. Ft. & Bags/Pallet & Weight/Pallet & Pallet Dimensions \\
\hline A8029 & Anthracite $\# 1(0.6-0.8 \mathrm{~mm})$ & 1 & $50 \mathrm{lbs}$. & 50 & $2550 \mathrm{lbs}$. & $40^{\prime \prime} \times 48^{\circ} \times 56^{\prime \prime}$ \\
A8030 & Anthracite $\# 1 \frac{1}{2}(0.85-0.95 \mathrm{~mm})$ & 1 & $50 \mathrm{lbs}$. & 50 & $2550 \mathrm{lbs}$. & $40^{\prime \prime} \times 48^{\circ} \times 56^{\prime \prime}$ \\
A8031 & Anthracite $\# 2(1.7-2.0 \mathrm{~mm})$ & 1 & $50 \mathrm{lbs}$. & 50 & $2550 \mathrm{lbs}$. & $40^{\prime \prime} \times 48^{\circ} \times 56^{\prime \prime}$ \\
\hline
\end{tabular}

-Weight per cubic foot is approximate.

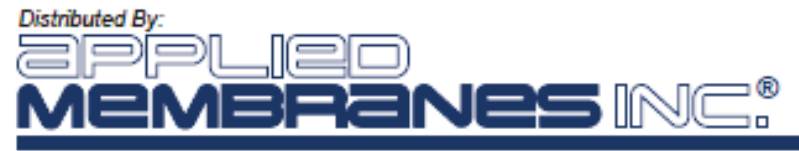

Form Na. 2354

Deplacos Form 1785

Upthod 3.01

The information and recornmendations in this publication are based on data we believe to be reliable. They are offered in good faith, but do not imply any warranty or performance guarantee, as conditions and methods of use of our products are beyond our control. As such, Clack makes no express or implied warranties of any kind with respect to this product, including but not limited to any implied warranty of merchantability or fitness for a particular purpose. We recommend that the user determine whether the products and the information given are appropriate, and the suitability and performance of our products are appropriate, by testing with its own equipment. Specifications are subject to change without notice.

The information and recornmendations given in this publication should not be understood as recomrnending the use of our products in violation of any patent or as a license to use any patents of the Cladk Corporation.

The filter medias listed in this brochure do not remowe or kill bacteria. Do not use with water that is microbiologically unsafe or of unknown quality without adequate disinfection before or after the system.

Clack will not be liable under any circumstance for consequential or incidental damages, including but not limited to, lost profits resulting from the use of our products. 


\section{Appendix F: Operating Manual for the Reverse Osmosis System (first six pages, no endorsement implied)}

\section{MANUAL FOR \\ OPERATION \& MAINTENANCE \\ OF \\ L SERIES \\ REVERSE OSMOSIS SYSTEMS}
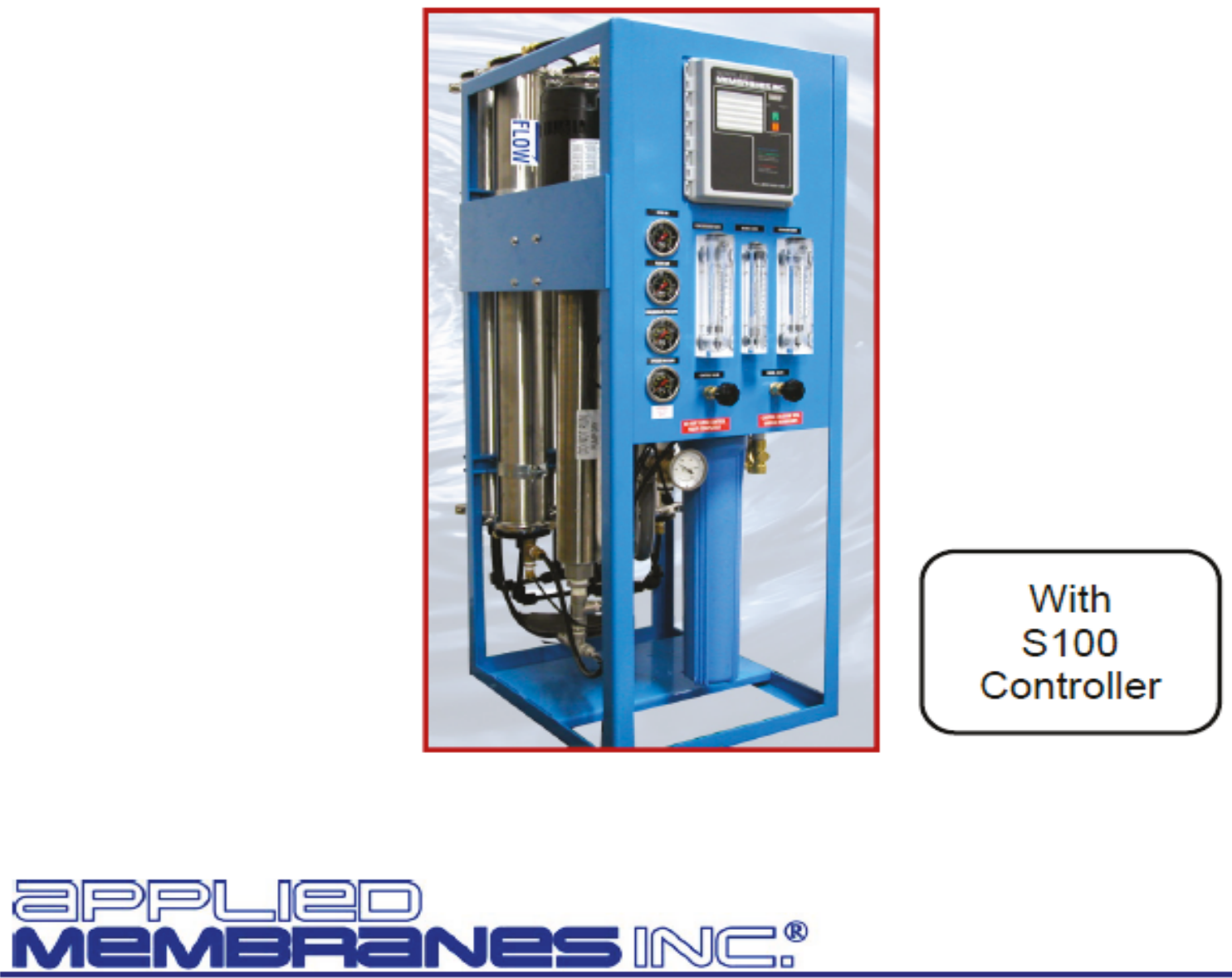

Industry Leader in RO Expertise and Membrane Applications since $1983^{\mathrm{TM}}$

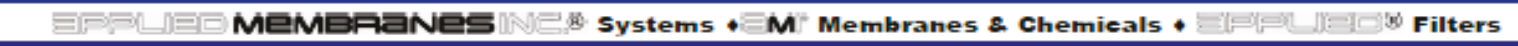

2450 Business Park Dr., Vista, CA 92081 C (760) 727-3711 目 (760) 727-4427 


\section{TABLE OF CONTENTS}

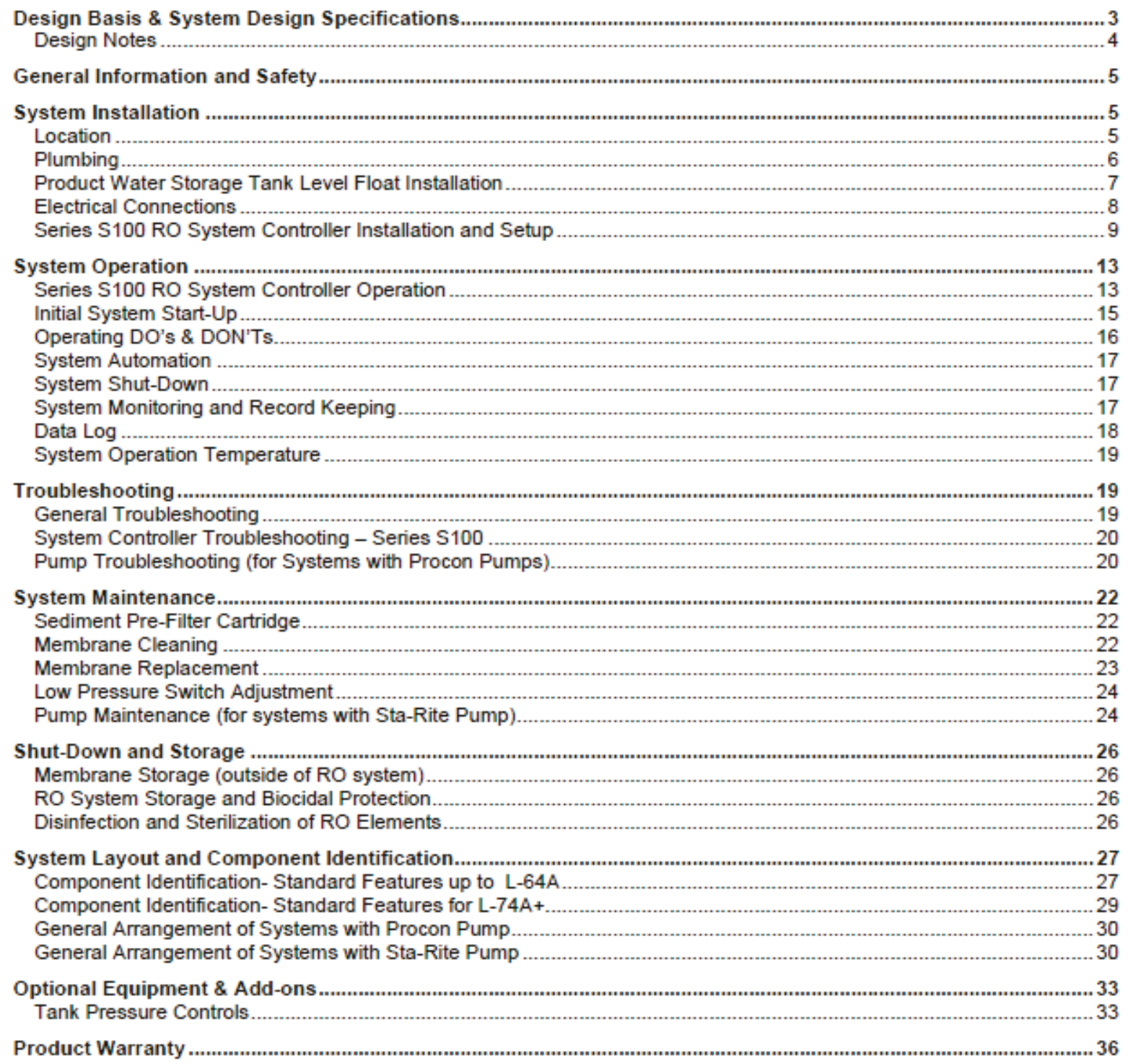




\section{DESIGN BASIS \& SYSTEM DESIGN SPECIFICATIONS}

\begin{tabular}{|c|c|c|c|c|c|c|c|c|c|c|c|c|c|c|c|}
\hline \multirow[b]{2}{*}{ Modol } & \multicolumn{5}{|c|}{ Decilen Conditionc } & \multicolumn{2}{|c|}{ Limiter } & \multicolumn{3}{|c|}{ Une sizec (Inohoc) } & \multicolumn{5}{|c|}{ Pump model and HP } \\
\hline & $\begin{array}{l}\text { Permeat } \\
\text { GPD }\end{array}$ & $\begin{array}{l}\text { Flow } \\
\text { GPM }\end{array}$ & $\begin{array}{l}\text { Cono. } \\
\text { Flow to } \\
\text { Draln } \\
\text { (GPM) }\end{array}$ & $\begin{array}{l}\text { Declon } \\
\text { Rooyolo } \\
\text { Flow } \\
\text { (GPM) }\end{array}$ & $\begin{array}{c}\text { Declon } \\
\text { Reoovery } \\
\text { (56) }\end{array}$ & $\begin{array}{c}\text { Max. } \\
\text { Rooovery } \\
\text { (3) }\end{array}$ & $\begin{array}{l}\text { Max. } \\
\text { Rooysio } \\
\text { Flowt } \\
\text { (GPM) }\end{array}$ & Iniet & Perm. & Cona & $\begin{array}{l}\text { Docign } \\
\text { Pump } \\
\text { Flow } \\
\text { (BPM) }\end{array}$ & Pump Model No. & $\begin{array}{l}\text { Motor } \\
\text { Model }\end{array}$ & $\begin{array}{c}\text { Motor } \\
\text { HP }\end{array}$ & $\begin{array}{l}\text { Full Load } \\
\text { Ampe } \\
\text { IFLAvg } \\
\text { Indlostod } \\
\text { voltage }\end{array}$ \\
\hline L-12521A-116 & 300 & 0.2 & 1.5 & 0 & 15 & 40 & 1.1 & 0.75 & 0.38 & 0.38 & 1.7 & $1128100 \mathrm{~F} 31 \mathrm{XX}$ & P-MP828 & $1 / 3$ & 7 \\
\hline L-12521A-216 & 300 & 0.2 & 1.5 & 0 & 15 & 40 & 1.1 & 0.75 & 0.38 & 0.38 & 1.7 & $1126100 \mathrm{~F} 31 \mathrm{XX}$ & P-MP828 & $1 / 3$ & 4 \\
\hline L-12521A-215 & 300 & 0.2 & 1.1 & 0 & 15 & 40 & 0.8 & 0.75 & 0.38 & 0.38 & 1.3 & $1128100 \mathrm{~F} 31 \times \mathrm{X}$ & P-MP871 & $1 / 3$ & 5 \\
\hline$L-125 A-116$ & 600 & 0.4 & 1.7 & 0 & 20 & 50 & 1.2 & 0.75 & 0.38 & 0.38 & 2.1 & 112A125F11XX & P-MP871 & $1 / 2$ & 10 \\
\hline L-125A-216 & 600 & 0.4 & 1.7 & 0 & 20 & 50 & 1.2 & 0.75 & 0.38 & 0.38 & 2.1 & 112A125F11XX & P-MP871 & $1 / 2$ & 5 \\
\hline L-125A-215 & 600 & 0.4 & 1.3 & 0 & 20 & 50 & 0.8 & 0.75 & 0.38 & 0.38 & 1.7 & 112A125F11XX & P-MP872 & $1 / 2$ & 7 \\
\hline L-225A-116 & 1,200 & 0.8 & 3.2 & 0 & 20 & 50 & 2.7 & 0.75 & 0.38 & 0.38 & 4.0 & 114B240F11BA250 & P-MP872 & $3 / 4$ & 14 \\
\hline L-225A-216 & 1,200 & 0.8 & 3.2 & 0 & 20 & 50 & 2.7 & 0.75 & 0.38 & 0.38 & 4.0 & 114B2ADF11BA250 & P-MP872 & $3 / 4$ & 7 \\
\hline L-225A-215 & 1,200 & 0.8 & 3.2 & 0 & 20 & 50 & 2.7 & 0.75 & 0.38 & 0.38 & 4.0 & 114E330F11XX & P-MG574 & 1 & 10 \\
\hline L-14A-116 & 1,800 & 1.2 & 4.3 & 0 & 25 & 60 & 3.4 & 0.75 & 0.5 & 0.5 & 5.5 & 114E330F11XX & P-MG573 & 1 & 16 \\
\hline$L-14 A-216$ & 1,800 & 1.2 & 4.3 & 0 & 25 & 60 & 3.4 & 0.75 & 0.5 & 0.5 & 5.5 & 114E330F11XX & P-MG573 & 1 & 8 \\
\hline$L-14 A-215$ & 1,800 & 1.2 & 4.3 & 0 & 25 & 60 & 3.4 & 0.75 & 0.5 & 0.5 & 5.5 & HPS2OH3-D1-MS4 & \begin{tabular}{|l|} 
WIPUMP \\
\end{tabular} & 3 & 17 \\
\hline$L-24 A-116$ & 3,000 & 2.2 & 2.6 & 0.8 & 45 & 60 & 1.8 & 0.75 & 0.5 & 0.5 & 5.5 & 114E330F11XX & P-MG573 & 1 & 16 \\
\hline$L-24 A-216$ & 3,000 & 2.2 & 2.6 & 0.8 & 45 & 60 & 1.8 & 0.75 & 0.5 & 0.5 & 5.5 & 114E330F11XX & P-MG573 & 1 & 8 \\
\hline L-24A-215 & 3,000 & 2.2 & 2.6 & 0.8 & 45 & 60 & 1.8 & 0.75 & 0.5 & 0.5 & 5.5 & HPS20H3-D1-MS4 & WIPUMP & 3 & 17 \\
\hline L-34A-216 & 5,200 & 3.5 & 3.5 & 1.0 & 50 & 60 & 2.2 & 0.75 & 0.5 & 0.5 & 8 & $\mathrm{HPS} 20 \mathrm{H}$ & WIPUMP & 3 & 17 \\
\hline L-34A-215 & 5,200 & 3.5 & 3.5 & 1.0 & 50 & 60 & 2.2 & 0.75 & 0.5 & 0.5 & 8 & HPS20H3-D1-MS4 & WIPUMP & 3 & 17 \\
\hline L-34A-235 & 5,200 & 3.5 & 3.5 & 1.0 & 50 & 60 & 2.2 & 0.75 & 0.5 & 0.5 & 8 & HPS2DH3-D1MS3 & WIPUMP & 3 & 10 \\
\hline L-34A-335 & 5,200 & 3.5 & 3.5 & 1.0 & 50 & 60 & 2.2 & 0.75 & 0.5 & 0.5 & 8 & HPS2OH3-D1MS3 & WIPUMP & 3 & 10 \\
\hline$L-34 A-236$ & 5,200 & 3.5 & 3.5 & 1.0 & 50 & 60 & 2.2 & 0.75 & 0.5 & 0.5 & 8 & $\mathrm{HPS} 2 \mathrm{OH} 3$ & WIPUMP & 3 & 10 \\
\hline$L-344-436$ & 5,200 & 3.5 & 3.5 & 1.0 & 50 & 60 & 2.2 & 0.75 & 0.5 & 0.5 & 8 & $\mathrm{HPS} 2 \mathrm{OH} 3$ & WIPUMP & 3 & 5 \\
\hline$L-44 A-216$ & 6,500 & 4.5 & 3.0 & 1.0 & 55 & 60 & 2.5 & 0.75 & 0.5 & 0.5 & 9 & $\mathrm{HPS} 2 \mathrm{OH}$ & WIPUMP & 3 & 17 \\
\hline$L-44 A-215$ & 6,500 & 4.5 & 3.0 & 1.0 & 55 & 60 & 2.5 & 0.75 & 0.5 & 0.5 & 9 & HPS2OH3-D1-MS4 & WIPUMP & 3 & 17 \\
\hline$L-44 A-235$ & 6,500 & 4.5 & 3.0 & 1.0 & 55 & 60 & 2.5 & 0.75 & 0.5 & 0.5 & 9 & PS20H3-D1MS3 & WIPUMP & 3 & 10 \\
\hline$L-44 A-236$ & 6,500 & 4.5 & 3.0 & 1.0 & 55 & 60 & 2.5 & 0.75 & 0.5 & 0.5 & 9 & $\mathrm{HPS} 2 \mathrm{OH} 3$ & WIPUMP & 3 & 10 \\
\hline$L-44 A-436$ & 6,500 & 4.5 & 3.0 & 1.0 & 55 & 60 & 2.5 & 0.75 & 0.5 & 0.5 & 9 & $\mathrm{HPS} 2 \mathrm{OH} 3$ & WIPUMP & 3 & 5 \\
\hline$L-54 A-216$ & 8,500 & 5.5 & 4.0 & 1.5 & 60 & 75 & 3.5 & 0.75 & 0.5 & 0.5 & 11 & $\mathrm{HPS} 2 \mathrm{OH}$ & WIPUMP & 3 & 17 \\
\hline L-54A-215 & 8,500 & 5.5 & 4.0 & 1.5 & 60 & 75 & 3.5 & 0.75 & 0.5 & 0.5 & 11 & HPS2OH3-D1-MS4 & WIPUMP & 3 & 17 \\
\hline L-54A-235 & 8,500 & 5.5 & 4.0 & 1.5 & 60 & 75 & 3.5 & 0.75 & 0.5 & 0.5 & 11 & HPS2DH3-D1MS3 & WIPUMP & 3 & 10 \\
\hline$L-54 A-236$ & 8,500 & 5.5 & 4.0 & 1.5 & 60 & 75 & 3.5 & 0.75 & 0.5 & 0.5 & 11 & HPS2OH3 & WIPUMP & 3 & 10 \\
\hline L- $54 A-436$ & 8,500 & 5.5 & 4.0 & 1.5 & 60 & 75 & 3.5 & 0.75 & 0.5 & 0.5 & 11 & $\mathrm{HPS} 2 \mathrm{OH} 3$ & WIPUMP & 3 & 5 \\
\hline L- $644-216$ & 10,000 & 6.6 & 4.0 & 1.5 & 60 & 75 & 3.5 & 0.75 & 0.5 & 0.5 & 12 & $\mathrm{HPS} 20 \mathrm{H}$ & WIPUMP & 3 & 17 \\
\hline L-64A-215 & 10,000 & 6.6 & 4.0 & 1.5 & 60 & 75 & 3.5 & 0.75 & 0.5 & 0.5 & 12 & HPS2OH3-D1-MS4 & WIPUMP & 3 & 17 \\
\hline L- $64 A-235$ & 10,000 & 6.6 & 4.0 & 1.5 & 60 & 75 & 3.5 & 0.75 & 0.5 & 0.5 & 12 & HPS2OH3-D1MS3 & WIPUMP & 3 & 10 \\
\hline L-64A-236 & 10,000 & 6.6 & 4.0 & 1.5 & 60 & 75 & 3.5 & 0.75 & 0.5 & 0.5 & 12 & $\mathrm{HPS} 2 \mathrm{OH} 3$ & WIPUMP & 3 & 10 \\
\hline$L-64 A-436$ & 10,000 & 6.6 & 4.0 & 1.5 & 60 & 75 & 3.5 & 0.75 & 0.5 & 0.5 & 12 & $\mathrm{HPS} 2 \mathrm{OH} 3$ & WIPUMP & 3 & 5 \\
\hline$L-74 A-216$ & 10,800 & 7.5 & 4.0 & 1.5 & 65 & 75 & 3.0 & 0.75 & 0.5 & 0.5 & 13 & $\mathrm{HPS} 2 \mathrm{OH}$ & WiPUMP & 3 & 17 \\
\hline$L-74 A-215$ & 10,800 & 7.5 & 4.0 & 1.5 & 65 & 75 & 3.0 & 0.75 & 0.5 & 0.5 & 13 & HPS20H3-D1-MS4 & WIPUMP & 3 & 17 \\
\hline$L-74 A-235$ & 10,800 & 7.5 & 4.0 & 1.5 & 65 & 75 & 3.0 & 0.75 & 0.5 & 0.5 & 13 & HPS2DH3-D1MS3 & WIPUMP & 3 & 10 \\
\hline L-74A-236 & 10,800 & 7.5 & 4.0 & 1.5 & 65 & 75 & 3.0 & 0.75 & 0.5 & 0.5 & 13 & HPS2OH3 & WIPUMP & 3 & 10 \\
\hline$L-74 A-436$ & 10,800 & 7.5 & 4.0 & 1.5 & 65 & 75 & 3.0 & 0.75 & 0.5 & 0.5 & 13 & $\mathrm{HPS2OH3}$ & WIPUMP & 3 & 5 \\
\hline$L-84 A-216$ & 13,000 & 9.0 & 4.5 & 2.0 & 65 & 75 & 3.0 & 0.75 & 0.75 & 0.5 & 14.5 & $\mathrm{HPS} 2 \mathrm{OH}$ & WIPUMP & 3 & 17 \\
\hline$L-84 A-215$ & 13,000 & 9.0 & 4.5 & 2.0 & 65 & 75 & 3.0 & 0.75 & 0.75 & 0.5 & 14.5 & HPS2OH3-D1-MS4 & WIPUMP & 3 & 17 \\
\hline$L-844-235$ & 13,000 & 9.0 & 4.5 & 2.0 & 65 & 75 & 3.0 & 0.75 & 0.75 & 0.5 & 14.5 & HPS2OH3-D1MS3 & WIPUMP & 3 & 10 \\
\hline$L-84 A-236$ & 13,000 & 9.0 & 4.5 & 2.0 & 65 & 75 & 3.0 & 0.75 & 0.75 & 0.5 & 14.5 & $\mathrm{HPS} 2 \mathrm{OH} 3$ & WIPUMP & 3 & 10 \\
\hline$L-84 A-436$ & 13,000 & 9.0 & 4.5 & 2.0 & 65 & 75 & 3.0 & 0.75 & 0.75 & 0.5 & 14.5 & HPS2OH3 & WIPUMP & 3 & 5 \\
\hline
\end{tabular}


Installation and Service Manual - L Series Reverse Osmosis System

\begin{tabular}{|c|c|c|c|c|c|c|c|c|c|c|c|c|c|c|c|}
\hline \multirow[b]{2}{*}{ Modol } & \multicolumn{5}{|c|}{ Decilen Conditione } & \multicolumn{2}{|c|}{ Lmiter } & \multicolumn{3}{|c|}{ Une slzec (Inohoc) } & \multicolumn{5}{|c|}{ Pump modol and $\mathrm{HP}$} \\
\hline & $\begin{array}{l}\text { Permest } \\
\text { GPD }\end{array}$ & GPM & $\begin{array}{l}\text { Cono. } \\
\text { Fiow to } \\
\text { Draln } \\
\text { (GPM) }\end{array}$ & $\begin{array}{l}\text { Doscign } \\
\text { Alooyolo } \\
\text { Fow } \\
\text { (OMP) }\end{array}$ & $\begin{array}{l}\text { Desclon } \\
\text { Reosovory } \\
\text { (\$6) }\end{array}$ & $\begin{array}{c}\text { Max. } \\
\text { Roooovery+ } \\
\text { (**) }\end{array}$ & $\begin{array}{l}\text { Max } \\
\text { Rooysio } \\
\text { Fow } \\
\text { (OPM) }\end{array}$ & Inilet & Porm. & cona. & $\begin{array}{l}\text { Docion } \\
\text { Pump } \\
\text { Flow } \\
\text { (GPM) }\end{array}$ & Pump Model No. & $\begin{array}{l}\text { Motor } \\
\text { Model }\end{array}$ & $\begin{array}{c}\text { Motor } \\
\text { HP }\end{array}$ & $\begin{array}{l}\text { Full Losd } \\
\text { Ampec } \\
\text { IFLaveg } \\
\text { Innillostiod } \\
\text { voltage }\end{array}$ \\
\hline L-94AA-216 & 14,400 & 10 & 4.5 & 2.0 & 65 & 75 & 3.0 & 0.75 & 0.75 & 0.5 & 15.5 & HPS2OH & WIPUMP & 3 & 17 \\
\hline L-94A-215 & 14,400 & 10 & 4.5 & 2.0 & 65 & 75 & 3.0 & 0.75 & 0.75 & 0.5 & 15.5 & HPS2OH3-D1-MS4 & WIPUMP & 3 & 17 \\
\hline L-94A-235 & 14,400 & 10 & 4.5 & 2.0 & 65 & 75 & 3.0 & 0.75 & 0.75 & 0.5 & 15.5 & HPS2OH3-D1MS3 & WIPUMP & 3 & 10 \\
\hline L-94A-236 & 14,400 & 10 & 4.5 & 2.0 & 65 & 75 & 3.0 & 0.75 & 0.75 & 0.5 & 15.5 & HPS2OH3 & WiPUMP & 3 & 10 \\
\hline L-94A-436 & 14,400 & 10 & 4.5 & 2.0 & 65 & 75 & 3.0 & 0.75 & 0.75 & 0.5 & 15.5 & HPS2OH3 & WIPUMP & 3 & 5 \\
\hline$L-104 A-216$ & 16,000 & 11 & 4.5 & 2.0 & 65 & 75 & 3.0 & 0.75 & 0.75 & 0.5 & 16.5 & HPS2OH & WIPUMP & 3 & 17 \\
\hline L-104A-215 & 16,000 & 11 & 4.5 & 2.0 & 65 & 75 & 3.0 & 0.75 & 0.75 & 0.5 & 16.5 & HPS2OH3-D1-MS4 & WIPUMP & 3 & 17 \\
\hline L-104A-235 & 16,000 & 11 & 4.5 & 2.0 & 65 & 75 & 3.0 & 0.75 & 0.75 & 0.5 & 16.5 & HPS2OH3-D1MS3 & WIPUMP & 3 & 10 \\
\hline L-104A-236 & 16,000 & 11 & 4.5 & 2.0 & 65 & 75 & 3.0 & 0.75 & 0.75 & 0.5 & 16.5 & HPS2OH3 & WIPUMP & 3 & 10 \\
\hline$L-104 A-436$ & 16,000 & 11 & 4.5 & 2.0 & 65 & 75 & 3.0 & 0.75 & 0.75 & 0.5 & 16.5 & HPS20H3 & WIPUMP & 3 & 5 \\
\hline L-114A-216 & 17,300 & 12 & 4.5 & 2.0 & 65 & 75 & 3.0 & 0.75 & 0.75 & 0.5 & 17.5 & $\mathrm{HPS2OH}$ & WIPUMP & 3 & 17 \\
\hline L-114A-215 & 17,300 & 12 & 4.5 & 2.0 & 65 & 75 & 3.0 & 0.75 & 0.75 & 0.5 & 17.5 & HPS2OH3-D1-MS4 & WIPUMP & 3 & 17 \\
\hline L-114A-235 & 17,300 & 12 & 4.5 & 2.0 & 65 & 75 & 3.0 & 0.75 & 0.75 & 0.5 & 17.5 & HPS2OH3-D1MS3 & WIPUMP & 3 & 10 \\
\hline$L-114 A-236$ & 17,300 & 12 & 4.5 & 2.0 & 65 & 75 & 3.0 & 0.75 & 0.75 & 0.5 & 17.5 & HPS2OH3 & WIPUMP & 3 & 10 \\
\hline$L-114 A-436$ & 17,300 & 12 & 4.5 & 2.0 & 65 & 75 & 3.0 & 0.75 & 0.75 & 0.5 & 17.5 & $\mathrm{HPS} 2 \mathrm{OH} 3$ & WIPUMP & 3 & 5 \\
\hline L-124A-216 & 19,000 & 13 & 4.5 & 2.0 & 65 & 75 & 3.0 & 0.75 & 0.75 & 0.5 & 18.5 & $\mathrm{HPS} 20 \mathrm{H}$ & WIPUMP & 3 & 17 \\
\hline L-124A-215 & 19,000 & 13 & 4.5 & 2.0 & 65 & 75 & 3.0 & 0.75 & 0.75 & 0.5 & 18.5 & HPS20H3-D1-MS4 & WIPUMP & $\overline{3}$ & 17 \\
\hline L-124A-235 & 19,000 & 13 & 4.5 & 2.0 & 65 & 75 & 3.0 & 0.75 & 0.75 & 0.5 & 18.5 & HPS2OH3-D1MS3 & WIPUMP & 3 & 10 \\
\hline L-124A-236 & 19,000 & 13 & 4.5 & 2.0 & 65 & 75 & 3.0 & 0.75 & 0.75 & 0.5 & 18.5 & $\mathrm{HPS} 2 \mathrm{OH} 3$ & WIPUMP & 3 & 10 \\
\hline$L-124 A-436$ & 19,000 & 13 & 4.5 & 2.0 & 65 & 75 & 3.0 & 0.75 & 0.75 & 0.5 & 18.5 & HPS2OH3 & WIPUMP & 3 & 5 \\
\hline
\end{tabular}

"Water must be softened or have anuiscalant injection. Check with factory to make sure this recovery will not cause any scaling problems wanh your feedwater.

- L-12521A uses 21" Membrane M-T2521AHF \& Housing PV2521SSAW-316

- All other $2.5^{\circ}$ diameter use $40^{\circ}$ Membrane M-T2540AHF and Housing PV2540SSAW-316

- 4.0* diameter model no. M-T4040AHF. Vessel model: PV4040SSAW-316

\section{DESIGN BASIS}

- Systems rated at: $77^{\circ} \mathrm{F}\left(25^{\circ} \mathrm{C}\right)$ using 1000 PPM sodium chloride solution operating at 200 psi pressure.

- Minimum feed pressure to RO System: 40 PSI. System capacity changes significantly with water temperature. For higher TDS a water analysis must be supplied and could result in modifications to the system.

- Chlorine must be removed if present in feed water prior to RO with a carbon filter or with chemical injection.

- Water must be pretreated with a softener or antiscalant injection to avoid scaling the membranes.

- Feed water turbidity: Less than 1 NTU; Feed water silt density index (SDI): 3 maximum. If exceeded, pretreatment with media filter recommended. All pretreatment equipment and SDI test kits are available from Applied Membranes.

- Capacity Basis: 24 hrs/day

\section{DESIGN NOTES}

1. Pump flow/Feed flow: The pump has been designed to include recycle flow (if any) coming back to the pump inlet from the concentrate stream based on desired recovery. The sum of permeate flow, concentrate flow and recycle flow (if any) will equal the pump design flow.

2. Permeate flow: Indicates design flow rate from RO membranes as product water for use.

3. Concentrate flow: Water flowing to the drain. Concentrate flow is critical for proper system operation. For proper concentrate flows, refer to the system design information on pages 3-4.

4. Recycle flow: Flow stream that returns from the concentrate line back to the pump intake, rather than to the drain.

Note: Permeate flow should not exceed recommended flow.

Note: System pressure is a variable. It is important to adjust the pressure to get the correct permeate and concentrate flows. The exact value of the pressure is not important.

Note: Permeate flow will increase at higher temperature. 
Installation and Service Manual - L Series Reverse Osmosis System

\section{GENERAL INFORMATION AND SAFETY}

\section{DISCLAIMER:}

The information contained in this document is subject to change without notice.

Applied Membranes, Inc. shall not be liable for technical or editorial omissions made herein; nor for incidental or consequential damages resulting from the furnishing, performance, or use of this material.

\section{READ THIS MANUAL:}

Prior to operating or servicing this unit, this manual must be read and understood. If anything is not clear, call for assistance before proceeding. Keep this and other associated manuals for future reference and for new operators or qualified service personnel.

\section{A use proper power connections:} Use proper wiring and connection methods to satisfy local electrical codes. SHOCK HAZARD: Connect this unit to a properly grounded connection in accordance with the National Electrical Code. DO NOT, under any circumstances, remove the ground wire or ground prong from any power plug. Do not use extension cords or an adapter without proper consideration.
A service WARNIIG:

To prevent electrical shock, disconnect power to the system prior to servicing.

\section{A warning:}

Do not make any alteration or modification in the wiring or plumbing of the system. This can result in damage to the system and cause injury to operators or users.

\section{A warning:}

Flush the system for at least 30 minutes before use to remove all chemicals present.

\section{- CAUTION:}

Chlorine will damage the membranes. Chlorine must be removed from the feed stream before entering the system.

$\rightarrow$ CAUTION:

Never let the system freeze. Freezing can damage the membrane and plumbing.

\section{SYSTEM INSTALLATION}

\section{LOCATION}

Select a location for the RO system with adequate clearance from walls and other equipment to enable servicing of the pump / motor assemblies, membranes, cartridge prefilter and other serviceable components. Allow at least four (4) feet of clearance at the top end of the membrane housings for future membrane replacement.

The unit must be located near a drain able to accommodate up to $10 \mathrm{GPM}$. This is in addition to any other equipment sharing the drain.

A grounded power supply of the appropriate voltage matching your system model's voltage with 15 amp fuse protection and a local disconnect switch is required.

Caution: The system must not be located near any corrosive chemicals, or in an area where the temperature may exceed $113^{\circ} \mathrm{F}\left(45^{\circ} \mathrm{C}\right)$.

A Warning: The system must be properly grounded to avoid injury from electrical shock. 


\title{
Appendix G: List of Stakeholder Participants who attended the DETS Field Evaluation
}

\section{Attendees List for Treatment of CBRN Decontamination Effluent Demo}

\author{
Environmental Quality and Installations US Army Engineer \\ Research and Development Center \\ ERDC Lead
}

Victor F. Medina, Ph.D., P.E.

Team Leader: Environmental Security Engineering Principal Investigator \& Environmental Engineer U.S. Army Corps of Engineers Engineer Research \& Development Center 3909 Halls Ferry Rd., Vicksburg, MS 39180

6016344283 , fax 6016343518 , cell 6018317251

victor.f.medina@usace.army.mil

GSL Rep.

Rick Gurtowski

Military Analyst (Engineering)

ERDC-GSL

3909 Halls Ferry Road, Bldg. 3396, Vicksburg, MS 39180

601-634-5432 (office), 601-634-3453 (fax) 
Liaison

Bernard Doctor (DOC)

ERDC LNO to JPEO-CBD/IEWS/Senior Acquisition /S\&T Technical Program Analyst

Integrated Mission Solutions Group (Camber Corporation) Joint Project Manager Guardian

E280o Bush River Road, Aberdeen Proving Ground, MD 21001

Bernard.Doctor.ctr@mail.mil

(410) 417-3317 Office

JPMG Joint Product Manager CBRNE A\&RS

Howard M. Beardsley

JPdM CBRNE A\&R Systems (Integrated Mission Solutions Group (Camber Corporation))

Technical Solutions, A Division of Huntington Ingalls Industries

Office: 4104173370

Mobile PH\#443-243-4328

E-mail: howard.m.beardsley.ctr@mail.mil 
Joint Product Manager Protection (JPM-P)

Gerald A. Jones

Chief of Staff

JPM-P

50 Tech Parkway, Suite 301, Stafford, VA 22556

Off: 703.617 .2426

Cell: 703.675 .1547

Email: gerald.jones@usmc.mil

Megan Kreider

T\&E Analyst

mkreider@mltsystems.com

\section{DTRA}

Glenn Lawson

glenn.e.lawson8.civ@mail.mil 


\section{ECBC}

Lawrence Procell

Research Chemist

Decon Sciences Branch, R\&T Directorate

U.S. Army Edgewood Chemical Biological Center RDCB-DRP-D, Bldg E3400

5183 Blackhawk Rd, APG, MD 21010

Ph: 410-436-1746

Lawrence.r.procell2.civ@mail.mil

Mr. Brian M. Luthardt

Leidos Inc.

Decontamination Sciences Branch ECBC

E340o Ricketts Point Rd, Aberdeen Proving Grnds, Md 21010

Brian.m.luthardt.ctr@mail.mil

410-417-0725 
MSCoE

Dennis Hutchinson

MSCoE, Battle Laboratory

Fort L. Wood

dennis.g.hutchinson.civ@mail.mi

573.563 .5253

SFC Corriner Thomas

MSCoE

corriner.s.thomas.mil@mail.mil

\section{USEPA HSRC}

John Hall

James Goodrich, SES

USEPA-Homeland Security Research Center

Cincinnati $\mathrm{OH}$.

Goodrich.James@epa.gov 


\section{Appendix H: Notes Collected from the Stakeholder Discussion immediately following the DETS Field Evaluation (Brame and Medina)}

\section{Notes, June 272017}

Glen Lawson, DTRA

Need to characterize the cartridge filter media, to determine differences in sand, carbon (ECBC, Edith)

-S\&T bench top study for type of sand and how it works as a media filter

Jerry Jones, JPM-P

Size of our system - Company level. Good size

Looking at what's next after the JSLS??

-new suit, aviation, amphibious, naval, homeland defense. Rugedise A. B and $\mathrm{C}$ suits for military operations.

-ConOps differences throughout US

-Milspec standard for equipment.

-same requirement for mass casualty decon system

CBRN response committee

-MCD is next

JPO does developments once the requirements are built

-if MSCoE goes to JRO requesting WWT capability 
NGB in NYC about what to do in city decon (needs to be modular. -could be complimentary with our system)

JPM protection is POMed for 2020

Looking to build system

-they are interested in the technology, including Vic Murphy from SOCom

-They require TRL6 for TTA, frequently go through DTRA as eyes and ears

\section{KEEP THEM INFORMED}

Tom Kloehn is the PM running the mass cas decon

Howard Beardsley, JPdM CBRNE A\&R

Spun fiber tanks will probably absorb agents, may need liners ${ }^{* * *}$ need to test*

Test at old "O" field? Compare to current operations

Jerry Jones, JPM-P

JPM-P is doing live testing in the open air in the Czech Republic. (Starting negotiations)

Group Discussion

Collection of water will be an issue in some cases

Short term benefit is for homeland. And urban warfare

Emergency treatment and response, as well as supplementary treatment to traditional facilities

Design an expandable/collapsible decon facility

Coast guard LDS - lightweight decontamination system 


\section{System Operation}

Suggestion from MSCoE, SFC Thomas - System failure warnings to beep, flash, or carry a tablet around that will tell you when there's an issue

Best if it can be operated from the command zone

Discussion on contaminants

Live agent testing and/or TIMS

-Cesium is toughest to test, so a good surrogate

-Use technetium as a surrogate

-could we build up enough radiation to get the radioactive material hot? Probably not.

-Virus removal by RO

NORTHCOM exercises

North com publishes large exercises, maybe we can partner with them? Good to check on! They did one in NY, one in Ohio, having one in Georgia in the fall?

Have to get aligned with a program of record to shorten acquisition from 5- 8 years?

Bilge water application?

How realistic was our decon?

M26 pressure wash rather than fire hose.

By the time they spray water on a vehicle, all the big chunks are removed (scraping brooms and mops)

Reserve unit in Fort McClellan 
Cold environment - will freezing be an issue?

Not all contaminants are water borne - airborne contaminants might be released during decon.

Overspray can spread contamination, through which a cleaned vehicle has to drive.

Online sensing - conductivity is not as good as a real time sensor for specific contaminants.

-final disposal requires additional proof of removal.

What is acceptable to the EPA?

Comparison with old "o" field in MD. Do a side by side comparison at Aberdeen.

PFOS/PFOA treatment 


\title{
Appendix I: Report on the DETS Field Evaluation Prepared by Mr. Howard Beardsley, JPEOCBD
}

\author{
Trip Report
}

\section{Evaluation of Decontamination Wastewater Treatment Unit}

1. DATE: 26-28 June 2017

2. LOCATION: Environmental Laboratory (Bldg\#3297), Kaskaskia Street, of Vicksburg COE location at 3909 Halls Ferry Rd, Vicksburg, MS 39180, USA

3. EQUIPMENT FIELDED: Decontamination Wastewater Treatment Unit (Portable Water Treatment System)

4. ATTENDEES: SEE Enclosure 1. Two representatives from the EPA, one of which was an SES, were in attendance.

\section{DETAILS:}

a. System: System consists of a stake bed dual axle trailer approximately 15 ' long by 6' wide with the following items mounted on it:

(1) Generator, Diesel 9.8KW

(2)

(3) Sedimentation Tank Portable (DBL-HI) - 3,00o Gallon tank in which chlorine is added.

(4)

(5) Three fiber glass reinforced (outside) with an ABS (Acrylonitrile Butadiene Styrene) liner for these cylinders (Fleck) of which the first was filled with approximately 2.5 feet of sand that filtered the water, second tank is a water softener and the third tank is a GAC (Granular Activated Carbon) filled tank that filters the water.

(a) Each of these fiber wrapped cylinders when filled with water weigh approximately 800 pounds $(3 \times 800=$ 2,400 pounds).

i. Approximately twelve stainless steel cylinders that perform the Reverse Osmosis (RO) process.

ii. Water pump, Breda 40 Peristaltic type of pump.

iii. Hoses in three rolls.(two on the "Driver's" Side of cart and one on the "Passenger" side of the cart) 
iv. Auto-Sampler - Used to collect samples for testing of effluents and influents.

v. Control panels:

(i) Computer laptop touch system contained in vapor proof container with a clear view to the computer screen.

(ii) RO control panel

(iii) GAC control panel

(iv) Diesel control panel inside housing of generator

(b) Evaluation: Pumped water, approximately 1,000 gallons, from drainage that was being filled from cleaning of vehicles (muddy) and the addition of 3,000 PPM mixture of Malathion, Cs (non-radioactive isotope) and other compounds to the mixture before being pumped into the system for treatment. Malathion was added as a simulant for nerve agent.

1. After Action Review (AAR):

a. Training: Training, once the automation of the system is complete, would be relatively simple.

b. Equipment:

(1) Commercial equipment was used for this system.

(a) Equipment would need to be more securely attached to the cart which would increase the weight of the components on the cart. May need to go to a larger cart to ensure the 'hardening' does not impact the weight capacity of the trailer unless the weight capacity is significantly more than what it is being loaded with it in its current configuration.

i. Cylinders (Sand, water softener and GAC) loaded with water weigh approximately 2,400 pounds,

ii. Portable tank weighs approximately $200 \mathrm{lbs}$ (When empty).

iii. Generator weighs approximately 300 pounds,

iv. RO Setup weighs approximately 400 pounds w/water,

v. Water Pump weighs approximately 40 pounds,

vi. Hoses and reels weigh approximately150 pounds, vii. Control panels weigh approximately 60 pounds, viii. Auto sampler weighs approximately 50 pounds, 


\section{ix. Estimated weight of all components currently} on the trailer: 3,600 pounds.

(i) Cost of system as currently configured is approximately $\$ 75,000$.

1) Cost of replacing media is approximately $10 \%$ of Cost; i.e. $\$ 7,500$

2) Was the ICP-MS included in this cost estimate?

c. Issues/Comments:

(1) Acceptance by EPA appears to be an issue or open question based on limited feedback from the two EPA folks attending the evaluation.

Answer: Appears that the suggestion of a side-by-side test between this and the Old "O" Field Water Treatment Facility might 'answer'/solve this issue initially for the state of Maryland and then applying state by state or region by region depending on its acceptance by Maryland/EPA Region (Covering Maryland).

(2)Testing of effluent to determine level of 'cleanliness' of water needs to be more fully addressed.

Answer: Appears that this might be addressed through the use of a sentinel species similar to what Old O Field is using in the 'clean' side of the stream.

i. Need a separate storage container in case the water needs to be run through the system 'one more time.'

ii. Authority to Operate (ATO) may be required if hooking the software from this system into the Department of Defense (DoD) Non-Secure IP Routing (NIPR).

iii. Had issue with generator capacity but appears to be a solvable problem that is being addressed by team.

iv. Decontamination of trailer: 
1. As currently configured the Fleck valves and cylinders, hoses, storage containers, Breda pump, and Auto Sampler would appear to absorb several of the chemical warfare agents.

2. Whether this can be decontaminated by running bleach or other decontaminant through it remains to be seen.

3. Other option discussed was disposal of trailer after incident but this appears to be an extreme option when only the insides of the Fleck valves and cylinders, hoses, storage containers, Breda pump and Auto sampler are actually contaminated.

Howard Beardsley PH\#443-243-4328 


\section{Enclosure 1 - Attendee List}

\begin{tabular}{|l|l|l|l|}
\hline Name & PH\# & Agency & EMail \\
\hline Larry Procell & $410-436-1747$ & ECBC & Lawrence.r.procell2.civ@mail.mil \\
\hline Brian Luthardt & $410-417-0725$ & ECBC & Brian.m.luthardt.ctr@mail.mil \\
\hline Gerald Jones & $703-617-2426$ & JPM-P & Gerald.jones@usmc.mil \\
\hline Megan Kreider & & JPM-P & mkreider@mltsystems.com \\
\hline Dr. Christopher Griggs & $601-634-4821$ & ERDC & Chris.S.Griggs@usace.army.mil \\
\hline Rick Gurtowski & $601-634-5432$ & ERDC & Richard.s.gurtowski@usace.army.mil \\
\hline Doctor Bernard & $410-417-3317$ & JPEO-CBD & Bernard.doctor.ctr@mail.mil \\
\hline James Goodrich, SES & $513-569-7605$ & EPA HSRC & Goodrich.james@epa.gov \\
\hline Scott Waisner & $601-634-2286$ & ERDC & Scott.a.waisner@usace.army.mil \\
\hline Dr. Edith Martinez-Guerra & $601-634-4847$ & ERDC & edith.martinez-guerra@usace.army.mil \\
\hline Dr. Victor Medina & $601-634-4283$ & ERDC & Victor.f.medina@usace.army.mil \\
\hline Dennis Hutchinson & $573-563-5253$ & MSCoE & Dennis.g.hutchinson.civ@mail.mil \\
\hline Glen Lawson & & DTRA & \\
\hline SFC Corriner Thomas & & MSCoE & Corriner.s.thomas.mil@mail.mil \\
\hline Matthew Magnuson & & EPA HSRC & Magnuson.matthew@epa.gov \\
\hline Howard Beardsley & $443-243-4328$ & CBRNE A\&RS & Howard.m.beardsley.ctr@mail.mil \\
\hline
\end{tabular}




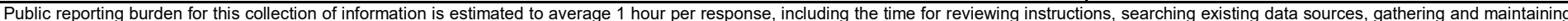

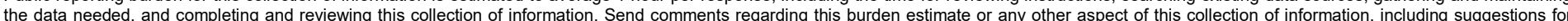

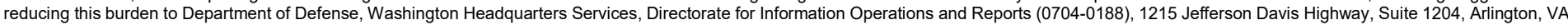

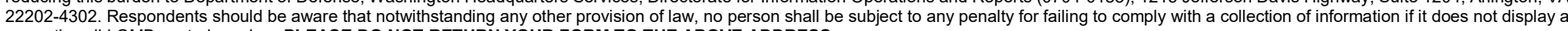
currently valid OMB control number. PLEASE DO NOT RETURN YOUR FORM TO THE ABOVE ADDRESS.
1. REPORT DATE (DD-MM-YYYY) 2. REPORT TYPE
November 2018 Final report

\section{TITLE AND SUBTITLE}

Simulated Vehicle Decontamination and Field Evaluation of the Decontamination Effluent Treatment System (DETS), 27 June 2017, and Associated Background Studies

\section{AUTHOR(S)}

Victor F. Medina, Scott A. Waisner, Edith Martinez-Guerra, Jared Johnson, Jonathan Brame, Elizabeth Gao, and Martin Page

3. DATES COVERED (From - To)

5a. CONTRACT NUMBER

5b. GRANT NUMBER

5c. PROGRAM ELEMENT NUMBER

5d. PROJECT NUMBER

5e. TASK NUMBER

5f. WORK UNIT NUMBER

33143

7. PERFORMING ORGANIZATION NAME(S) AND ADDRESS(ES)

U.S. Army Engineer Research and Development Center, Environmental Laboratory

3909 Halls Ferry Road, Vicksburg, MS 39180-6199

8. PERFORMING ORGANIZATION REPORT NUMBER

ERDC TR-18-19
9. SPONSORING / MONITORING AGENCY NAME(S) AND ADDRESS(ES)

Headquarters, U.S. Army Corps of Engineers

Washington, DC 20314-1000
10. SPONSOR/MONITOR'S ACRONYM(S)

\section{SPONSOR/MONITOR'S REPORT} NUMBER(S)

\section{DISTRIBUTION / AVAILABILITY STATEMENT}

Approved for public release; distribution unlimited.

\section{SUPPLEMENTARY NOTES}

\section{ABSTRACT}

A technical evaluation of a capability to treat and/or recycle the effluent from the Army's aqueous based chemical, biological, radiological and nuclear (CBRN) decontamination operations was conducted on 26-28 June 2017 at the U.S. Army Engineer Research and Development Center (ERDC) Waterways Experiment Station (WES), 3909 Halls Ferry Rd, Vicksburg, MS. The Decontamination Effluent Treatment System (DETS) is a reactor system specifically designed to address decontamination effluent. The objectives of the evaluation were to show an ability to reduce chemical hazards, reduce logistical burdens, and eliminate possible political impacts. The DETS is a fully functional system designed to treat waters containing contaminants, minimize decontamination water requirements, be rapidly deployable and easy to maintain, while minimizing the volume of decontamination waste requiring management/disposal. The field evaluation consisted of a simulation of vehicle decontamination followed by on-site treatment of the resulting effluent water.

15. SUBJECT TERMS a. REPORT

UNCLASSIFIED

\section{SECURITY CLASSIFICATION OF:}

\section{Biological decontamination--Sewage}

Radioactive decontamination--Sewage
Decontamination (from gases, chemicals, etc.)--Sewage

Sewage--Purification

b. ABSTRACT
UNCLASSIFIED

c. THIS PAGE

UNCLASSIFIED 17. LIMITATION
OF ABSTRACT

SAR
18. NUMBER OF PAGES

131 19a. NAME OF RESPONSIBLE PERSON

19b. TELEPHONE NUMBER (include area code) 